\title{
Light-toned salty soils and coexisting Si-rich species discovered by the Mars Exploration Rover Spirit in Columbia Hills
}

\author{
Alian Wang, ${ }^{1}$ J. F. Bell III, ${ }^{2}$ Ron Li ${ }^{3}$ J. R. Johnson, ${ }^{4}$ W. H. Farrand, ${ }^{5}$ E. A. Cloutis, ${ }^{6}$ \\ R. E. Arvidson, ${ }^{1}$ L. Crumpler, ${ }^{7}$ S. W. Squyres, ${ }^{2}$ S. M. McLennan, ${ }^{8}$ K. E. Herkenhoff, ${ }^{4}$ \\ S. W. Ruff, ${ }^{9}$ A. T. Knudson, ${ }^{1}$ Wei Chen, ${ }^{3}$ and R. Greenberger ${ }^{1}$ \\ Received 26 February 2008; revised 27 June 2008; accepted 29 July 2008; published 19 December 2008.
}

[1] Light-toned soils were exposed, through serendipitous excavations by Spirit Rover wheels, at eight locations in the Columbia Hills. Their occurrences were grouped into four types on the basis of geomorphic settings. At three major exposures, the light-toned soils are hydrous and sulfate-rich. The spatial distributions of distinct types of salty soils vary substantially: with centimeter-scaled heterogeneities at Paso Robles, Dead Sea, Shredded, and Champagne-Penny, a well-mixed nature for light-toned soils occurring near and at the summit of Husband Hill, and relatively homogeneous distributions in the two layers at the Tyrone site. Aeolian, fumarolic, and hydrothermal fluid processes are suggested to be responsible for the deposition, transportation, and accumulation of these light-toned soils. In addition, a change in Pancam spectra of Tyrone yellowish soils was observed after being exposed to current Martian surface conditions for 175 sols. This change is interpreted to be caused by the dehydration of ferric sulfates on the basis of laboratory simulations and suggests a relative humidity gradient beneath the surface. Sirich nodules and soils were observed near the major exposures of S-rich soils. They possess a characteristic feature in Pancam visible near-infrared (Vis-NIR) spectra that may be diagnostic of hydrated species, and this spectral feature can be used to search for additional Si-rich species. The exposures of hydrated salty soils within various geomorphic settings imply the potential existence of hydrous minerals in similar settings over a much wider area. Hydrous sulfates represent one of the candidates that may contribute the high level of water equivalent hydrogen in equatorial regions detected by the Neutron Spectrometer on Mars Odyssey.

Citation: Wang, A., et al. (2008), Light-toned salty soils and coexisting Si-rich species discovered by the Mars Exploration Rover Spirit in Columbia Hills, J. Geophys. Res., 113, E12S40, doi:10.1029/2008JE003126.

\section{Introduction}

[2] Over the past 3 years, the Mars Exploration Rover Spirit has been continuing to explore the surface of Mars at Gusev Crater [Arvidson et al., 2006a, 2008]. Along a $7.5 \mathrm{~km}$

\footnotetext{
${ }^{1}$ Department of Earth and Planetary Science and McDonnell Center for Space Sciences, Washington University, St. Louis, Missouri, USA.

${ }^{2}$ Department of Astronomy, Cornell University, Ithaca, New York, USA.

${ }^{3}$ Center for Mapping, CEEGS, Ohio State University, Columbus, Ohio, USA.

${ }^{4}$ U.S. Geological Survey, Flagstaff, Arizona, USA.

${ }^{5}$ Space Science Institute, Boulder, Colorado, USA.

${ }^{6}$ Department of Geography, University of Winnipeg, Winnipeg, Manitoba, Canada.

${ }^{7}$ New Mexico Museum of Natural History and Science, Albuquerque, New Mexico, USA.

${ }^{8}$ Department of Geosciences, State University of New York at Stony Brook, Stony Brook, New York, USA.

${ }^{9}$ School of Earth and Space Exploration, Arizona State University, Tempe, Arizona, USA.
}

Copyright 2008 by the American Geophysical Union. 0148-0227/08/2008JE003126 traverse from the Spirit landing site to Home Plate, more than a dozen types of rocks have been encountered [Squyres et al., 2006; McSween et al., 2008; Schmidt et al., 2008]. These rocks cover a wide range of oxidation states, with $\mathrm{Fe}^{3+} / \mathrm{Fe}_{\text {total }}$ varying between 0.00 and 0.88 , [Morris et al., 2006, 2008], and have very distinct characteristics in surface morphology, geochemistry and mineralogy [Herkenhoff et al., 2006; Ming et al., 2006, 2008]. The soils along the traverse can be subdivided into three types [Yen et al., 2005]. These include surface dust with higher oxidation state, shallow basaltic soils exposed in rover wheel tracks with very little evidence of alteration, and salty soils exposed by intentional and unintentional trenches made by the Spirit Rover [Haskin et al., 2005; Johnson et al., 2007; Rice et al., 2008; Wang et al., 2006a, 2007a, 2008a; Yen et al., 2008]. At eight locations along the $3.3 \mathrm{~km}$ traverse from the foot of Husband Hill to Home Plate within the Inner Basin, light-toned soils were exposed, in spite of the fact that no intentional trenching operations were conducted (Figure 1 and Table 1). Light-toned soils were identified to be sulfate-rich at three locations, and to be Si-rich at one location. The most dramatic exposures of 


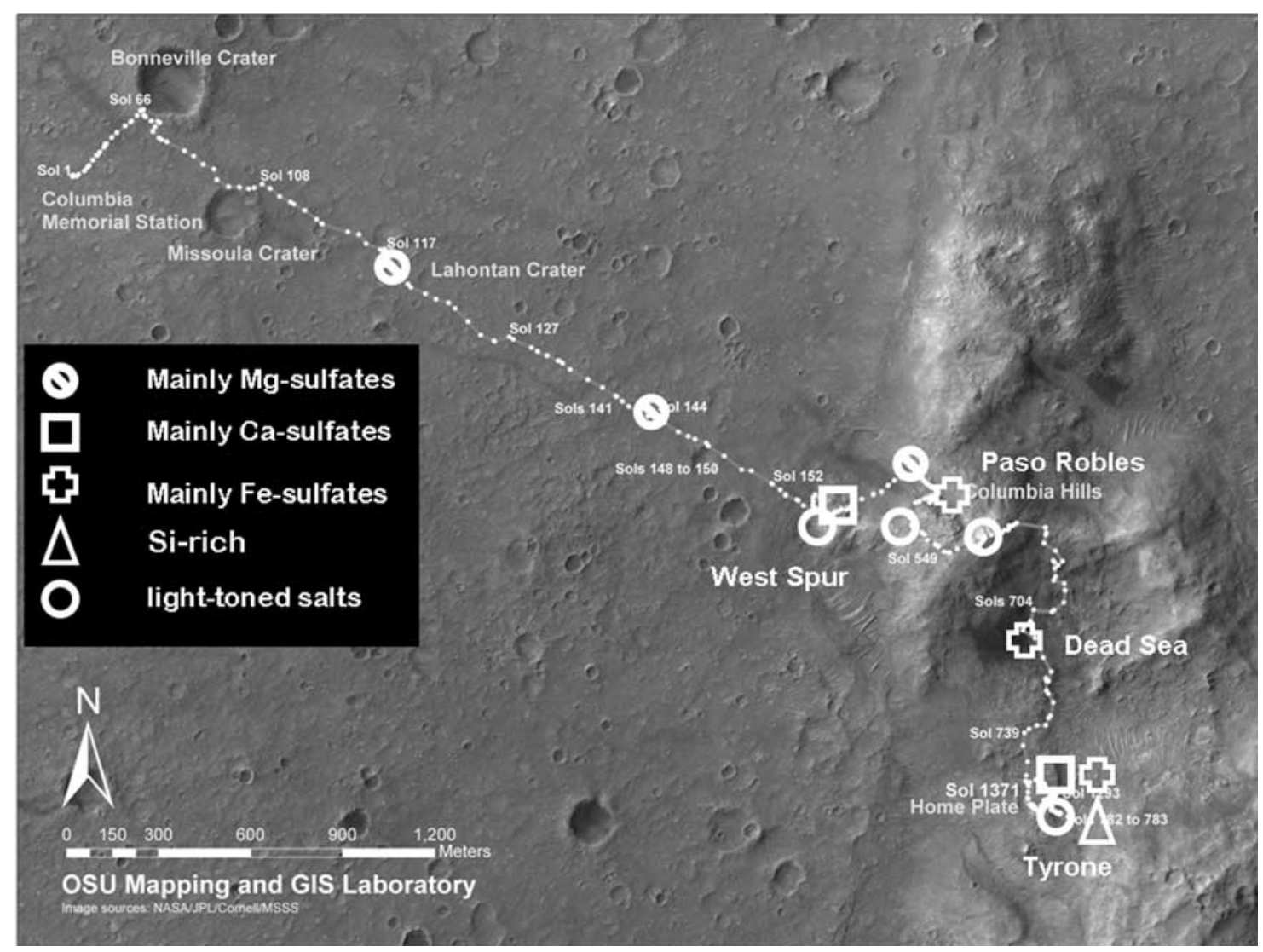

Figure 1. Locations of light-toned salty soils excavated by Spirit during its $7.5 \mathrm{~km}$ traverse in Gusev Crater up to sol 1371. The traverse route of the Spirit Rover is plotted over a Mars Orbiter Camera (MOC) image, the symbols marking the locations of excavated light-toned soils and the types of sulfates implied by in situ measurement. Rocks and nodular materials containing sulfates or Si-rich materials are also marked in the same way.

salty soils were revealed serendipitously at the Tyrone site because of the failure of the rover's right front wheel motor, and the subsequent trench that was created by dragging this stuck wheel backward through the soils. These bright, chemically anomalous soils are the subject of this study.

[3] In this paper, we will describe various geomorphic settings of these light-toned soils; their mineralogical and chemical characteristics; the spatial distributions of distinct salts and salt assemblages in the light-toned soils at different locations; the spectral property variations of Tyrone soils as a function of surface exposure time; and the Si-rich species that were found coexisting with light-toned soils at some locations. On the basis of these observations, we will discuss the paleoenvironment conditions, alteration of regional rocks, and various mechanisms that may have caused (or affected) the formation and accumulation of these lighttoned soils. Furthermore, we will discuss the potential contributions from these types of salty soils to the general water budget in the vicinity of Gusev Crater.

\section{Geomorphic Setting}

[4] Light-toned soils were excavated by Spirit's wheels at eight locations in the Columbia Hills region. These areas were covered by reddish surface dust and basaltic soil before they were exposed by the rover driving over the surface. At three locations (Paso Robles, Dead Sea (also named Arad), and Tyrone), the loose and deep fine-grained materials encountered by the rover were responsible for loss of traction and significant excavation into the soil. At Tyrone, the mobility was so impaired that several sols were required to extricate the rover from the soils, and large amounts of light-toned salty soils were exposed. In many other locations, the rover traversed through the areas without obvious difficulties, with only small amounts of lighttoned soils being exposed in the wheel tracks.

[5] Four types of geomorphic settings can be identified for the light-toned soils that were excavated by the Spirit Rover in the Columbia Hills region. The light-toned soils at different settings have different properties (quantities, heterogeneities, and coexisting phases), which may help to assign the origins of their formations or accumulations.

\subsection{Geomorphic Setting 1: Local Topographic Lows}

[6] The largest amounts of salty soils were excavated by Spirit in the Dead Sea site and in the Tyrone site; both are located in local topographic lows [Li et al., 2008]. Figures 2 and 5 are false color images obtained by the Panoramic Camera (Pancam [Bell et al., 2003]) from these sites. All false color Pancam images shown in this paper were made using L2 (753 nm), L5 (535 nm), and L7 (432 nm) filters. This filter set was also used for producing decorrelation 
Table 1. Light-Toned or Salty Soils Excavated at Gusev Crater and Coexisting Si-Rich Materials ${ }^{\mathrm{a}}$

\begin{tabular}{|c|c|c|c|c|c|c|c|}
\hline Duration & Area Name & Location & Size of Exposure & Remote Sensing & In Situ & \multicolumn{2}{|c|}{$\begin{array}{c}\text { Si-Rich Materials } \\
\text { Determined or Implied by }\end{array}$} \\
\hline Sol 113-115 & Big Hole trench & $\begin{array}{l}\text { Gusev basaltic } \\
\text { plains }\end{array}$ & depth $\sim 9 \mathrm{~cm}$ & $\begin{array}{c}\text { Pancam 13F, } \\
\text { Mini-TES }\end{array}$ & APXS, MB, MI & none & \\
\hline Sol $135-142$ & $\begin{array}{l}\text { The Boroughs } \\
\text { trench }\end{array}$ & $\begin{array}{l}\text { Gusev basaltic } \\
\text { plains }\end{array}$ & depth $\sim 11 \mathrm{~cm}$ & $\begin{array}{l}\text { Pancam 13F, } \\
\text { Mini-TES }\end{array}$ & APXS, MB, MI & none & \\
\hline Sol $158-180$ & Hank's Hollow & $\begin{array}{l}\text { base of steep } \\
\text { slope }\end{array}$ & Minor in $2 \times 3 \mathrm{~m}$ & $\begin{array}{l}\text { Pancam 13F, } \\
\text { Mini-TES }\end{array}$ & & cases & Pancam, morphology \\
\hline Sol 343-362 & Champagne-Penny & on slope & Minor in $4 \times 2 \mathrm{~m}$ & Pancam 13F & & none & \\
\hline Sol 399-432 & Paso Robles & on slope & mid in $1.7 \times 1.9 \mathrm{~m}$ & $\begin{array}{l}\text { Pancam 13F, } \\
\text { Mini-TES }\end{array}$ & APXS, MB, MI & $\begin{array}{l}\text { Soils and } \\
\text { nodules }\end{array}$ & APXS, Pancam \\
\hline Sol 422-432 & $\begin{array}{l}\text { Return to Paso } \\
\text { Robles }\end{array}$ & & & $\begin{array}{c}\text { Pancam 13F, } \\
\text { Mini-TES }\end{array}$ & APXS, MB, MI & & \\
\hline Sol $455-486$ & near Jibsheet & $\begin{array}{l}\text { adjacent to large } \\
\text { outcrop }\end{array}$ & Trace in $7 \times 2 \mathrm{~m}$ & Pancam 13F & & none & \\
\hline Sol $621-628$ & near Hillary & $\begin{array}{l}\text { adjacent to large } \\
\text { outcrop }\end{array}$ & Trace in $10 \times 15 \mathrm{~m}$ & Pancam 13F & & none & \\
\hline Sol $721-728$ & Dead Sea (Arad) & local lowland & Major in $2.7 \times 7.4 \mathrm{~m}$ & $\begin{array}{c}\text { Pancam 13F, } \\
\text { Mini-TES }\end{array}$ & APXS, MB, MI & $\begin{array}{l}\text { Soils and } \\
\text { Nodules }\end{array}$ & APXS, morphology \\
\hline Sol 784-798 & Tyrone & local lowland & Major in $5.4 \times 3.8 \mathrm{~m}$ & $\begin{array}{l}\text { Pancam 13F, } \\
\text { Mini-TES }\end{array}$ & & Nodules & morphology \\
\hline Sol 864-1062 & $\begin{array}{l}\text { Tyrone from Low } \\
\text { Ridge }\end{array}$ & & & $\begin{array}{l}\text { Pancam 13F, } \\
\text { Mini-TES }\end{array}$ & & & \\
\hline Sol 1098-1103 & Return to Tyrone & & & $\begin{array}{c}\text { Pancam 13F, } \\
\text { Mini-TES }\end{array}$ & APXS, MB, MI & $\begin{array}{l}\text { Soils and } \\
\text { Nodules }\end{array}$ & $\begin{array}{l}\text { APXS, Mini-TES, } \\
\text { Pancam }\end{array}$ \\
\hline Sol 1158-1306 & Eastern Valley & local lowland & Minor in $5.7 \times 4.1 \mathrm{~m}$ & $\begin{array}{c}\text { Pancam 13F, } \\
\text { Mini-TES }\end{array}$ & APXS, MB, MI & $\begin{array}{l}\text { Soils and } \\
\text { Nodules }\end{array}$ & $\begin{array}{c}\text { APXS, Mini-TES, } \\
\text { Pancam }\end{array}$ \\
\hline
\end{tabular}

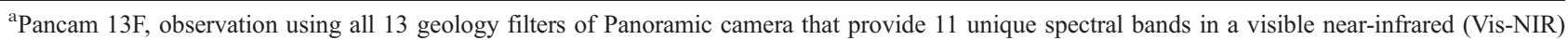
spectral range from $432 \mathrm{~nm}$ to $1009 \mathrm{~nm}$ [Bell et al., 2003]; Mini-TES, observation using Miniature Thermal Emission Spectrometer [Christensen et al., 2003]; APXS, observation using Alpha Particle X-ray Spectrometer [Rieder et al., 2003]; MB, observation using Mössbauer Spectrometer [Klingelhöfer et al., 2003]; MI, observation using Microscopic Imager [Herkenhoff et al., 2003].

stretched Pancam images (DCS [e.g., Gillespie et al., 1986]) in this paper, in order to enhance the color differences and the spatial distributions of distinct salty soil patches. Figures 2 d, $2 \mathrm{e}$, and $2 \mathrm{f}$ are DCS images to match the false color images in Figures 2a, 2b, and 2c, obtained at the Dead Sea site. In these Pancam images, Dead Sea light-toned soil patches show different colors and very heterogeneous spatial distributions, very different from the Tyrone light-toned soils
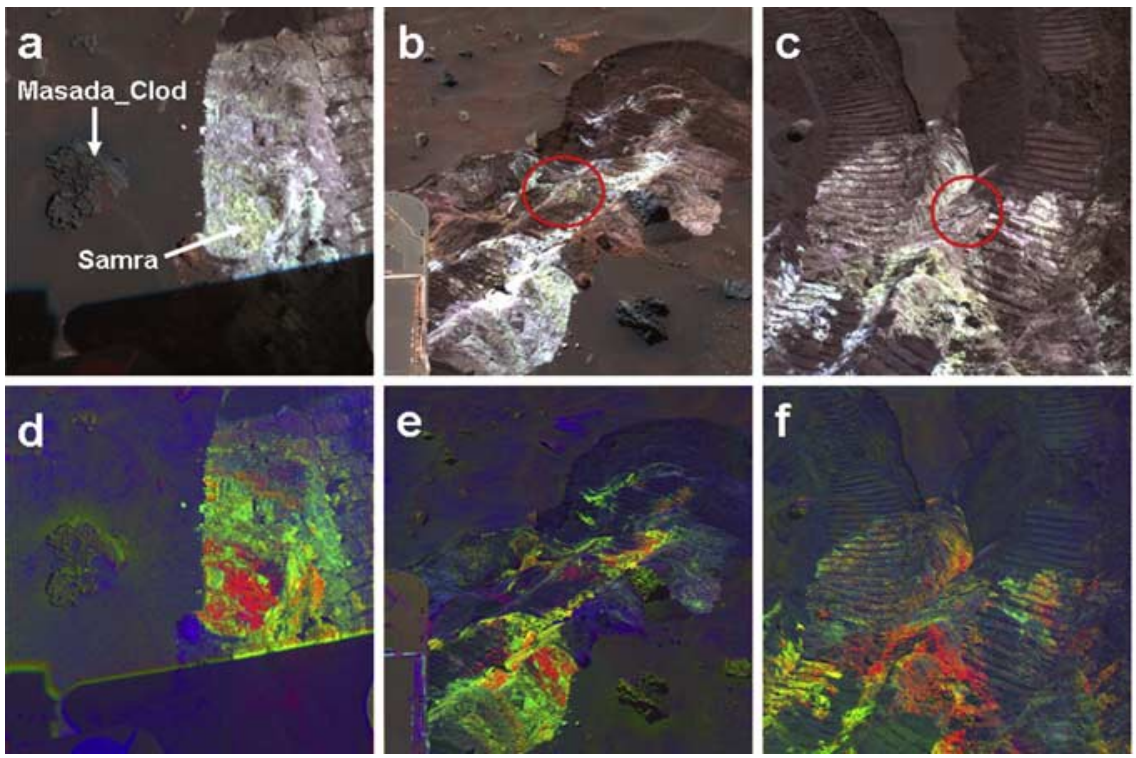

Figure 2. Pancam false color images (using L2 $(753 \mathrm{~nm})$, L5 $(535 \mathrm{~nm})$, and L7 (432nm) of excavated soils in the Dead Sea area. (a) Sol 722, Sequence_P2514, (b) sol 721_P2538, (c) sol 725_P2547, and corresponding decorrelation stretched (DCS) images also using (d) L2, (e) L5, and (f) L7, show distinct varieties and spatial distributions of the light-toned salty soils excavated at the Dead Sea (Arad) area (site $122)$ and their spatial distributions. Circles in Figures $2 b$ and $2 c$ indicate pieces of more cohesive material (crusts). For scaling purpose, the width of rover wheel track is about $16 \mathrm{~cm}$. 


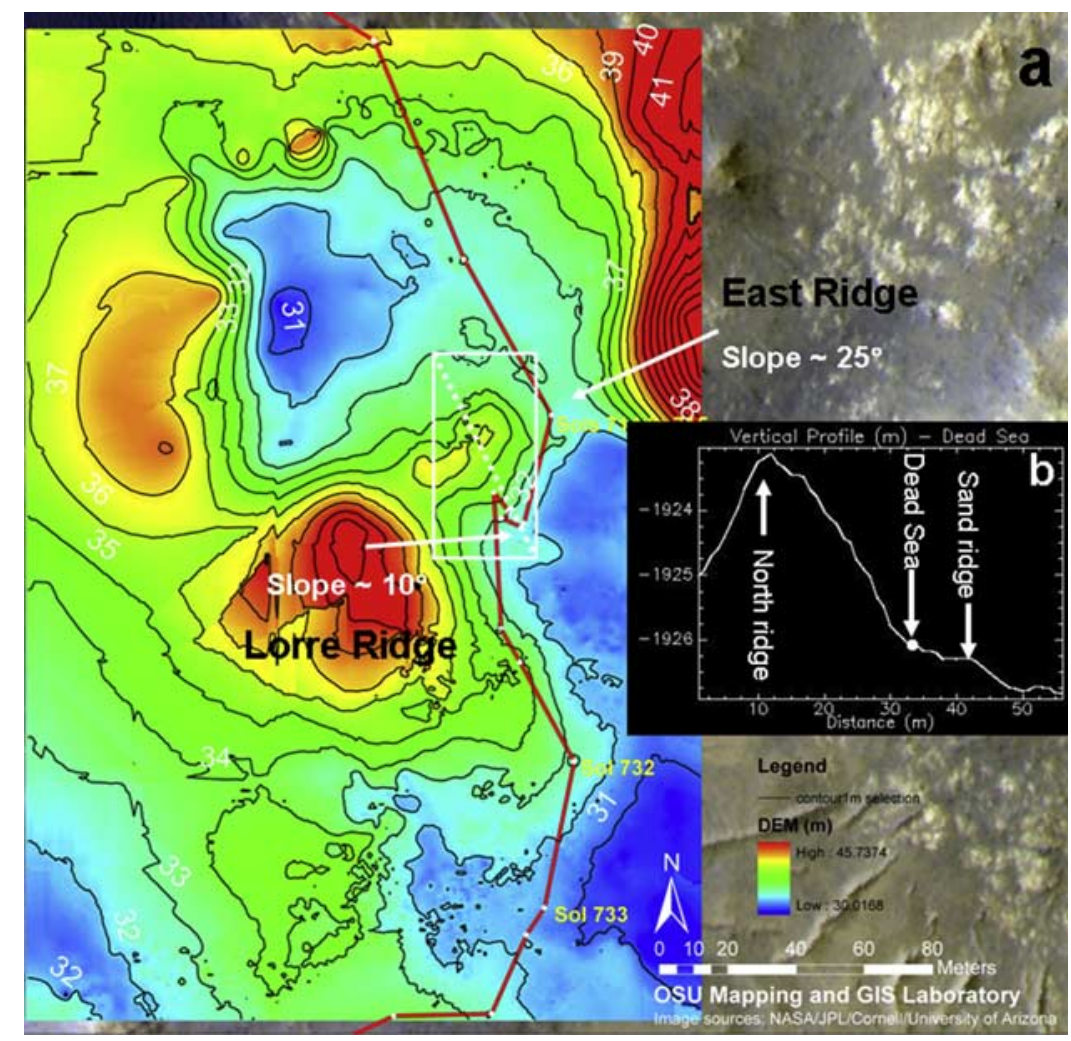

Figure 3. (a) A contour map overlain on a High Resolution Imaging Science Experiment (HiRISE) image in the vicinity of the Dead Sea site, showing the slopes of surrounding hills. (b) Vertical profile taken along the diagonal within the white rectangle in Figure 3a in the vicinity of the Dead Sea site.
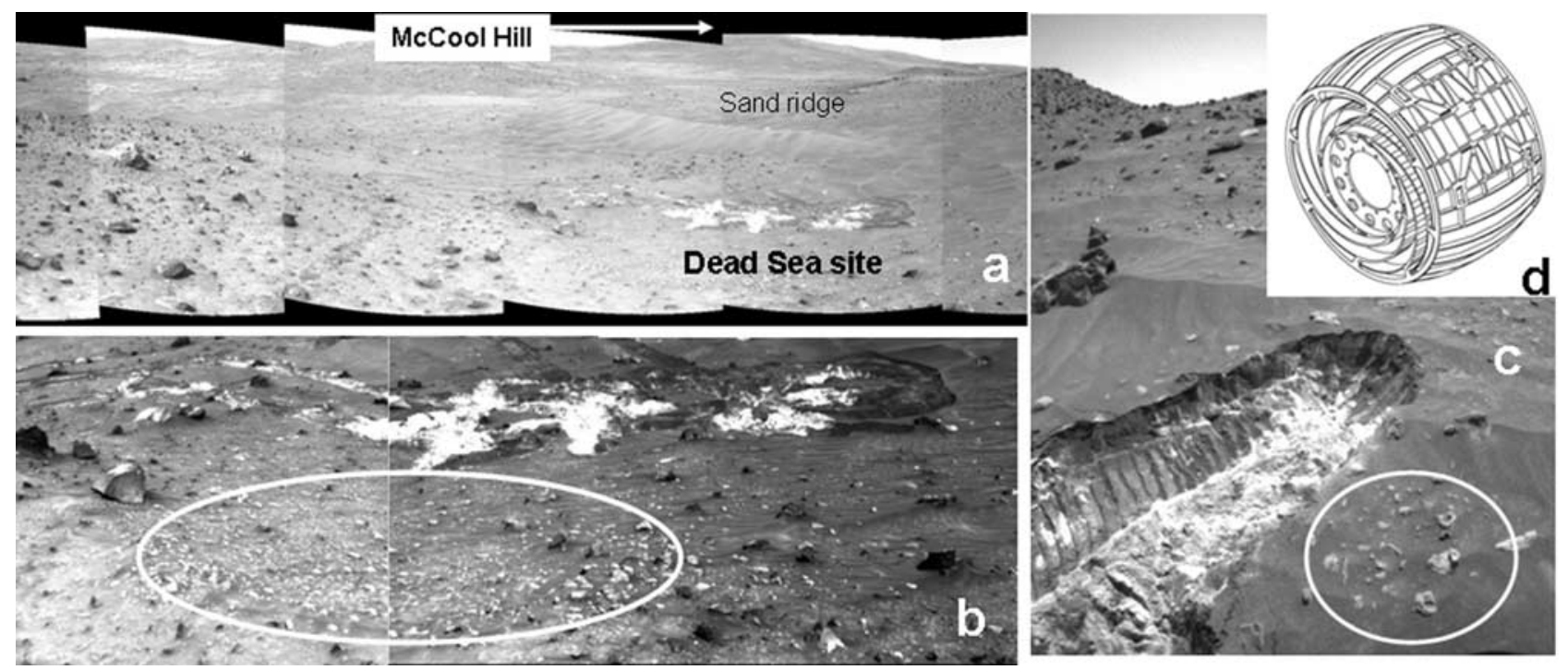

Figure 4. (a) Navcam panorama (sol 727_P0695) showing that the Dead Sea site is within the valley and also enclosed by local topographic highs, including the sand ridge marked in Figure 3c. (b) Navcam image (sol 727_P0695) of the excavated light-toned salty soils at the Dead Sea site and the light-toned nodules nearby (shown by white oval). (c) A rear Hazcam image (sol726_P1312) shows a near field view of S-rich soils in the rover tracks and light-toned nodules (within white circle). (d) Schematic drawing of rover wheel showing the cleats and tie-down plate that helped to serendipitously excavate buried lighttoned soils. The diameter of the wheel is $26 \mathrm{~cm}$; the width of its outer rim is $16 \mathrm{~cm}$. 


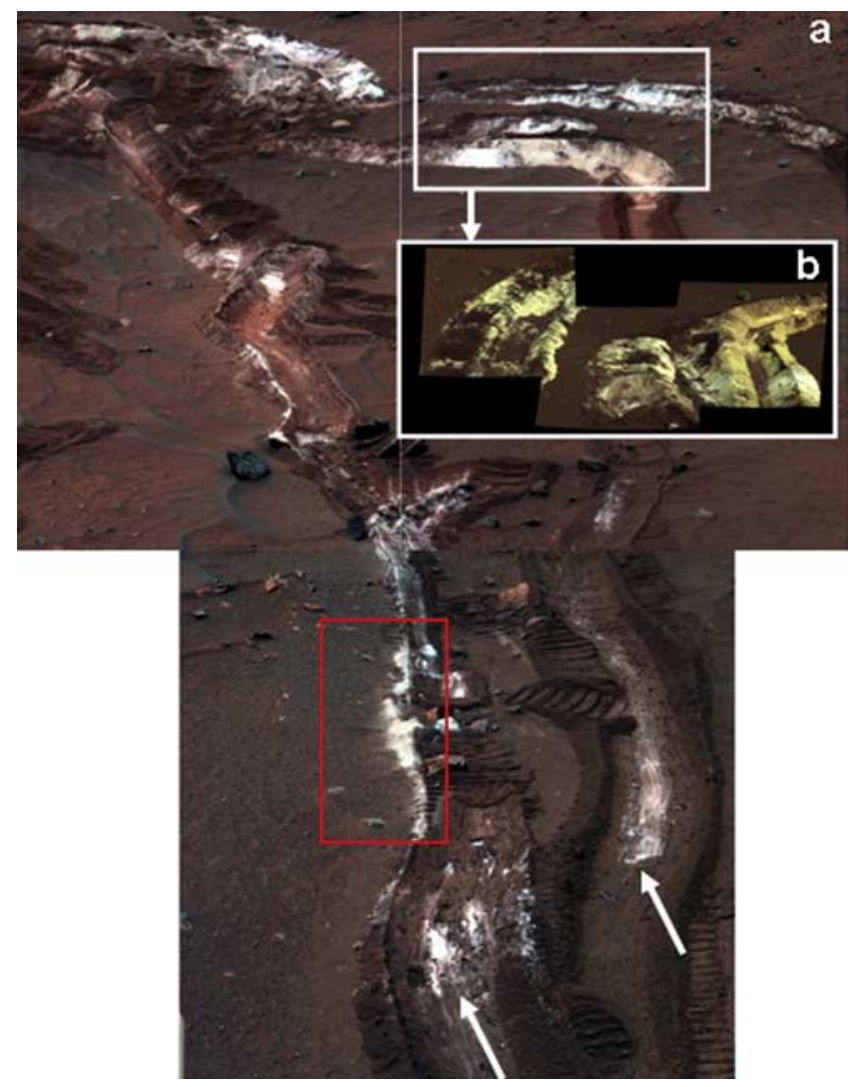

Figure 5. Pancam false color images of the light-toned salty soils at the Tyrone site excavated during sols 784-798 of Spirit's travel and revisited during sols 1098-1103. (a) Pancam false color images (sol 1098 P2548, sol1099 P2549, sol1100 P2550) of Tyrone site from about $12 \mathrm{~m}$ away. The red rectangle indicates the light-toned salty soils collected by nonrolling right front wheel and redistributed along the drive. The write color arrows indicate more light-toned materials exposed in the tracks. (b) Pancam false color image (sol 788_P2396) of the salty soils at Tyrone viewed after the first excavation and from a different viewing angle. For scaling purpose, the width of rover wheel track is about $16 \mathrm{~cm}$.

shows two different colors but a more or less homogeneous spatial distribution that will be discussed in section 4 .

[7] The Dead Sea site (site 122, sols 719-728) is to the south of the El Dorado sand dunes and north of Mitcheltree Ridge, within a valley $\sim 30-50 \mathrm{~m}$ wide and northwestsoutheast oriented, between East Ridge and Lorre Ridge (Figure 3). Figure $3 \mathrm{a}$ is a contour map developed on the basis of stereo Pancam and Navigation Cameras (Navcam) images taken along the traverse route of the Spirit Rover overlain on an image from the High Resolution Imaging Science Experiment (HiRISE) on Mars Reconnaissance Orbiter (MRO). Figure $3 \mathrm{~b}$ is a vertical profile obtained from the Digital Elevation Model (DEM) generated using HiRISE stereo image pairs (provided by Kirk et al. [2008]), along a line passing through the Dead Sea site (white-dotted diagonal line marked within white rectangle in Figure 3a).

[8] On the basis of these maps, the excavated Dead Sea salty soils are located at the base of a northeast extension of Lorre Ridge, on a terrace near the bottom of the valley floor (Figures $3 \mathrm{a}$ and $3 \mathrm{~b}$ ). The soil exposure is about $14 \mathrm{~m}$ lower than the top of East Ridge and $8 \mathrm{~m}$ lower than the top of Lorre Ridge on the west. Both ridges have steep slopes $\left(25^{\circ}\right.$ and $10^{\circ}$ respectively) toward the valley. The northwest side of the Dead Sea site is enclosed by the extension of Lorre Ridge protruding into the valley (of $4 \mathrm{~m}$ height, Figures 3a and $3 \mathrm{~b})$; its southeast side is blocked by a sand ridge $(<1 \mathrm{~m}$ height, also seen in Figure 4a). In other words, the Dead Sea site is within a partially enclosed low, but not at the lowest spot of the valley floor. Vesicular and blocky basaltic float rocks appear on the slopes immediately to the north, and aeolian sand ripples partially cover the south portion of the valley floor (Figure 4).

[9] The major exposure of salty soils in the Dead Sea area covers an area about $2.7 \mathrm{~m}$ in width (north-south orientation) and about $4.2 \mathrm{~m}$ in length (east-west orientation). The tracks with exposed light-toned salty soils extend over a larger distance, about $7.4 \mathrm{~m}$ in east-west orientation (Figure $4 \mathrm{~b}$ ). In the images taken by Pancam, Navcam, and Hazard avoidance cameras (Hazcam), the aeolian deposits originally on top of the salty soils are fine-grained and typically thin (Figure 2a), but with variable thickness (Figure 2b). In this paper, the size of the Spirit Rover wheel will be used, wherever possible, to give an estimation of the thickness of any overlying aeolian deposits and the possible burial depth of salty soils. The wheels have a diameter of $26 \mathrm{~cm}$, and a width of $16 \mathrm{~cm}$. The height of the ridged cleats on the outside rim of the wheels is about $5 \mathrm{~mm}$ (Figure 4d).

[10] A Hazcam image (sol 726, P1312) (Figure 4c) shows light-toned soils exposed at the bottom of the trench made by the rover wheel, as well as some light-toned soil spots on the trench wall. The soils are mostly loose, but a few pieces of crust were also observed (circled in Figures $2 b$ and $2 c$ ). Figure $4 \mathrm{c}$ also shows a group of light-toned cobbles next to the exposed light-toned soils (in white circle in Figure 4c). These cobbles have uneven surfaces and rounded edges, unlike the flat facets and angular edges often seen on pieces of blocky basaltic rock typically seen in Gusev images. Cobbles with such specific surface morphologies will be referred to as "nodules" in the rest of this paper. Small pieces of vesicular basalt are also seen on the ground. Their dark-toned nature (Figure $2 b$ ) is clearly distinguishable from the light-toned nodules. Figure $4 \mathrm{~b}$ shows a lot of light-toned nodules half buried in the slightly higher ground right next to the exposed Dead Sea light-toned soils.

[11] Multiple remote sensing measurements using Pancam with all 13 geology filters (providing 11 unique spectral bands in a visible near-infrared (Vis-NIR) spectral range from $432 \mathrm{~nm}$ to $1009 \mathrm{~nm}$ [Bell et al., 2003]) and Miniature Thermal Emission Spectrometer (Mini-TES) [Christensen et al., 2003] were made at Dead Sea light-toned soils. In situ measurements using Alpha Particle X-ray Spectrometer (APXS) [Rieder et al., 2003], Mössbauer Spectrometer (MB) [Klingelhöfer et al., 2003], and Microscopic Imager (MI) [Herkenhoff et al., 2003] were made on light-toned soils and a dark toned vesicular basaltic cobble.

[12] The excavated Tyrone light-toned soils (Figure 5) also occur within a local topographic low, defined by Low Ridge, Home Plate, Mitcheltree Ridge, and McCool Hill (Figure 6). McCool Hill is on the southeast side of the Tyrone site, with a summit about $64 \mathrm{~m}$ higher and about $300 \mathrm{~m}$ away, and flanks sloping toward the Tyrone site with an average incline of $12^{\circ}$. The Tyrone site is within a triangular-shaped 


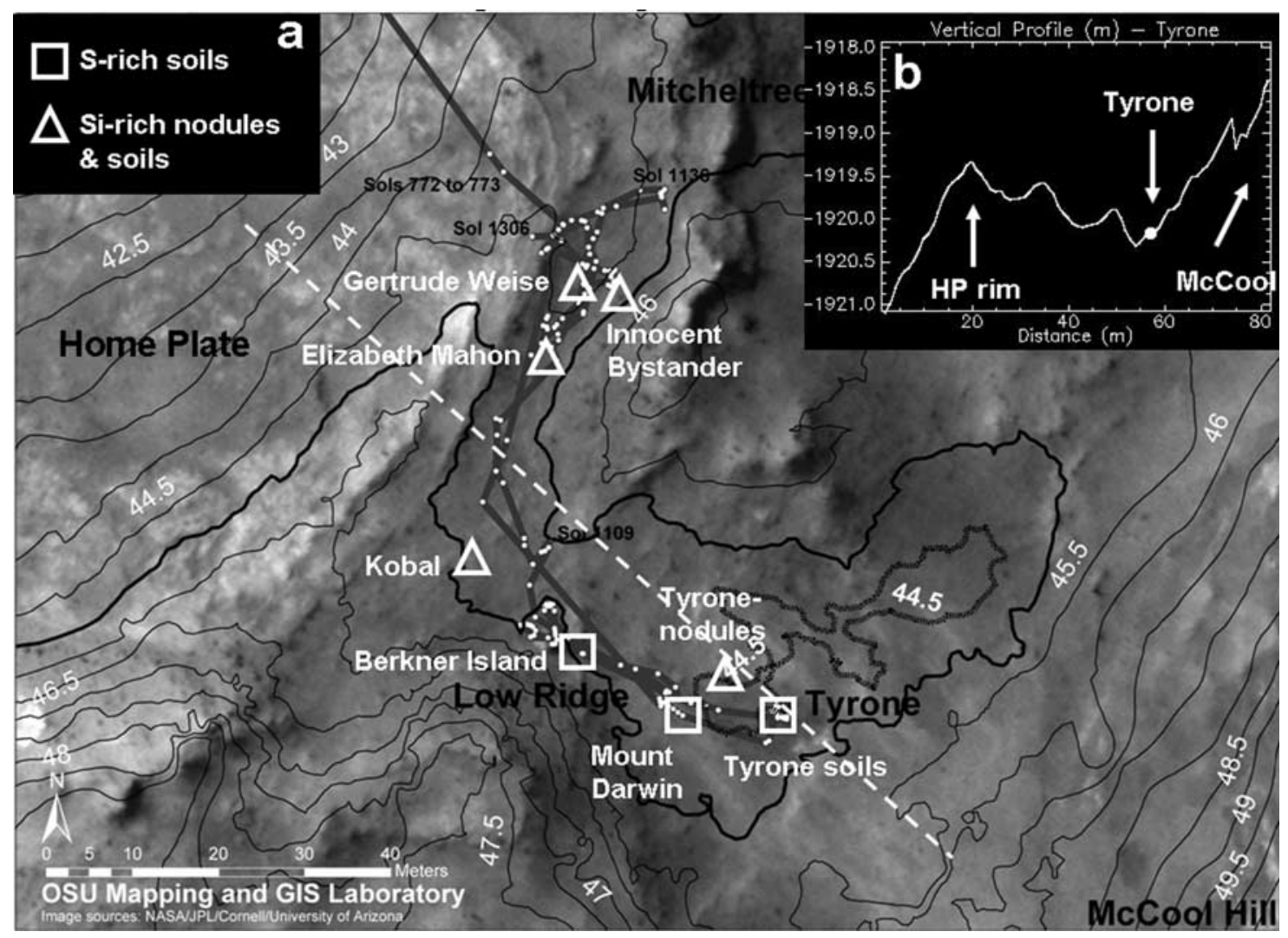

Figure 6. (a) Contour map, overlain on a HiRISE image, of the Tyrone and Eastern Valley region. Notice that the locations of Tyrone S-rich soils (squares) and Si-rich nodules and soils (triangles) in the Eastern Valley are within the $45.0 \mathrm{~m}$ contour lines. It shows that the Tyrone site is at the edge of the lowest area enclosed by a $44.5 \mathrm{~m}$ contour line. (b) Vertical profile along the white dotted line in Figure 6a across Home Plate-Tyrone-McCool flank, that shows the location of excavated Tyrone salty soils.

low marked by the $45.0 \mathrm{~m}$ contour line (coarse black contour line in Figure 6a), which is surrounded by Low Ridge (about $4 \mathrm{~m}$ higher), Home Plate (about half meter higher), and Mitcheltree Ridge (about $1 \mathrm{~m}$ higher).

[13] The lowest area within the triangular-shaped low is marked by the $44.5 \mathrm{~m}$ contour line (gray contour line in Figure 6a). The excavated Tyrone salty soils are located at the edge of this lowest area (Figure 6b, vertical profile). Spirit drove along the southern edge of the lowest area only once, got trapped by the excavated Tyrone salty soils and took several sols to free itself. Therefore, we do not know if there are light-toned soils at the lowest area and, and if so, what their distributions might be. In other words, the potential existence of light-toned soils within the $44.5 \mathrm{~m}$ contour line at Tyrone site cannot be excluded. It is important to mention that light-toned Si-rich soils and nodular materials [Arvidson et al., 2008; Squyres et al., 2008] were also identified within the same topographic low where Tyrone salty soils occur (45.0 m contour line), on the floor of Eastern Valley between Mitcheltree Ridge and the east side of Home Plate. These Si-rich targets are marked as white triangles in Figure 6a, and will be discussed in section 3.2.

[14] Around sol 784, just before Spirit entered the Tyrone region, the drive motor on its right front wheel ceased working. Since then, Spirit has been driving backward, dragging the right front wheel behind. At Tyrone, the dragging wheel made long trenches and large amounts of light-toned soils were exposed (Figure 5). The trenches made by dragging the right front wheel are much deeper than the tracks made by the other five rolling wheels (for example, compare the right side track with the left tracks in Figure $7 \mathrm{c}$ ). These trenches have depths of $\sim 8-16 \mathrm{~cm}$. At a few spots, manipulation to free the Spirit Rover made the dragged front right wheel sink into deeper "holes" of roughly 14-16 cm depth, and even more light-toned soils were exposed (white arrow in Figures $7 \mathrm{a}$ and $7 \mathrm{c}$ ). These observations imply that there may be several centimeters of similar materials beneath the surface dust and basaltic soils at the Tyrone site.

[15] Only a few remote sensing measurements using Pancam and Mini-TES were made on the exposed Tyrone light-toned soils during sols 779 to 799 , because the focus in that period was on successfully extricating the rover rather than obtaining science measurements. Over 300 sols later, from sols 1096 to 1103 , Spirit Rover returned to a Tyrone-offset location (Mount Darwin target in Figure 6a), where remote sensing on Tyrone-proper light-toned soils and in situ measurements (APXS, MB, and MI) on target Mount Darwin were made. Mount Darwin is the light-toned soil carried away by Spirit's wheels from Tyrone-proper site to this Tyrone-offset site ( $\sim 15 \mathrm{~m}$ away). Because the inoperative right front wheel of Spirit Rover had sunk quite deep at Tyrone-proper site, a moderate amount of lighttoned salty soil was collected by this nonrolling wheel. The 

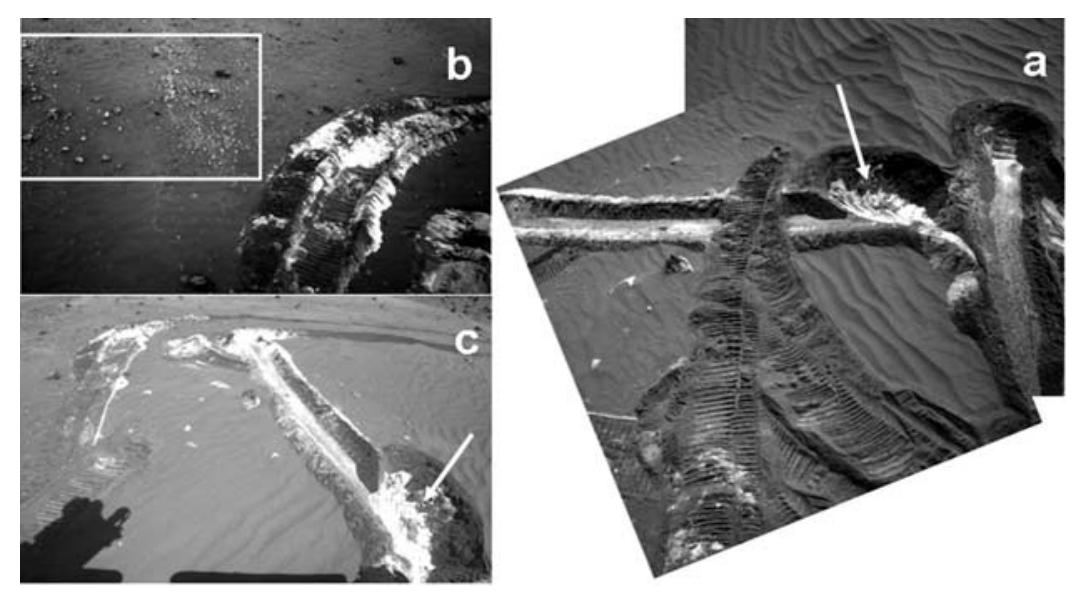

Figure 7. (a) a Navcam image (sol 794_P1911) shows the exposure of light-toned salty soils at Tyrone from different depths (arrow indicates deepest spot); (b) Navcam image (sol 787_P1908) shows a patch of light-toned nodules (indicated by a white rectangle) occurring right next to the exposure of Tyrone salty soils; (c) Front Hazcam image (sol 788_P1211) shows the "trench" made by dragging the right front wheel and the tracks made by other wheels of Spirit (arrow indicates the deepest spot). The width of rover wheel track is about $16 \mathrm{~cm}$ for scale.

soil was then carried and distributed in the wheel tracks (red rectangle in lower portion of Figure 5a) during the travel, until Spirit reached its 2nd winter haven location at Low Ridge. Another Tyrone-offset target (Berkner Island in Figure $6 \mathrm{a}$, on light-toned Tyrone soils that were carried to $\sim 30 \mathrm{~m}$ away) was investigated at that winter haven location. These two in situ measurements confirmed the sulfaterich nature of Tyrone light-toned soils.

[16] The major exposure of light-toned salty soils at Tyrone (Figure 5) covers an area of about $5.4 \times 3.8 \mathrm{~m}$ (upper portion in Figure 5a), although the tracks with exposed light-toned salty soils actually extend to long distances (e.g., light-toned soils in tracks at lower portion of Figure 5a, indicated by white arrows). There are small aeolian ripples throughout the area (Figure 7a) as well as sparsely distributed clasts of what are interpreted to be both vesicular and massive basalt. As was the case at the Dead Sea site, plentiful light-toned nodules with uneven surfaces and rounded edges are seen near the Tyrone salty soils (Figure $7 \mathrm{~b}$ ). These nodules are usually gathered in patches, and usually occur on the peripheral slopes surrounding the Tyrone site.

[17] In images taken by Pancam, Navcam, and Hazcam, the aeolian deposits originally covering the Tyrone salty soils can be seen to vary in thickness. Thickness can be estimated using the surface indentations left by Spirit's wheel cleats (Figure $4 \mathrm{~d}, \sim 5 \mathrm{~mm}$ ) and the exposed patterns of light-toned salty soils created when the wheels repeatedly rolled over the same areas during the rover's attempts to free itself from the Tyrone salty soils. In some places, the salty soils are exposed by a single wheel rollover, and in other places, the salty soils were apparently exposed only after repeated rollovers (Figures 7a, 7b, and 7c). These observations imply a variable burial depth of salty soils at the Tyrone site ranging from about $<5 \mathrm{~mm}$ to $>1 \mathrm{~cm}$.

\subsection{Geomorphic Setting 2: At the Base of a Steep Slope}

[18] Small amounts of light-toned soils were excavated by Spirit at the Hank's Hollow-Shredded area (Figure 8b) with different colors and heterogeneous distributions. Hank's Hollow is located at the base of a relatively steep slope on West Spur [Li et al., 2006] (Figures 8a and 8c), whose summit is $\sim 18 \mathrm{~m}$ above the basaltic plains, and $\sim 14 \mathrm{~m}$ above Hank's Hollow. The side of West Spur facing toward Hank's Hollow has an average slope of $\sim 10^{\circ}$, with a maximum of $\sim 16^{\circ}$ at its steepest. Spirit explored the Hank's Hollow region from sols 158 to 182 , where detailed investigations (in situ and remote sensing) on rock targets Pot of Gold and Breadbox were conducted. The efforts at repositioning the rover to achieve the best orientation for in situ measurements of these rocks greatly disturbed the local soils. As a result, light-toned soils were exposed at multiple places in the wheel tracks and the disturbed area was named Shredded (Figure 8b). Pancam images using 13 geologic filters and Mini-TES long-duration thermal infrared spectral measurements were made on these light-toned soils, but no in situ measurements (APXS, MB, and MI,) were made.

[19] Hank's Hollow is a circular depression 7-8 $\mathrm{m}$ in diameter and possibly represents a degraded small impact crater (Figure 9a). It is filled with regolith and a few patches of rocks, presumably formed and/or modified by aeolian process and impact events (Figure 9b). The Shredded area, where several patches of light-toned soils were exposed, occupies an area about $2 \times 3 \mathrm{~m}$ in size (Figure $8 \mathrm{~b}$ ). Most of the light-toned soil patches appear to be exposed by the cleats on the rover wheels as they cut into the surface by a single rollover. At a few places, somewhat larger amounts of light-toned soils were exposed when the wheel apparently dug deeper. The light-toned soils appear to be buried beneath a layer of surface soil of irregular thickness, generally $<5 \mathrm{~mm}$ thick.

[20] The rocks in Hank's Hollow that occur along with the light-toned soils are generally small $(<20 \mathrm{~cm}$ in diameter), and are characterized by a variety of surface morphologies (Figure 9b). Some appear to be broken pieces from dense basalt (Figure 9d); a few appear to be basaltic rocks or clasts with sparsely distributed vesicles (Figure 9c). The rock Breadbox (Figure 9f), at the rim of a circular 


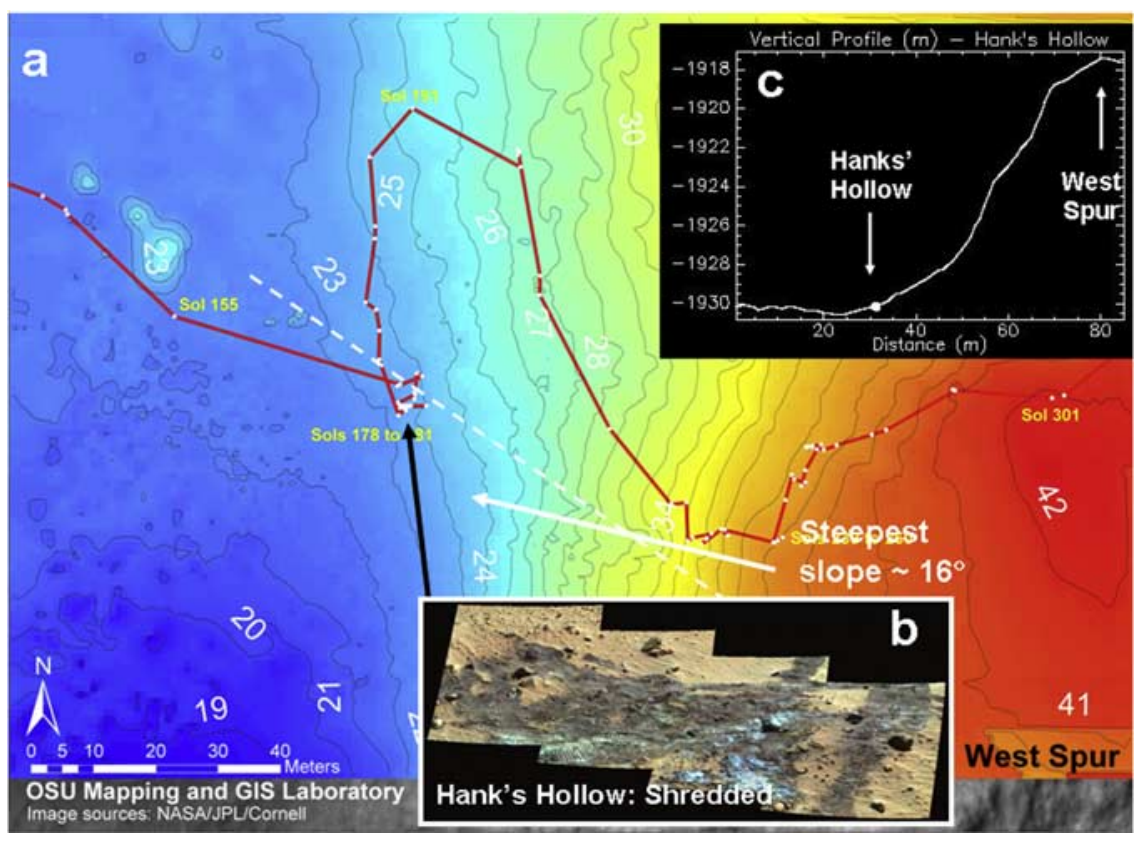

Figure 8. (a) A contour map overlain on a HiRISE image shows the location of Hank's Hollow at the base of West Spur; (b) Pancam false color images (sol 170_P2379) of the light-toned soils excavated by Spirit at Hank's Hollow "Shredded" site; (c) vertical profile along the white dotted line in Figure 8a shows that "Shredded" site is at the foot of West Spur.

depression inside of Hank's Hollow (Figure 9b), appears to be extensively physically weathered, with a rectangular shaped residual case. The nearby rock Pot of Gold (Figure 9e), and others like it, appears to consist of irregularly shaped millimeter-sized clasts (Figures 9g, 9h, and 9i). The positions of these rocks around Hank's Hollow (some near the rim of that circular depression, some in the middle) suggest that some of them may be locally excavated impact ejecta, and some of them may be distal ejecta from nonlocal impacts (Figures 9c and 9d). The arrangement, clustering, and circular distribution of many of the clasts around the rim of a circular depression in particular (Figure 9b) suggest that they may represent the exposed margins of a small impact crater.

\subsection{Geomorphic Setting 3: Adjacent to Large Outcrops}

[21] Trace amounts of light-toned soils were exposed in Spirit's tracks in a region adjacent to the Jibsheet Outcrop on Cumberland Ridge (Figure 10), and in front of the Hillary Outcrop at the summit of Husband Hill (Figure 12). In Pancam images, those light-toned soils show quite homogeneous color at both locations. The light-toned soils appear as cyan colored patches in false color Pancam images (Figures 10 and 12). This color tone is different from that of the compressed rover tracks, which are also light-toned in false color Pancam images (Figure 10c). Cumberland Ridge is on the western side of Tennessee Valley and on the northnorthwest flank of Husband Hill [Arvidson et al., 2008]. The terrain there generally slopes downward to the northwest. The Jibsheet Outcrop and nearby Larry's Lookout Outcrop (Figures 10 and 11) consist of northwest dipping laminated rocks exposed along a northeast-southwest trend. Both outcrops face southeast, and are about 1-2 $\mathrm{m}$ above the area traversed by Spirit [Arvidson et al., 2008; Li et al., 2006].
[22] Spirit's exploration in the Jibsheet and Larry's Lookout area occurred from sols 435 to 510 . The wheel tracks with exposed light-toned soils are to the southeast of the Jibsheet Outcrop, extending across an area of about $7 \times 2 \mathrm{~m}$ (Figures 10b, 10c, and 10d). The exposures of light-toned soils are seen either in the tracks made by wheels during a single traverse (Figures $10 \mathrm{~b}$ and $10 \mathrm{c}$ ), or in the tracks made during repeated traverses of the same terrain (Figure 10d), thus suggesting a thickness of the overlying dust/soil surface layer in a range of $<5 \mathrm{~mm}$ up to $1 \mathrm{~cm}$. Interestingly, the tracks showing exposed light-toned soils do not occur at the immediate base of the Jibsheet Outcrop (yellow and red arrows in Figure 10a), but at locations a few meters away (Figures 10b, 10c, and 10d); that is, the light-toned subsurface soils exist in the areas where overlying aeolian deposits have minimum thickness. A thick layer of aeolian drift occurs on the immediate southeastern slope of the Jibsheet Outcrop. Spirit made several deep tracks into this deposit while trying to reach a target on Jibsheet Outcrop for in situ measurements. There is no light-toned soil exposed in these particular deep tracks (yellow arrows in Figure 10a), or in other tracks near the immediate base of Jibsheet (red arrows in Figure 10a). This observation suggests that the accumulation of light-toned soils in this area should have occurred prior to the accumulation of modern aeolian deposits. Additional light-toned soil patches were observed farther from the Jibsheet Outcrop, for example, about $10 \mathrm{~m}$ southeast of Jibsheet (Figure 11b and marked by an open white cross in Figure 11a) and between the Jibsheet and Larry's Lookout outcrops (similar indication in Figure 11a). They suggest that a wide distribution of light-toned material may exist underneath the surface dust/soil in this area.

[23] Trace amounts of light-toned soils were also exposed in the wheel tracks in the Husband Hill summit area, 


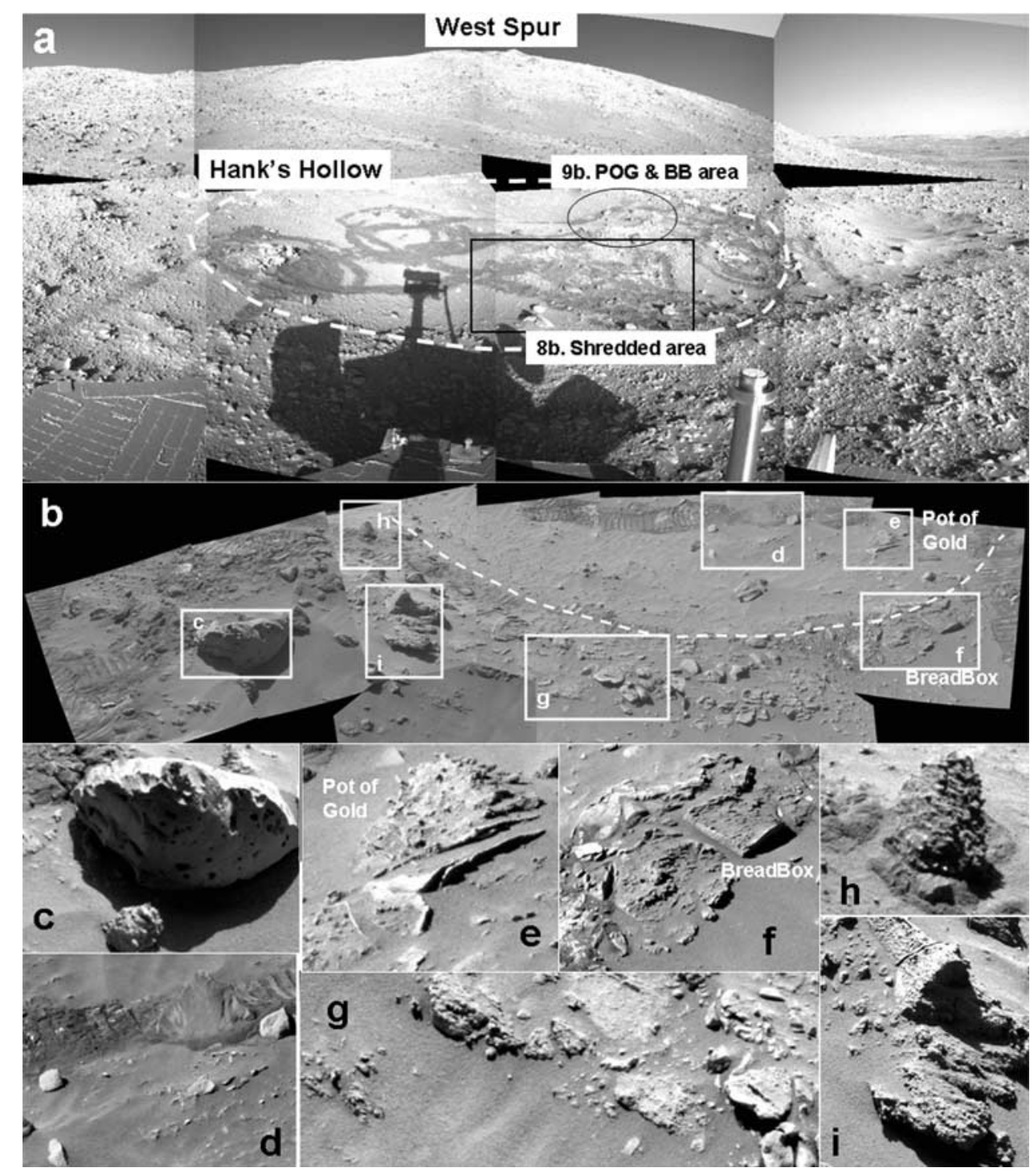

Figure 9. (a) Navcam panorama (sol165 P2377) taken near Hank's Hollow shows the location of excavated light-toned soils (close-up shown in Figure 8b), and the location of the small circular depression where the rocks Pot of Gold and Breadbox occur (close-up shown in Figure 9b). (b) Pancam image that covers Pot of Gold, Breadbox, and (c, d, e, f, g, h, i) other rocks with widest range of surface morphology. See text for further discussion. The width of rover wheel track is about $16 \mathrm{~cm}$ for scale.

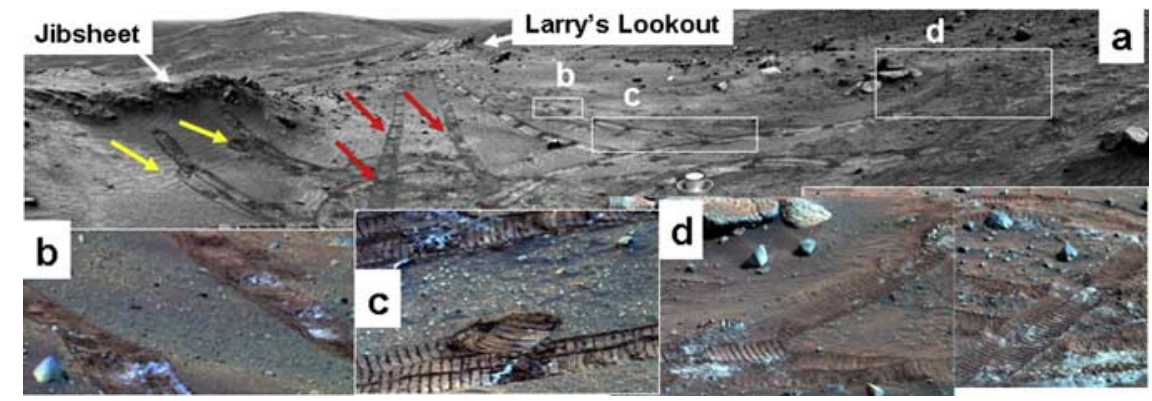

Figure 10. (a) Navcam panorama at position 436 of site 110 near the Jibsheet Outcrop that shows the locations where the Pancam images were taken. Red arrows indicate the tracks at the immediate base of the Jibsheet Outcrop that did not expose light-toned soils. Yellow arrows indicate where wheel tracks are deepest. (b) Sol 456_P2279, (c) sol 486_P2598, and (d) sol 510_P2290 Pancam false color images show that a thin layer of light-toned soils was exposed a few meters away from the base of the Jibsheet Outcrop. The width of rover wheel track is about $16 \mathrm{~cm}$ for scale. 


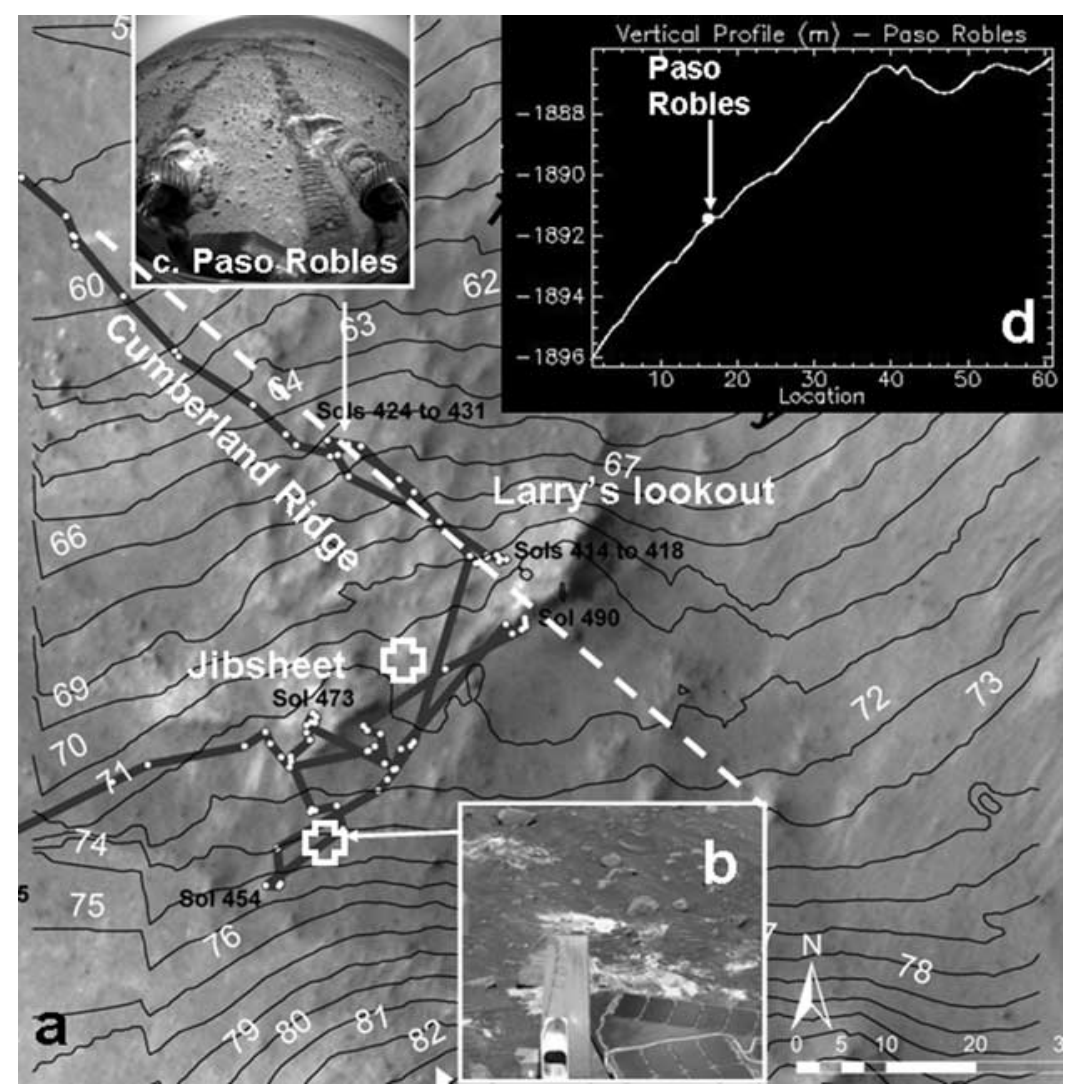

Figure 11. (a) Contour map overlain on a HiRISE image over the Paso Robles site and Larry's Lookout outcrops; (b) sol 455_P2548 is a Pancam image showing the exposed light-toned soils located about $10 \mathrm{~m}$ away from Jibsheet Outcrop, it is marked as an open white cross in Figure 11a. A similar occurrence happened at a location between Jibsheet and Larry's Lookout outcrops marked in Figure 11a. They suggest that a significant distribution of light-toned material may exist underneath the surface soils and dust in this area. (c) Front Hazcam image (sol 398_P1212) shows the exposure of light-toned salty soils at the Paso Robles site; (d) vertical profile along the white dotted line across the Paso Robles site.

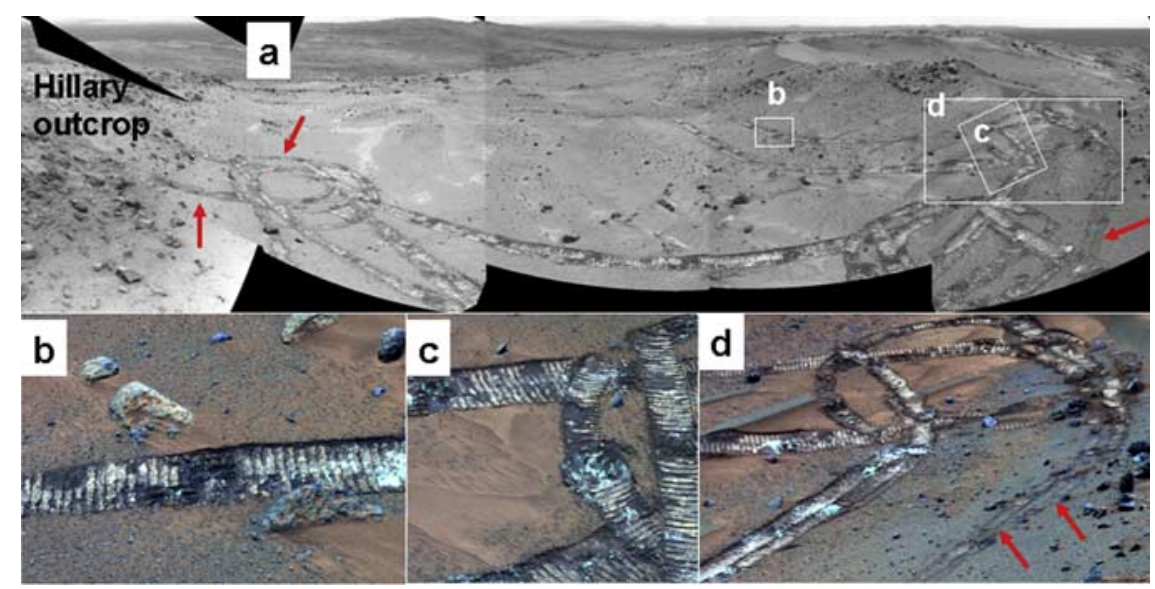

Figure 12. (a) Navcam panorama at position 852 of site 114 at the summit of Husband Hill that shows the locations where the Pancam images were taken; (b) sol 628_P2537, (c) sol 628_P2538, and (d) sol 621 P2294 are Pancam false color images that show the relatively small amount of light-toned soils exposed in rover tracks at a few meters from the base of the Hillary Outcrop. Red arrows indicate the tracks at the base of outcrop that did not expose light-toned soils. The width of rover wheel track is about $16 \mathrm{~cm}$ for scale. 


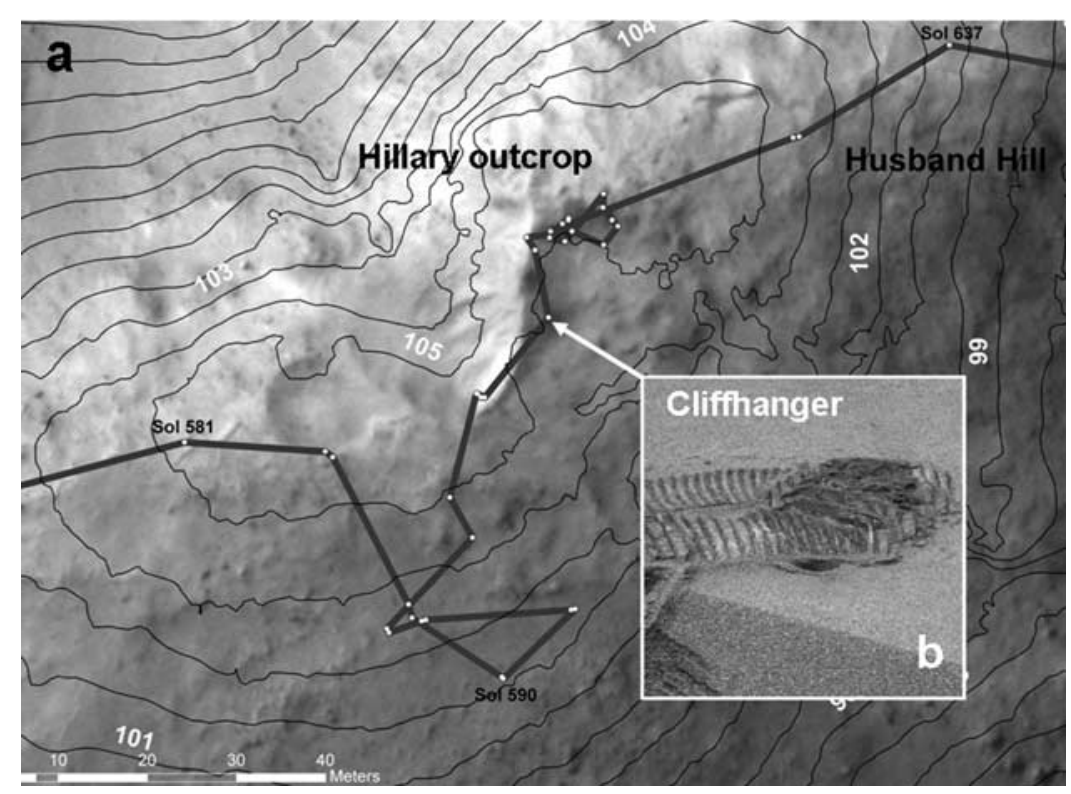

Figure 13. (a) Contour map of site 114 overlain on a HiRISE image of the summit of Husband Hill; (b) Pancam image (sol621_P2589) of Cliffhanger, a wheel scuff on a relatively recent aeolian ripple without any light-toned soil exposure.

especially in front of the Hillary Outcrop (Figure 12). Spirit explored this area from sols 613 to 628 . The tracks that exposed trace amounts of light-toned soils extend over an area of about $10 \times 15 \mathrm{~m}$ in between a large sand ripple Cliffhanger and the Hillary Outcrop (Figures 13a and 13b). Only sparse exposures of light-toned soils are seen in the tracks here (Figures 12b, 12c, and 12d). They occur more often in the part of the tracks (Figure 12c) made by the "tiedown plate" on the rover wheels (the part on the rim of wheel in Figure 4d that consists of many rectangular shaped frames), where the relief of ridges can approach $\sim 23 \mathrm{~mm}$. The light-toned soils exposed by the typical $\sim 5 \mathrm{~mm}$ wheel cleats are rare but still occasionally visible. These observations suggest burial depths of $\geq 1-2 \mathrm{~cm}$ for the light-toned soils in the summit area, deeper than those near the Jibsheet Outcrop.

[24] Similar to those near the Jibsheet Outcrop, the tracks at the base of the Hillary Outcrop have not exposed any light-toned soils (red arrows in Figures 12a and 12d), whereas the tracks a few meters farther away have exposed light-toned soils at sparsely distributed places (Figures 12b, $12 \mathrm{c}$, and 12d). Near the tracks with exposed light-toned soils, aeolian deposits appear to be the thinnest (Figures 12b and $12 \mathrm{c}$ ). No light-toned soils were exposed in a wheel scuff made into the aeolian ripple named Cliffhanger (Figure 13b). These observations suggest that the accumulation of light-toned soils in the vicinity of the Hillary Outcrop should have occurred earlier than the accumulation of the modern aeolian deposits in this area, similar to the inferred situation near the Jibsheet Outcrop at Cumberland Ridge described above.

[25] In a contour map overlain on a HiRISE image (Figure 13a), the Hillary Outcrop and a long sand ripple form an " $L$ " shaped feature that opens toward the southeast. The wheel tracks that exposed some light-toned soils are located in this L shaped opening. The Hillary Outcrop itself is about $1-1.5 \mathrm{~m}$ above the region the rover traversed, and thus it could be a favorable location at the summit for collecting wind-blown materials from the south.

\subsection{Geomorphic Setting 4: On the Slopes}

[26] On the slope of Cumberland Ridge $\left(\sim 14^{\circ}\right.$ average slope), two occurrences of light-toned soils were encountered. Near the base, in the vicinity of the rock target Champagne and the soil target Penny, a small amount of light-toned soils was excavated by Spirit (Figures 14a and 14b). Near the top of Cumberland Ridge, about $30 \mathrm{~m}$ from and $6 \mathrm{~m}$ below the Larry's Lookout Outcrop, a moderate amount of salty soils was excavated at the Paso Robles site (Figures 11c and 15). In Pancam images, the light-toned soils show different colors and heterogeneous distributions at both locations.

[27] Spirit traversed along the northwest slope of Husband Hill from sols 342 to 360 , and in situ measurements were made on the soil Penny (Figure 14b), the rock Dreaming (not shown), and the rock Champagne (not shown). During this period, Spirit circled through an area covering about $4 \times 3 \mathrm{~m}$. A small amount of light-toned soils was found near the rock Wishstone (sols 343 to 351, Figure 14a), and a trace amount occurs near the rock Champagne (sols 359 and 360 , not shown). None of these rocks appear to be in-place outcrop. Rather, they appear to be float from an unknown source, perhaps from farther upslope or perhaps from a distant impact crater.

[28] Relatively thick aeolian ripples cover most of the slope northwest of the Champagne-Penny site. The exposure of light-toned soils occurs in the area where the aeolian deposits appear to be the thinnest (e.g., Figure 14a). We speculate that beneath aeolian deposits of irregular thickness at this site, light-toned soils may exist and be distributed in a region much larger than the area serendipitously excavated by Spirit. The light-toned soils were targeted in four 13-filter Pancam observations and one 4-filter Pancam 


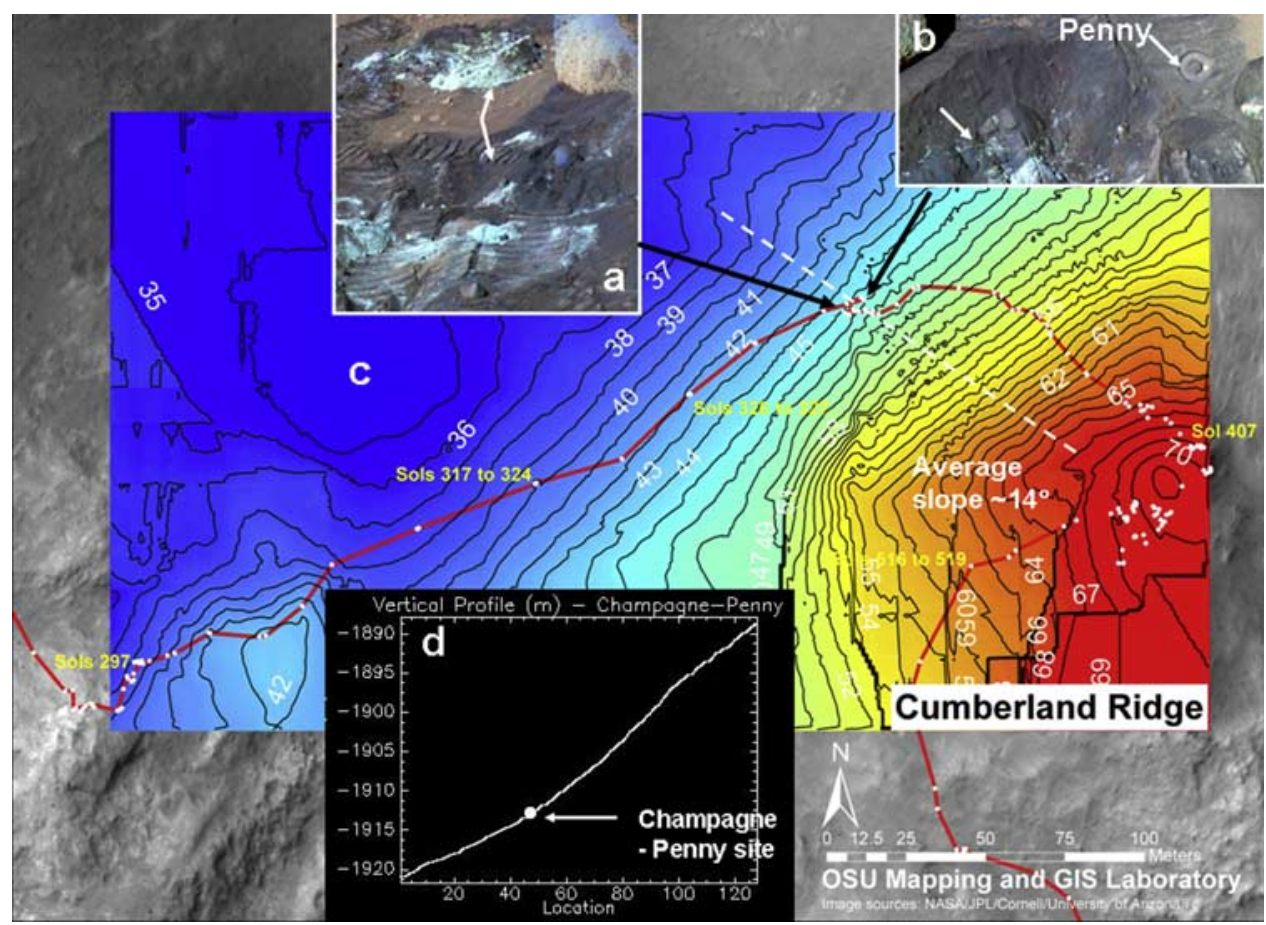

Figure 14. Pancam false color images (a) sol 351_P2588 and (b) sol343_P2573 of light-toned soils excavated at the Champagne-Penny site; (c) contour map of the region overlain onto a HiRISE image; (d) vertical profile along the white dotted line in Figure 14c that shows the Champagne-Penny site is on a long slope of Cumberland Ridge.

observation. No Mini-TES and in situ chemical or mineralogic measurements were made on them.

[29] On sol 398, an uphill traverse by Spirit "faulted out" because of significant wheel slip. The wheels exposed a moderate amount of light-toned soils as shown in the image from the front Hazcam (Figure 11c). APXS, MI, and 13-filter Pancam observations were taken on the exposed lighttoned soils, named Paso Robles. A 2-sol Mössbauer data

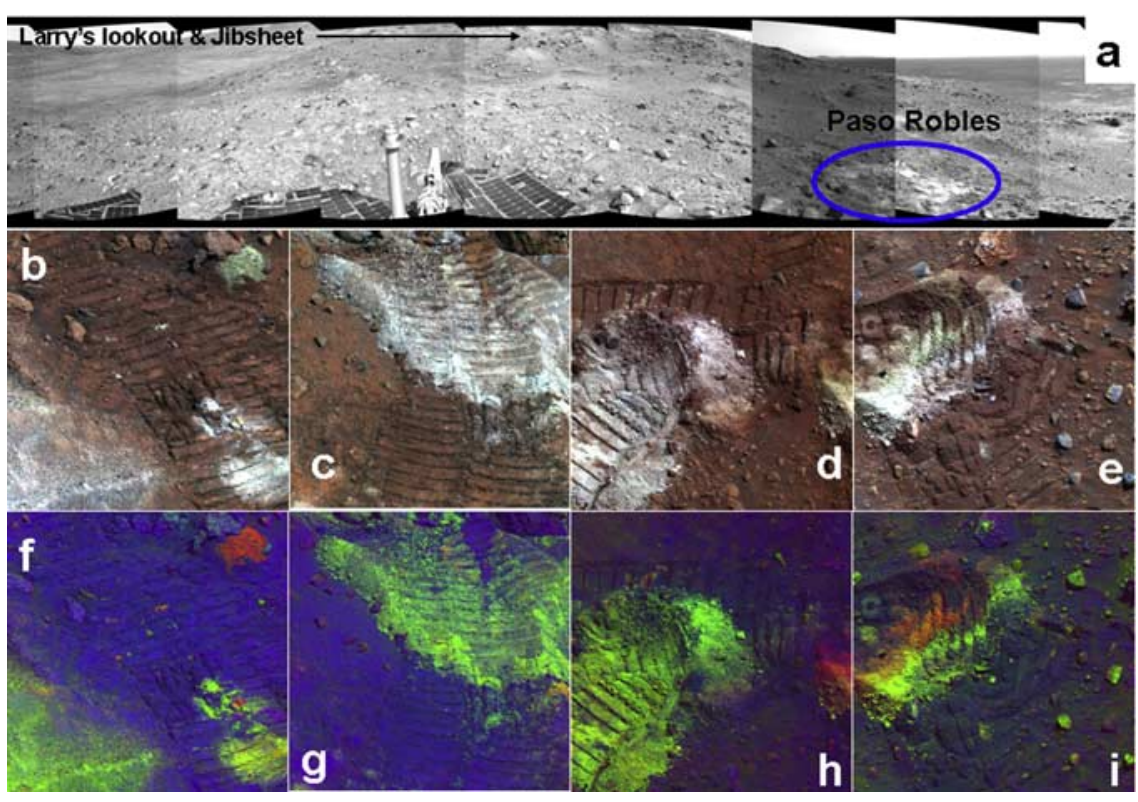

Figure 15. (a) Navcam panorama at position 117 of site 108 shows the location of the Paso Robles site (indicated by a blue circle); (b) sol 427 P2584, (c) sol 429 P2591, (d) sol 431_P2599, and (e) sol 431 P2530 are Pancam false color images of "spotty" occurrences of light-toned salty soils at Paso Robles. (f, g, h, i) Decorrelation stretched Pancam images corresponding to Figures 15b, 15c, 15d, and $15 \mathrm{e}$, respectively. See text for further discussion. The width of rover wheel track is about $16 \mathrm{~cm}$ for scale. 

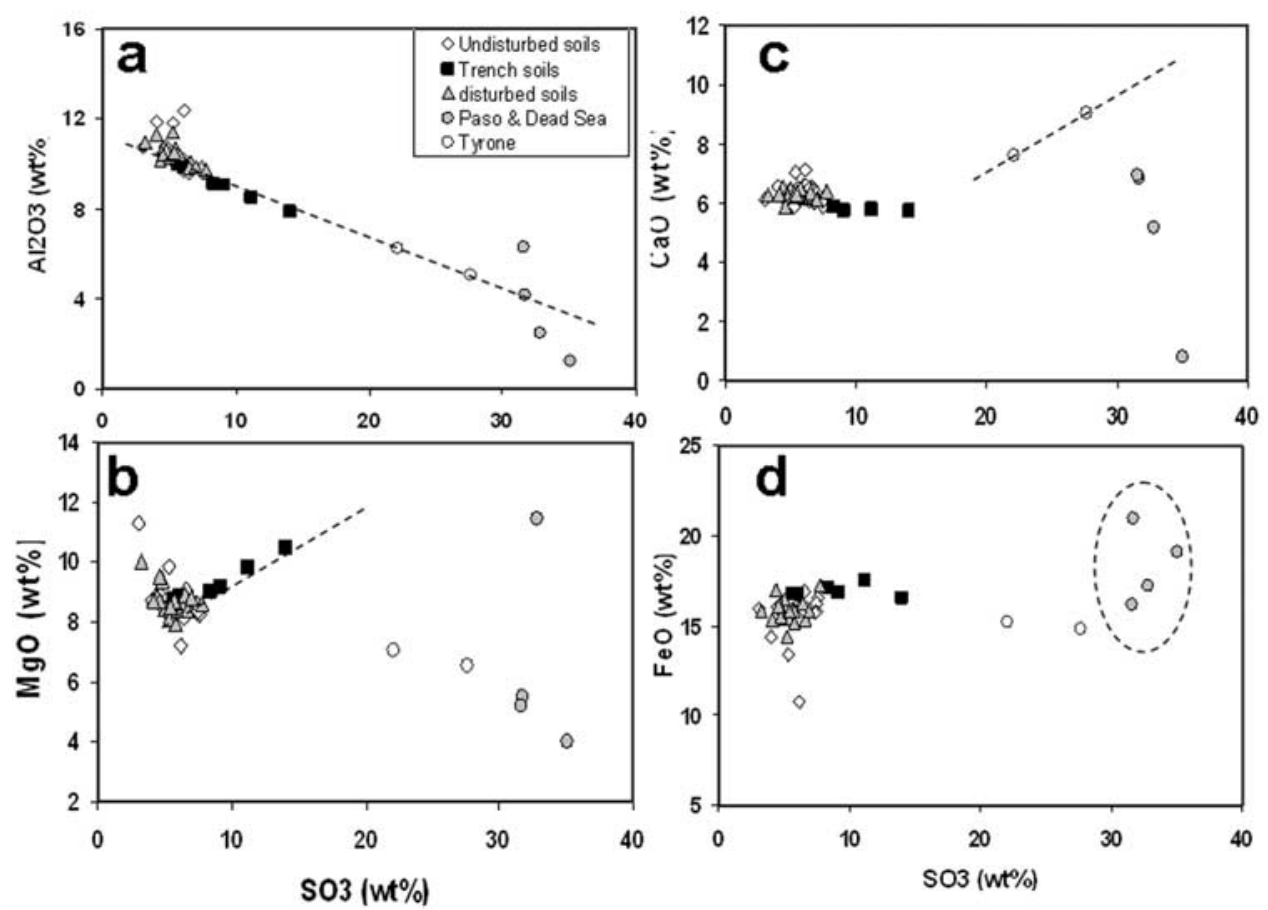

Figure 16. Compared with the general Gusev soils (disturbed and undisturbed, white diamonds and gray triangles in Figures 16a, 16b, 16c, and 16d), sulfur enrichments were found in the light-toned soils excavated by Spirit Rover. The compositional correlations imply different type of sulfates as the major component in the salt assemblages at different locations; (a) The increases of $\mathrm{SO}_{3}$ are accompanied by decreases of $\mathrm{SiO}_{2}$ and $\mathrm{Al}_{2} \mathrm{O}_{3}$, suggesting that $\mathrm{S}$-bearing phases are add-on components to local basaltic soils at those sites. (b) $\mathrm{MgO}$ versus $\mathrm{SO}_{3}$ correlation in the soils of two trenches at Gusev basaltic plains (black squares). (c). $\mathrm{CaO}$ versus $\mathrm{SO}_{3}$ correlation found in the "whitish" soils at Tyrone-offsets (white circles). (d). An increase of $\mathrm{SO}_{3}$ is accompanied by an increase of $\mathrm{FeO}$ in the excavated light-toned soils at Dead Sea and Paso Robles sites (gray circles).

acquisition followed. Spirit drove away from this location on sol 404, and then returned on sol 424 for additional in situ measurements (APXS, MI, MB) on exposed light-toned soils, plus 13-filter Pancam and Mini-TES measurements. Spirit finished the Paso Robles campaign on sol 431.

[30] At Paso Robles, there are no obvious aeolian ripples or thick surface dust/soil accumulations (Figures 15a-15e). Light-toned cobbles with rough surfaces are found coexisting with the light-toned salty soils at Paso Robles (one of them, named Ben's Clod, appears in the center of the upper edge of Figure 15e). The tracks with exposed salty soils cover approximately a $1.7 \times 1.9 \mathrm{~m}$ area (blue circle in Figure 15a). Minor surface crusts were observed near the wheel tracks in some places (Figure 11c), but overall the salty soils are quite loose and caused excessive slippage during the rover's drive.

[31] Unlike the light-toned salty soils in the Tyrone and Dead Sea area, the occurrences of light-toned salty soils at Paso Robles appear spatially discontinuous, and with much less quantity. For example, Figure 15b shows a light-toned salty soil spot in the middle of a wheel track that otherwise does not expose any light-toned salty soils. Figure $15 \mathrm{c}$ shows another example of a high concentration of lighttoned salty soils exposed in half of a wheel track. Additionally, heterogeneous distributions of light-toned salty soils of different colors are seen in these Pancam images. For example, the right edge of Figure 15d reveals a small patch of light-toned soil that appears yellower in Pancam false color images. This "yellowish" soil is just a few centimeters away from a more typical "whitish" soil. Figure 15e shows an occurrence of both yellowish and whitish soils in the same wheel track. Each Pancam false color image (Figures 15b, 15c, 15d, and 15e) is matched with a 3-band decorrelation stretched image (DCS [e.g., Gillespie et al., 1986]) to enhance the color differences and the spatial distributions of distinct salty soil patches (Figures 15f, 15g, 15h, and 15i). These observations suggest a very "spotty" occurrence (at the centimeter to tens of centimeters scale) of light-toned salty soils, and highly heterogeneous distribution of distinct types of light-toned salty soils with different chemical and/or physical properties. Where exposed, the light-toned salty soils appear to be buried just beneath the surface, on the basis of the observation that many were exposed by the $\sim 5 \mathrm{~mm}$ penetration depth of the rover wheel cleats.

[32] For completeness, we reiterate that sulfate-rich though not anomalously light-toned soils were also found in the soils of two trenches; the Big Hole and The Boroughs, in the Gusev basaltic plains between Bonneville Crater and the base of Columbia Hills. These salty soils appeared to be heavily mixed with the basaltic soil, and occurred immediately beneath the surface dust/soils. At The Boroughs trench site, the S-content is higher in the soils on the trench wall than on the trench floor. Detailed descrip- 


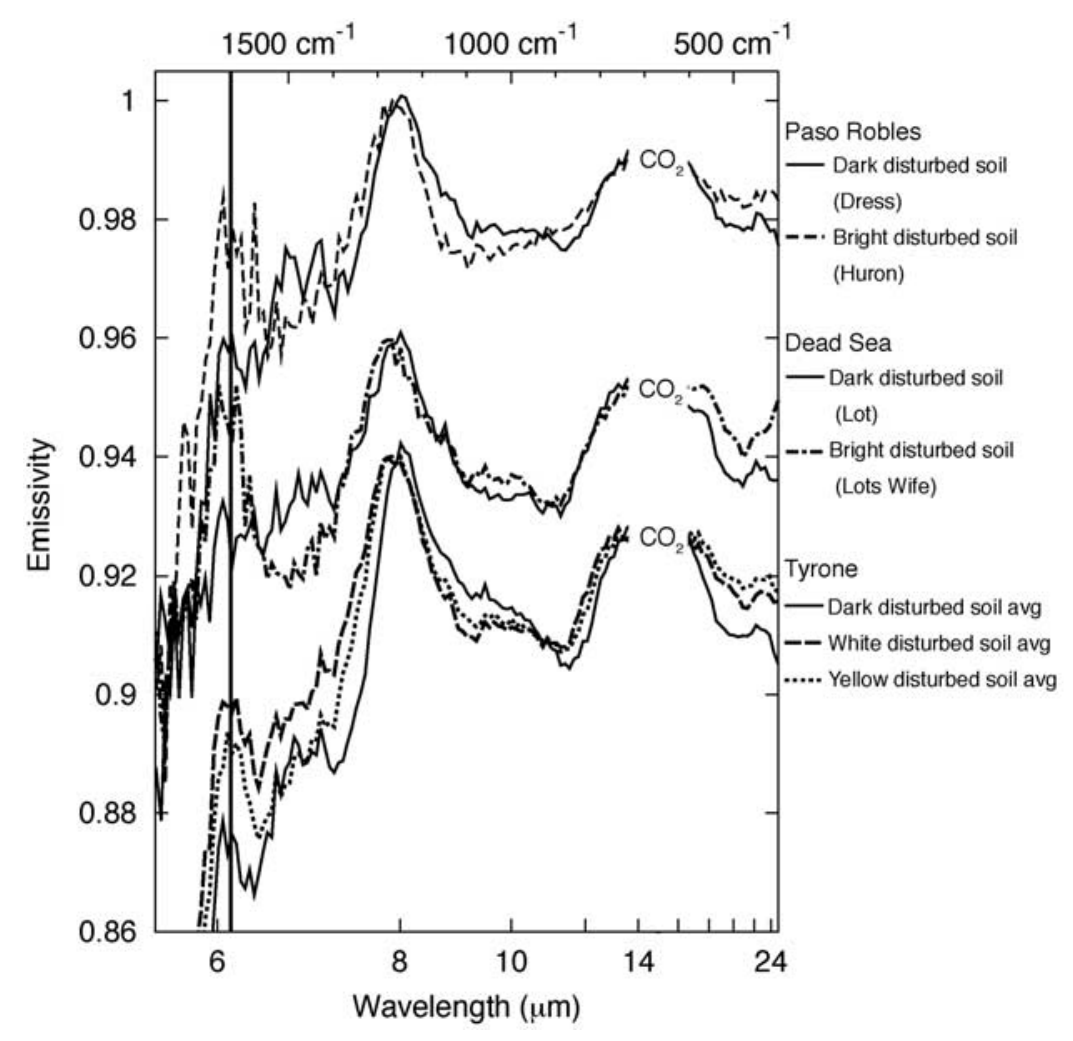

Figure 17. Miniature Thermal Emission Spectrometer (Mini-TES) spectra for bright and dark soils at three exposures: Paso Robles, Dead Sea, and Tyrone. Spectra from each site are vertically offset for clarity. Solid lines indicate spectra taken from a local dark disturbed soils for contrast with the bright, salt enriched soils which are plotted with dashed lines. The vertical line near $6 \mu \mathrm{m}$ indicates the position of a peak that occurs because of the presence of water in a transparency region of the thermal spectra. Note that all of the bright soils have enhanced peaks in comparison to the local dark soils, most likely due to a hydrated sulfate (A. T. Knudson et al., manuscript in preparation, 2008).

tions and analyses of these anomalous basaltic plains trench soils were presented by Wang et al. [2006a].

\section{Mineralogy and Geochemistry}

\subsection{Light-Toned Soils}

[33] Among the light-toned soils found at eight locations in the Columbia Hills region, in situ measurements (APXS, MB, MI) were made at four sites (Paso Robles, Dead Sea (Arad), Tyrone-offsets, and Gertrude Weise). Multiple remote sensing measurements with Pancam multispectral imaging (with all geology filters) and Mini-TES longduration (200 ICKs, $\sim 15 \mathrm{~min}$ ) thermal infrared spectral observations were made at each location (Table 1).

3.1.1. APXS, MB, MI, and Mini-TES Analysis

[34] Compositional data [Gellert et al., 2006; Ming et al., 2006, 2008] obtained by APXS clearly show S-enrichments in the light-toned soils at Paso Robles, Dead Sea, Tyroneoffset, and in the soils excavated by two trenches on the Gusev basaltic plains (Big Hole and The Boroughs). The S-enrichments in these targets are accompanied by decreasing $\mathrm{SiO}_{2}$ and $\mathrm{Al}_{2} \mathrm{O}_{3}$ contents (Figure 16a), suggesting that S-bearing materials are an add-on component to local basaltic soil at those sites. In addition, different types of compositional correlations were found at the different sites. For example, a positive $\mathrm{MgO}$ versus $\mathrm{SO}_{3}$ correlation was observed at Big Hole and The Boroughs trench sites (Figure 16b [Haskin et al., 2005; Wang et al., 2006a]); a positive $\mathrm{CaO}$ versus $\mathrm{SO}_{3}$ correlation was observed in Tyrone-offset soils (Figure 16c, similar to the $\mathrm{CaO}$ versus $\mathrm{SO}_{3}$ correlation found in six measurements of a nearby Halley Outcrop [Ming et al., 2008]); and $\mathrm{FeO}$ enrichments were observed in soils at the Paso Robles and Dead Sea sites (Figure 16d) [Yen et al., 2008]. These correlations imply that (1) sulfates are the major constituents of the S-bearing species; and (2) Mg-sulfates, Ca-sulfates, and Fe-sulfates are likely to be the major sulfates, respectively, in the two trenches, in the Tyrone-offset salty soils, and in the Paso Robles and Dead Sea salty soils. In addition to these major sulfates at each site, model calculations based on APXS and $\mathrm{MB}$ data suggest coexistence of $\mathrm{Mg}$-, $\mathrm{Ca}$-, and $\mathrm{Fe}$-sulfates in these soils [Wang et al., 2006a; Yen et al., 2008].

[35] Mössbauer spectroscopic analyses indicate high $\mathrm{Fe}^{3+} / \mathrm{Fe}_{\text {total }}$ in the plains trench soil measurements $(0.42)$ [Morris et al., 2006], in the soils at Paso Robles (0.79$0.86)$, at Dead Sea (0.91), and at Tyrone-offset $(0.50-0.54)$, compared with the value of $0.22-0.23$ for typical Gusev disturbed soil [Morris et al., 2008; Yen et al., 2008]. Furthermore, MB measurements reveal abundant ferric sulfates among all Fe-bearing minerals in the soils at Paso Robles, Dead Sea, and Tyrone-offset (68\%, 88\%, and 29\% of $\mathrm{Fe}_{\text {total }}$ [Morris et al., 2008]). A general understanding 
based on APXS and MB data analyses is that the salty soils at three major exposures of light-toned soils in the Columbia Hills consist of sulfates, basaltic soils, opaline silica, and other minor phases. A silica phase is considered to be the best candidate constituent in these soils in order to balance the mineralogy and chemistry, especially for the Dead Sea soil target Samra, where the least amount of basaltic soil ( $\sim 5$ weight percent $\left(\mathrm{wt}^{\mathrm{O}} \%\right)$ ) is interpreted to mix with the largest quantity of sulfates [Ming et al., 2008; Yen et al., 2008].

[36] Mini-TES spectra taken from the major exposures of light-toned soils at Paso Robles, Dead Sea, and Tyrone all contain a spectral feature at $\sim 6 \mu \mathrm{m}$ (Figure 17) that arises from the bending mode of $\mathrm{H}_{2} \mathrm{O}$ bonded within a mineral phase. This feature has been observed previously in the anomalously S-rich outcrop rock on Husband Hill known as Peace-class [Ruff et al., 2006]. Hydrated Ca-sulfates are one of the constituents interpreted to exist in these soils, on the basis of the deconvolution of Mini-TES spectra (A. T. Knudson et al., Mini-TES derived mineralogy of soils at the Mars Exploration Rover "Spirit" landing site, manuscript in preparation, 2008).

\subsubsection{Pancam Analysis}

[37] Multispectral Pancam images from all eight locations clearly reveal the exposure of light-toned soils (Figures 2, 5, $8,10,12,14$, and 15). Furthermore, these images provide direct evidence of the coexistence and spatial distribution of distinct types of salt assemblages at the same location (Figures 18 and 20), as well as their stratigraphic correlations with surroundings [Wang et al., 2007a, 2007b, 2007c, 2008a; Rice et al., 2008]. In addition, Pancam images usually cover a wide area around the rover with a high spatial resolution and in color, thus providing additional information on the local geologic, topographic, and stratigraphic context, even for very localized occurrences of light-toned soils.

[38] The Pancam stereo camera has two 1024 by 1024 active-area charge-coupled devices (CCDs) with a $30 \mathrm{~cm}$ stereo separation and a $0.27 \mathrm{mrad}$ per pixel resolution. Each camera has an eight position filter wheel, with 13 filters used for multispectral geologic investigations. Two pairs of filters are common between both cameras, leaving 11 unique wavelengths. Multispectral data from the Pancam left eye and right eye cameras were analyzed separately. Multispectral data from images of the onboard calibration target were used in combination with prelaunch calibration information to convert raw image data to calibrated radiance and then to radiance factor $\operatorname{IOF}(\mathrm{I} / \pi \mathrm{F}$, where $\mathrm{I}$ is the measured radiance and $\pi \mathrm{F}$ is the incident solar irradiance) [Bell et al., 2003, 2006]. Accumulation of air fall dust on the calibration target over the course of the mission was corrected using a two-layer Hapke model along with the known photometric properties of the calibration target [Bell et al., 2006; Sohl-Dickstein et al., 2005]. The IOF data were converted to relative reflectance $\left(\mathrm{R}^{*}\right)$ (where $\mathrm{R} *$ is defined as IOF divided by the cosine of the solar incidence angle [Reid et al., 1999; Bell et al., 2006]). Bell et al. [2006] estimated filter-to-filter uncertainties in $\mathrm{R}^{*}$ of $1-5 \%$, providing confidence in the reality of even very small-scale spectral variations detected in the scene. For all Vis-NIR spectra extracted from multispectral Pancam images in this study, relative reflectance $\mathrm{R}^{*}$ was used.
[39] Figure 18 shows the results of three Pancam observations taken at the Paso Robles, Dead Sea, and Tyrone sites, using two types of Pancam data analyses: (1) a 3-band decorrelation stretch (DCS [Gillespie et al., 1986]) of Pancam images; and (2) an extraction of Vis-NIR spectra from 13-filter Pancam images. In the DCS images (Figures 18a, 18b, and 18c), the red orange colors correspond to the yellowish soils and the green colors correspond to the whitish soils observed in the corresponding false color images (Figures 15b, 2a, and 5b). Compared with false color images, these DCS images display more clearly the distribution and spatial relationships of these different soil color units. Figures $18 \mathrm{~g}, 18 \mathrm{~h}$, and $18 \mathrm{i}$ display the Pancam Vis-NIR spectra extracted from multiple regions of interest (ROIs), shown as small rectangles indicated by circles of corresponding colors in Figures 18d, 18e, and 18f.

[40] In general, the spectra from these light-toned soils show steep red spectral slopes from $434 \mathrm{~nm}$ to $673 \mathrm{~nm}$, and some have shallow absorption bands with band centers varying from $800 \mathrm{~nm}$ to $934 \mathrm{~nm}$. In addition, the spectra extracted from the light-toned soil patches at the three major exposures are very different from each other, suggesting differences in the intrinsic nature of the compositions and/ or physical properties of the salty soils at Paso Robles, Dead Sea and Tyrone. Johnson et al. [2007] selected six typical Pancam spectra from the salty soils at the Paso Robles, Dead Sea, and Tyrone sites, and used a database of 84 laboratory spectra and a multiple end-member spectral mixing model approach to identify candidate Fe-sulfate assemblages that may contribute to the observed Pancam spectra. Among the 63 sulfate and ferric oxide/oxyhydroxide minerals in the database, they found six ferric sulfates that could make significant contributions to the observed Pancam spectra (ferricopiapite $\left[\mathrm{Fe}_{2 / 3}^{2+} \mathrm{Fe}_{4}^{3+}\left(\mathrm{SO}_{4}\right)_{6}(\mathrm{OH})_{2} \cdot 20\left(\mathrm{H}_{2} \mathrm{O}\right)\right]$, hydronium jarosite $\left[\left(\mathrm{H}_{3} \mathrm{O}\right) \mathrm{Fe}^{3+}{ }_{3}\left(\mathrm{SO}_{4}\right)_{2}(\mathrm{OH})_{6}\right]$, fibroferrite $\left[\mathrm{Fe}^{3+}\left(\mathrm{SO}_{4}\right)(\mathrm{OH}) \cdot 5\left(\mathrm{H}_{2} \mathrm{O}\right)\right]$, rhomboclase $\left[\mathrm{HFe}^{3+}\left(\mathrm{SO}_{4}\right)_{2} \cdot 4\left(\mathrm{H}_{2} \mathrm{O}\right)\right]$, paracoquimbite $\left[\mathrm{Fe}_{2}^{3+}\left(\mathrm{SO}_{4}\right)_{3} \cdot 9\left(\mathrm{H}_{2} \mathrm{O}\right)\right]$, and a mixture of anhydrite $\left[\mathrm{CaSO}_{4}\right]$ with coquimbite $\left.\left[\mathrm{Fe}^{3+}{ }_{2}\left(\mathrm{SO}_{4}\right)_{3} \cdot 9\left(\mathrm{H}_{2} \mathrm{O}\right)\right]\right)$.

[41] In the selected images (Figures 18d, 18e, and 18f) at the three locations, multiple ROIs were chosen from whitish soil patches (corresponding the spectra with diamond symbols in Figures 18g, 18h, and 18i) and from yellowish soil patches (corresponding the spectra with square symbols in Figures $18 \mathrm{~g}, 18 \mathrm{~h}$, and 18i), on the basis of the false color and DCS images, in order to assess the uniformity of each type of material. The Pancam spectra exhibit relatively large changes from spot to spot at Paso Robles and Dead Sea (Figures $18 \mathrm{~g}$ and $18 \mathrm{~h}$ ), regardless of whether they were extracted from whitish or yellowish soils. These spectra variations include a change in spectral slope from 434 to $673 \mathrm{~nm}$ (Figure 18h), with or without a "kink" at $535 \mathrm{~nm}$ (Figure 18g), a change in the absorption band center from $800 \mathrm{~nm}$ to $934 \mathrm{~nm}$ (Figures $18 \mathrm{~g}$ and $18 \mathrm{~h}$ ), and a change in spectral slope from 934 to $1009 \mathrm{~nm}$ (Figure 18h). Soil patches with very different Pancam spectra are only centimeters apart (Figures 18d and 18e), demonstrating the heterogeneous nature of light-toned soils at the Paso Robles and Dead Sea sites. In contrast, at the Tyrone site, Pancam spectra extracted from different yellowish soil patches tens of centimeters apart possess a roughly consistent spectral pattern (spectra with square symbols in Figure 18i). The same is true for different patches of whitish Tyrone soils 

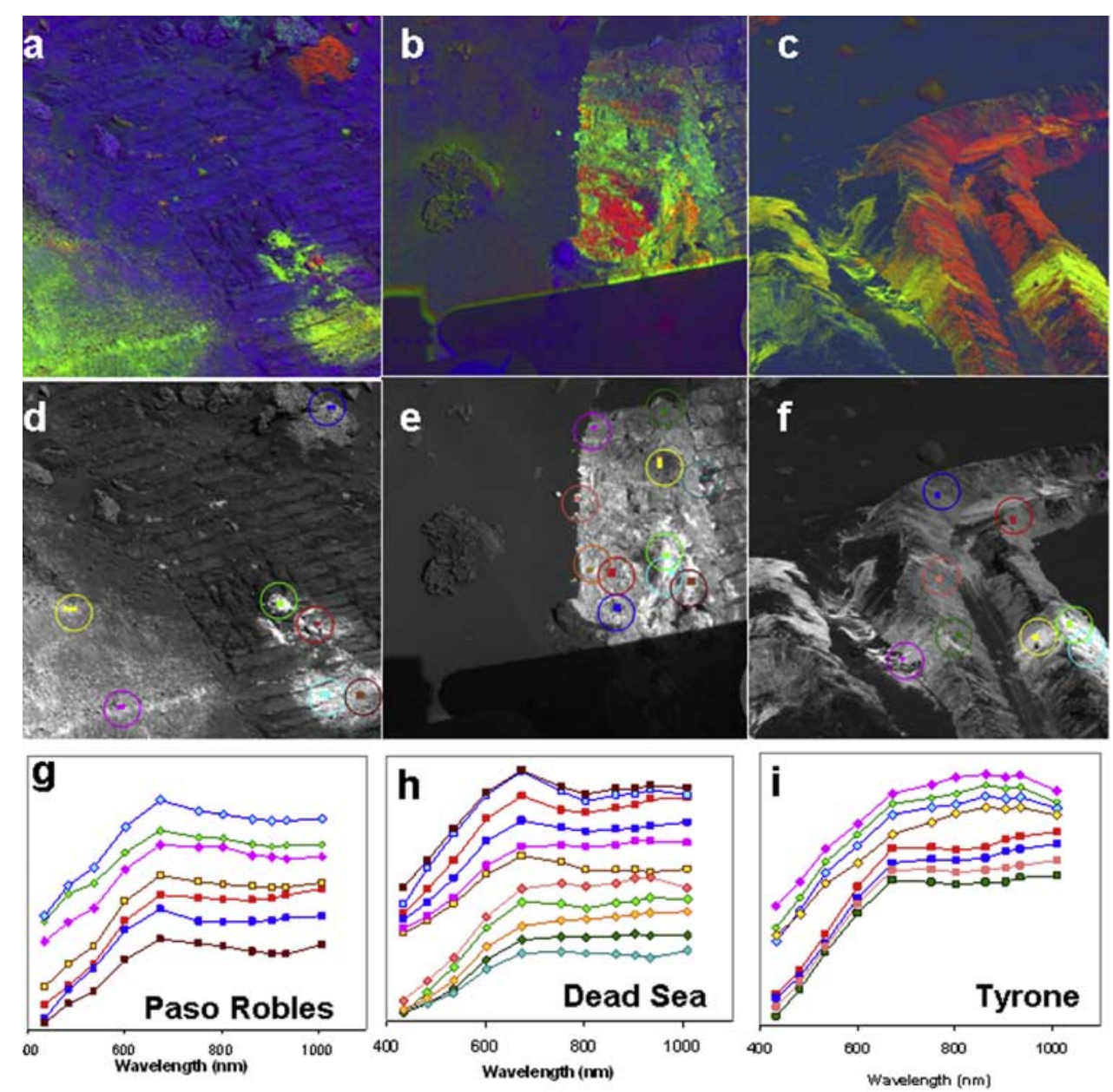

Figure 18. Selected Pancam frames from three major exposures of light-toned salty soils. $(a, b, c)$ Decorrelation stretched (DCS) Pancam images from sol 427_P2584, sol 722_P2514, and sol 790_P2531. (d, e, f) Pancam images through L7 filter $(432 \mathrm{~nm})$ with the color coded ROI (region of interest) as small rectangles marked by circles of same colors. (g, h, i) Pancam spectra extracted from each ROI, shown in the same color codes as the ROIs in Figures $18 \mathrm{~d}$, 18e, and $18 \mathrm{f} . \mathrm{R}^{*}$ values were used when extracting these Pancam visible near-infrared (Vis-NIR) spectra. Spectra with square symbols were obtained from soil patches with yellowish color (red orange color in DCS); while spectra with diamond symbols from whitish soils (green color in DCS). The width of rover wheel track is about $16 \mathrm{~cm}$ for scale.

(spectra with diamond symbols in Figure 18i). These observations suggest a more homogeneous nature for the Tyrone soils than those at Paso Robles and Dead Sea.

[42] It is important to note that target selection for in situ measurements (APXS, MB, and MI) was often limited by the reach of the rover's instrument deployment arm and by limits on the time and power resources required for those detailed investigations. Thus, for the soil deposits that apparently are very heterogeneous on the basis of variations in Pancam spectra (e.g., Figures $18 \mathrm{~g}$ and 18h), the APXS and MB data [Yen et al., 2008] obtained may not represent the full range of composition and mineralogy existing in these light-toned soils. Combining Pancam and Mini-TES data acquired across the entirety of these soil targets with detailed in situ chemical and mineralogical data from individual spots would be required for developing a comprehensive understanding of these deposits. For example, at the Paso Robles, Dead Sea, and Tyrone sites, Pancam data and the available in situ measurements reveal the spatial distribution of what appear to be multiple kinds of salts. Some of the heterogeneous Pancam color units were measured by in situ instruments and some were not. Therefore, Pancam analysis provides constraints on the potential phase mixing of the spots targeted by in situ measurements.

[43] At the Paso Robles site (Figure 19a), on the basis of Pancam false color and DCS images, data for the in situ soil target Pasadena_PasoRobles was acquired on a whitish soil patch that appeared to be slightly mixed with average dusty Gusev soil and yellowish soil (not shown); data for the Paso_Light target was acquired on an almost pure whitish soil patch mixed with a trace amount of yellowish soil; data for the Paso_Dark target was acquired on a wheel-disturbed and compressed basaltic soil patch; and data for the Paso DarkLight target was acquired on a disturbed basaltic soil patch contaminated by a considerable amount of yellowish soil (in Figure 19a, targets Paso-Light, Paso_Dark, and Paso_DarkLight are indicated by three white arrows). On the basis of these Pancam observations, the compositional 


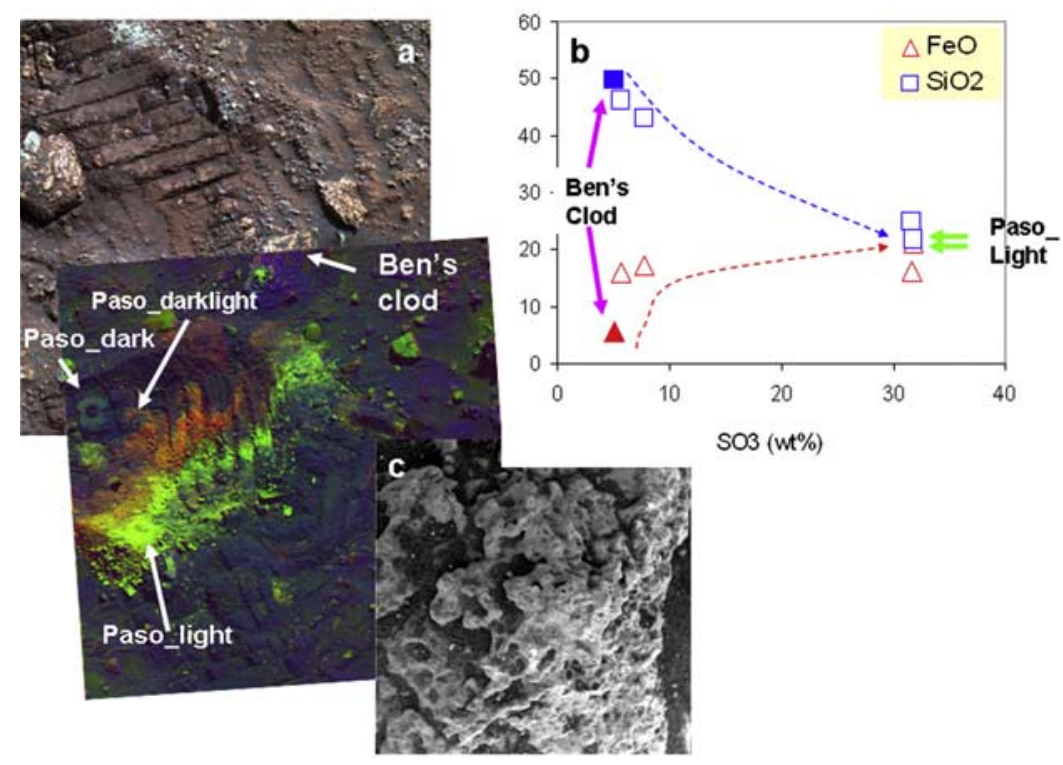

Figure 19. (a) Pancam false color image and decorrelation stretched image (sol 424_P2575 and sol 426_P2579) showing the mixed nature of yellowish, whitish, and basaltic soils at the target areas measured by in situ instruments at Paso Robles; (b) compositional "coupling" between salty soils and nodules at Paso Robles. Filled symbols represent the data from Ben's Clod and unfilled symbols the soils. The dotted lines mark the trend of $\mathrm{SiO}_{2}$ depletion and $\mathrm{Fe}$ enrichment from Ben's Clod-like nodules to the bright whitish soils (Paso-Light target); (c) Microscopic Imager (MI) image of Ben's Clod. See text for further discussion. The width of rover wheel track is about $16 \mathrm{~cm}$ for scale.

variations detected by APXS among those targets would suggest the presence of Fe-sulfate-rich mixtures for the Paso Robles yellowish soil (e.g., increases of $\mathrm{FeO}$ and $\mathrm{SO}_{3}$ in Paso_DarkLight compared with Paso_Dark), and sulfate mixtures with elevated $\mathrm{Ca}$ - and $\mathrm{Al}$-components in the Paso Robles whitish soils (e.g., increases of $\mathrm{CaO}$ in both Paso Light and Pasadena_PasoRobles, and increase of $\mathrm{Al}_{2} \mathrm{O}_{3}$ in Paso Light compared with Pasadena PasoRobles).

[44] Among the in situ soil targets in the Dead Sea area, on the basis of Pancam DCS images, the target Samra was a patch of mostly yellowish soil (red colored spectra in Figure 18h), and the target Masada was a vesicular basaltic cobble (Figure 2a). There is no Pancam 13-filter multispectral coverage of in situ soil target Hula. Nevertheless, Hula was probably on a whitish soil patch, judging by the similar Hazcam image brightness of Hula relative to a similar nearby soil patch that can be classified as whitish on the basis of Pancam data. Combining the Pancam observations with the compositional variation detected by APXS, it appears that the yellowish soils at the Dead Sea site are highly enriched in Fe-sulfates, and the whitish soils there have increased amounts of Mg-, Ca- (and possibly Al-) sulfates.

[45] On the basis of Pancam data analyses at Tyroneoffset targets, the APXS and MB targets Mount Darwin and Berkner Island [Yen et al., 2008] were on whitish salty soils. The yellowish Tyrone soils were never measured by these in situ instruments.

[46] The coexistence of more than one type of light-toned materials and the variations in their spatial distribution were also found in the light-toned soils at Hank's Hollow Shredded area, and near the Champagne-Penny targets, although only minor amounts of light-toned soils were exposed there. Figures 20a and 20b present the decorrelation stretch of Pancam multispectral images from these two sites. The false color images of the same frames are shown in Figures $8 \mathrm{~b}$ and 14a. The Vis-NIR spectra (Figures 20i and 20j) extracted from ROIs (Figures 20e and 20f) with centimeters of separation in these frames demonstrate a wide range of variations in spectral features. The different spectra suggest heterogeneity in the nature of the light-toned soils at these two sites, similar to Paso Robles and Dead Sea sites. The spectra from yellowish soil patches at the site near Champagne-Penny targets (spectra with square symbols in Figure 20j) show a broad absorption feature with a variable band center near $800 \mathrm{~nm}$, which may suggest variations in the makeup of Fe-mineral assemblages.

[47] Conversely, the light-toned soil patches in Pancam DCS images of the tracks in front of the Jibsheet and the Hillary outcrops have very small to almost no color difference (Figures 20c and 20d). The Vis-NIR spectra (Figures 20k and 201) extracted from the ROIs (Figures $20 \mathrm{~g}$ and $20 \mathrm{~h}$ ) in those light-toned soil patches demonstrate a generally similar spectra pattern (s) with a few exceptions (the cyan and yellow colored spectra in Figure $20 \mathrm{k}$ and the blue spectrum in Figure 20i). These less consistent spectra may be caused by the variation in excavation depths (e.g., by the "tie-down plate" of wheel rim with variable relief height of $\sim 5-23 \mathrm{~mm}$ in front of Hillary Outcrop). The general spectral pattern similarity suggests a well-mixed nature of light-toned soils at each of these two sites, i.e., relatively homogeneous in the chemistry and physical properties reflected in the Pancam Vis-NIR spectral range (432 to $1009 \mathrm{~nm}$ ). A distinct spectral feature of light-toned soils near Jibsheet is an absorption band centered near $934 \mathrm{~nm}$ that does not generally appear in the spectra of the light-toned 

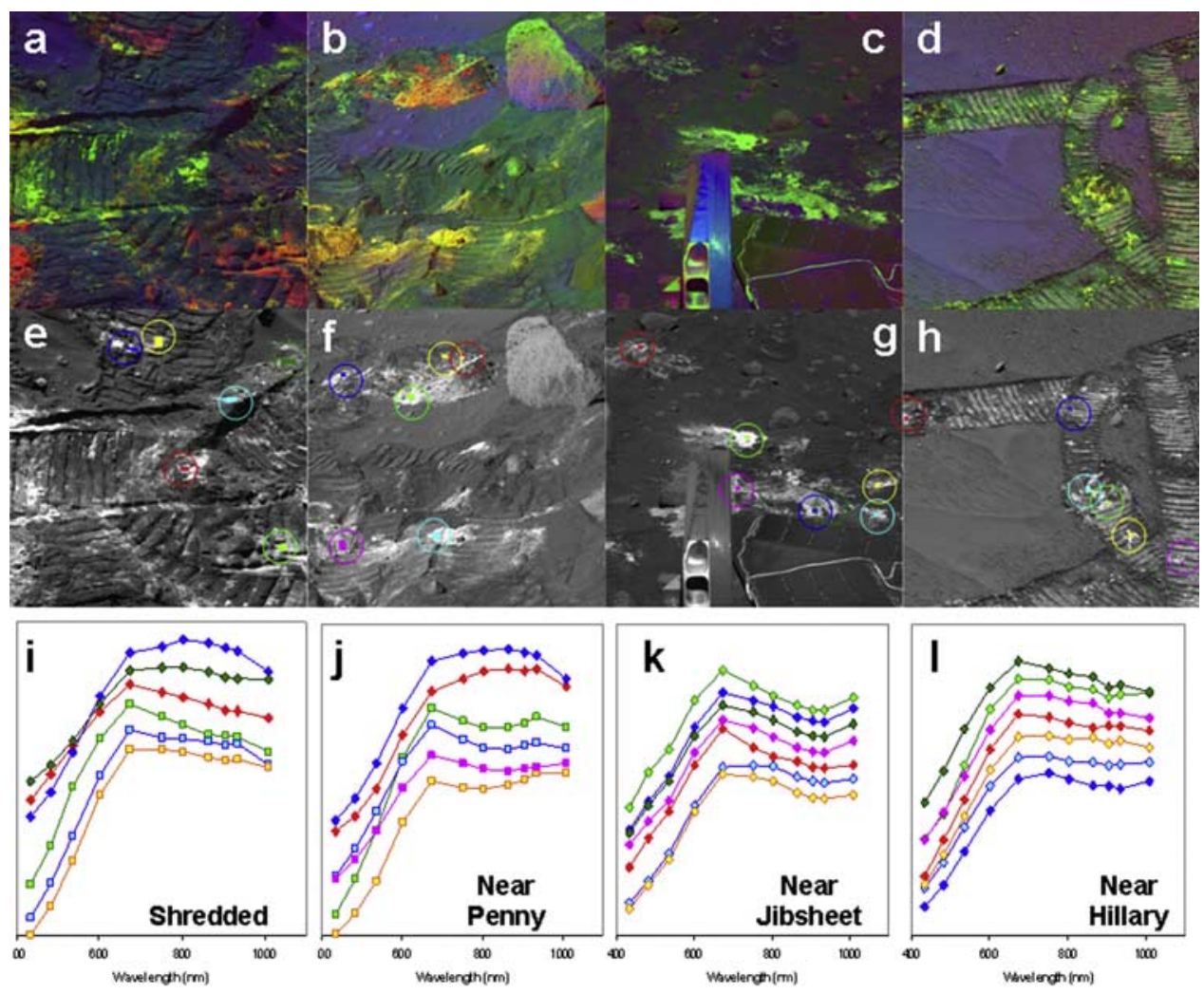

Figure 20. Decorrelation stretched Pancam images of the light-toned soils at (a) the Hank's HollowShredded site (sol 180_P2387), (b) the Champagne-Penny site (sol 351_P2588), and (c) in front of the Jibsheet (sol 486 P2598), and (d) Hillary outcrops (sol 628_P2538). (e, f, g, h) Pancam images through L7 filter (432nm) with the color coded ROI (region of interest) as small rectangles marked by circles of same colors. (i, j, k, 1) Pancam spectra extracted from each ROI, shown in the same color codes as the ROIs in Figures 20e, 20f, 20g, and 20h. The width of rover wheel track is about $16 \mathrm{~cm}$ for scale.

soils near the Hillary Outcrop, suggesting a compositional difference.

[48] Although large amounts of sulfates have been implied to occur at two of the plains trench sites by APXS (14.6 wt $\% \mathrm{SO}_{3}$ [Gellert et al., 2006]) and by mixing model calculation (sulfates make up $>20 \mathrm{wt} \%$ of the soils in the wall of The Boroughs trench [Wang et al., 2006a]), no obvious color differences can be distinguished in the Pancam images of these sites. This is most likely because Mg-sulfates are inferred to be the major salt component there ( $\sim 16 \mathrm{wt} \%$ [Wang et al., 2006a]), and these phases are much less (or not at all) distinct spectrally over the wavelength range of the Pancam instrument, especially when compared to Fe-sulfates.

\subsection{Coexistence of Light-Toned S-Rich Soils and Light-Toned Si-Rich Nodules}

[49] Light-toned nodules were observed coexisting with the light-toned salty soils at Paso Robles and Dead Sea. They were also observed in the vicinity of Tyrone salty soils and the Si-rich soil patch Gertrude Weise. In addition to their characteristics revealed by APXS and Mini-TES, we found that they have a common feature in the spectra extracted from multispectral Pancam images, which can be used to search for similar types of Si-rich species that potentially exist in other locations at Gusev.

\subsubsection{In the Vicinity of Paso Robles}

[50] As described in section 2, coexistence of light-toned nodules (cobbles with uneven surfaces and rounded edges) and light-toned soils is seen at many locations, but only one set of in situ measurements (APXS, MI, but no MB) was made on nodular materials prior to sol 1160 . At the Paso Robles site, APXS measurements were made on a lighttoned nodule named Ben's Clod (Figure 19a). Depletion of $\mathrm{S}$ and $\mathrm{Fe}$ and enrichment of $\mathrm{Si}$ were observed in the composition of Ben's Clod compared to adjacent Paso Robles soils enriched in $\mathrm{S}$ and $\mathrm{Fe}$ and depleted in $\mathrm{Si}$, (targets Pasolight and Pasadena_PasoRobles [Gellert et al., 2006; Clark et al., 2007]). Figure 19b shows this compositional "coupling" between nodular material and salty soils at Paso Robles, which may support a hypothesis that they are two end products of the same alteration process.

[51] In the Vis-NIR spectra extracted from Pancam images, Ben's Clod-like Si-rich nodules and S-rich soils at Paso Robles show different characteristics. A 2-dimensional image histogram (Figure 21b) using L2 (750 nm) versus L7 $(434 \mathrm{~nm})$ filter pairs illustrates two spectrally distinct trends (indicated by a purple and a green arrow), which correspond respectively to Paso Robles light-toned soils (green color patch in Figure 21c) and to all Ben's Clod-like nodules (purple color patch in Figure 21c). Figure 21d shows the 


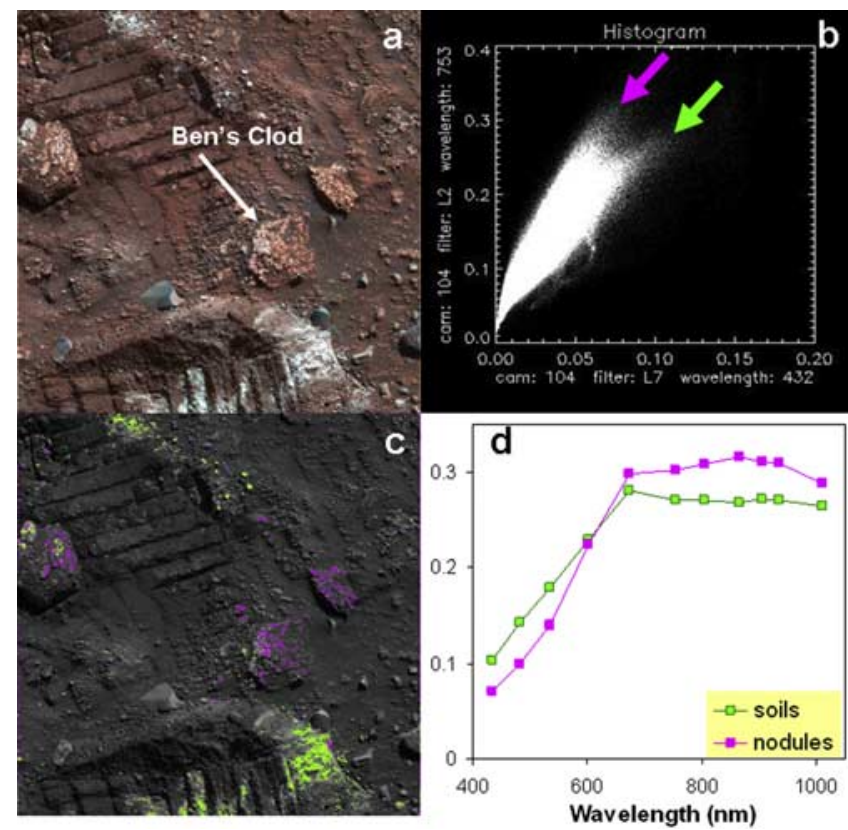

Figure 21. (a) False color Pancam image (sol 424_P2575) of light-toned soils and light-toned nodules at the Paso Robles site. (b) L2 (750 $\mathrm{nm})$ versus L7 (432 nm) 2-dimensional histogram showing two spectrally distinct trends. (c) Two types of spectra corresponding respectively to the S-rich soils (green color) and Si-rich nodules (mauve color). (d) Extracted Pancam spectra from the two spectral trends. The width of rover wheel track is about $16 \mathrm{~cm}$ for scale.

Pancam Vis-NIR spectra extracted from these two types of materials. Compared to the S-rich soils, the Fe-poor and Si-enriched Ben's Clod-like nodules have a characteristic spectrum that shows (1) a steeper spectral slope from $434 \mathrm{~nm}$ to $673 \mathrm{~nm}$ that may imply a higher oxidation state [Morris et al., 2000] (unfortunately, no MB measurement was made on Ben's Clod to confirm this); and (2) a negative spectral slope from $934 \mathrm{~nm}$ to $1009 \mathrm{~nm}$ that may be diagnostic of hydrated species [Rice et al., 2008]. Figure 21c shows that a few spots on at least one lighttoned nodule (upper left in Figures 21a and 21c) have Pancam spectral character similar to Paso Robles S-rich soils. Such a close spatial relationship between light-toned S-rich soils and light-toned Si-rich nodules further supports the hypothesis that they are genetically correlated.

\subsubsection{In the Vicinity of Dead Sea}

[52] In the Dead Sea area, coexistence of light-toned S-rich soils and light-toned nodules was observed in Navcam and Hazcam images (Figure 4c), but, unfortunately, neither in situ nor remote sensing measurements were made on those lighttoned nodules. The target Masada Clod that was measured by APXS there is actually a piece of dark-toned vesicular basalt (Figure 2a).

\subsubsection{In the Tyrone-Eastern Valley Region}

[53] In the vicinity of the Tyrone S-rich soil exposure, many light-toned nodules are observed (Figure 7b). A MiniTES spectrum obtained from a patch of nodules (Tyrone nodules, location marked in Figure 6a) near the Tyrone S-rich soil exposure first revealed their Si-rich nature, and was confirmed by many Mini-TES measurements on other nodular patches in Tyrone-Eastern Valley region (Figure 22)
[Arvidson et al., 2008; Squyres et al., 2008]. The Pancam spectrum (Figure 23e) of Tyrone nodules shows spectral features similar to those seen in the Si-rich Ben's Clod-like nodules at Paso Robles (Figure 21d), especially a negative spectral slope from $934 \mathrm{~nm}$ to $1009 \mathrm{~nm}$.

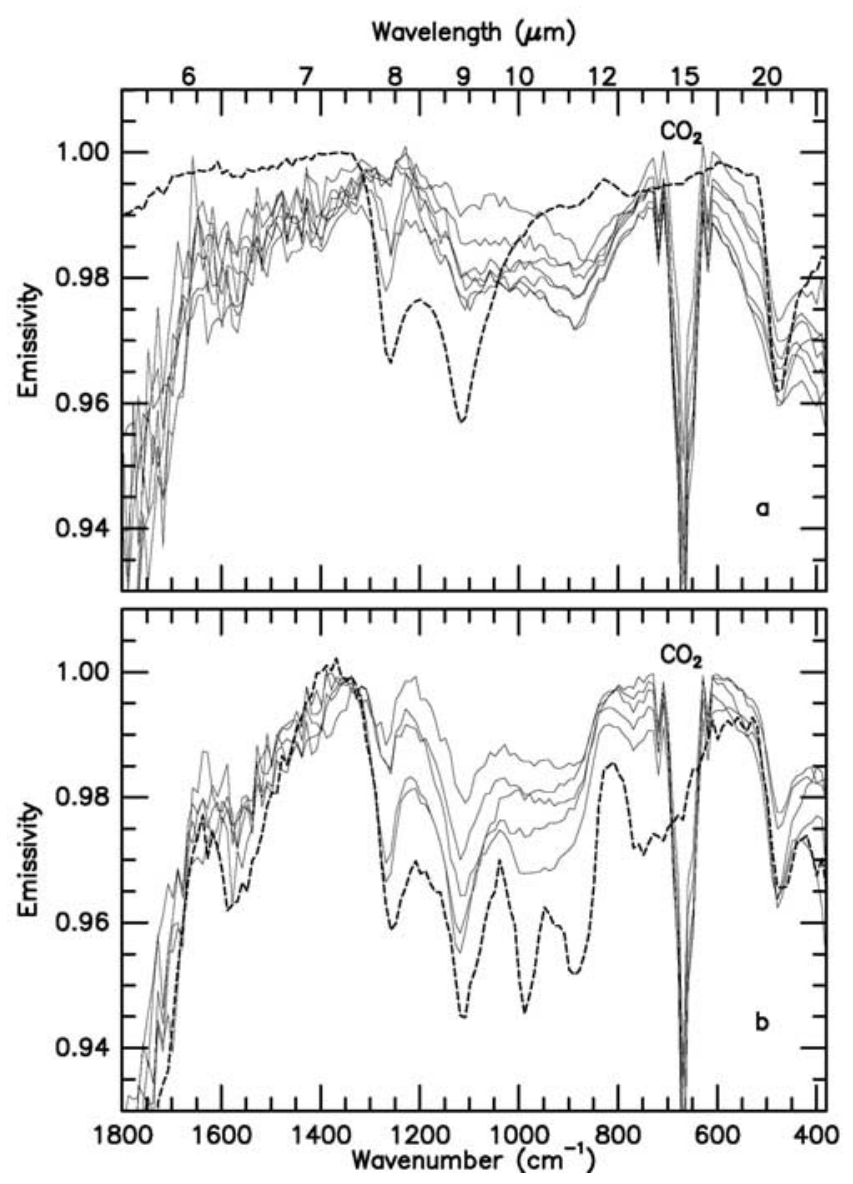

Figure 22. Mini-TES spectra of silica-rich materials near Home Plate compared to terrestrial amorphous silica (siliceous sinter in this case). All Mini-TES spectra have been corrected for mirror dust contamination according to the methodology of Smith et al. [2006]. (a) Seven examples of nodular materials contaminated by dust and soil (solid) compared with a scaled laboratory spectrum (dashed) from a hand sample of hydrated amorphous silica from Steamboat Springs, NV. The Mini-TES spectra are from the following named targets: Tyrone nodules, Kobal, Clara Zaph4, Philomena Zale, Virginia Bell, Nancy Warren, and Alice Blaski. Although there is a misfit in the $10-12 \mu \mathrm{m}$ region attributable to dust and soil contamination [Squyres et al., 2008], the three prominent absorptions of amorphous silica are displayed in the Mini-TES spectra. (b) Five spectra from the Gertrude Weise light-toned soil (solid) compared with a crushed (but not sieved) version of the Steamboat Springs silica. Here the absorption in the $10-12 \mu \mathrm{m}$ region is attributable to scattering effects of fine particles, although the presence of two absorption minima in the terrestrial silica is not yet understood [Squyres et al., 2008]. Note the weak emissivity maximum near $6 \mu \mathrm{m}$ that likely is due to bound molecular water. 

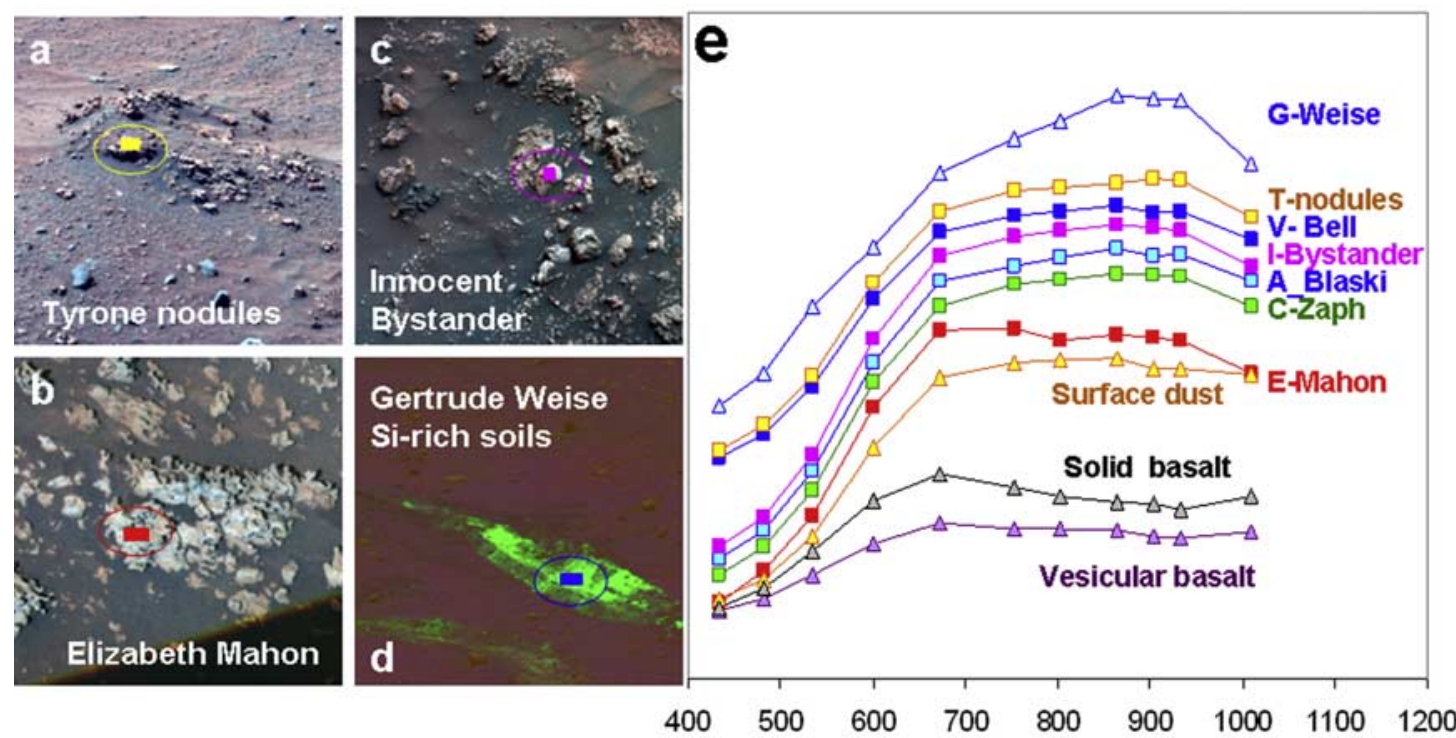

Wavelength $(\mathbf{n m})$

Figure 23. (a, b, c, d) Pancam false color images of three Si-rich nodular patches (sol 1101_P2552, sol1160_P2582, sol1294_P2581) and Pancam DCS image of Gertrude Weise Si-rich soils (sol1158 P2581). (e) Pancam spectra extracted from nodular patches (spectra with square symbols), that were confirmed by either Alpha Particle X-Ray Spectrometer (APXS) or Mini-TES to be Si-rich. These spectra are compared to the spectrum of Gertrude Weise and the spectra of surface dust, solid basalt, and vesicular basalt in the area (spectra with triangle symbols). Relative to Si-rich nodular patches marked in Figure 6a, target Clara Zaph occurs near Elizabeth Mahon, targets Virginia Bell and Alica Blaski occur near Innocent Bystander.

[54] During the exploration after Spirit's 2nd winter on Mars, a large number of nodular patches were encountered in the Eastern Valley, which lies between Home Plate and Mitcheltree Ridge and within the same topographic low as the Tyrone site (45 m contour line in Figure 6a). A few nodular patches (Elizabeth Mahon, Nancy Warren, Innocent Bystander, white triangles in Figure 6a) were investigated by Spirit using the full Athena payload [Squyres et al., 2008]. Additional 13-filter Pancam and Mini-TES observations were made at a larger number of them (i.e., Kobal, Virginia Bell, Alice Blaski, Clara Zaph, and Philomena Zale; Figure 23e). The APXS results (on undisturbed and broken surfaces of nodules) indicate that they are all enriched in $\mathrm{Si}\left(61.8-72.8 \mathrm{wt} \% \mathrm{SiO}_{2}\right.$ [Ming et al., 2008]). Mini-TES spectral analyses confirm their Si-rich nature and further suggest that they are made of amorphous (opaline) silica (Figure 22) [Ruff et al., 2008]. Furthermore, a patch of light-toned soils Gertrude Weise was exposed by Spirit in Eastern Valley near several Si-rich nodular patches (white triangles in Figure 6a). This patch of soils was found to have the highest silica content on Mars ( $>90 \mathrm{wt} \% \mathrm{SiO}_{2}[$ Ming et al., 2008]). In addition, it is apparently homogeneous, as reflected in Pancam DCS image (Figure 23d) and Vis-NIR spectral properties (not shown).

[55] The spatial distributions of Si-rich nodules and soils targets, as well as S-rich soil targets, within the topographic low that includes the Tyrone site are shown in Figure 6a. It is worth noting that (1) Si-rich nodules are spread over large distances within the low encircled by the $45 \mathrm{~m}$ contour line; (2) the Gertrude Weise Si-rich soil exposure occurs next to a group of Si-rich nodular outcrops; and (3) S-rich soils were excavated at the edge of the topographically lowest place (44.5 $\mathrm{m}$ contour line) of this low.

[56] Figure 23e shows the Vis-NIR spectra extracted from multispectral Pancam images of several nodular patches (ROIs in false color images in Figures 23a, 23b, and 23c and the spectra with square symbols in Figure 23e) that were confirmed by either APXS or Mini-TES to be Si-rich. Compared with spectra of surface dust, solid basalt, and vesicular basalt in the area (three spectra with triangle symbols in the lower portion of Figure 23e), the Si-rich nodules have a Pancam spectral pattern very similar to that of the Si-rich Ben's Clod-like nodules at Paso Robles, i.e., a positive spectral slope from $434 \mathrm{~nm}$ to $673 \mathrm{~nm}$ and a negative spectral slope from $934 \mathrm{~nm}$ to $1009 \mathrm{~nm}$. There are differences, however, in their spectral details. For example, the steepness of positive slope from $434 \mathrm{~nm}$ to $673 \mathrm{~nm}$ varies among different nodular patches (spectra with square symbols in Figure 23e), although it is relatively consistent among the different spots from the same nodular patch (not shown). In general, Gertrude Weise Si-rich soils have a spectrum with a much steeper negative slope from 943 to $1009 \mathrm{~nm}$ and a shallower positive slope from 434 to $673 \mathrm{~nm}$ (top spectrum with triangle symbols in Figure 23e) than those of nodular patches, which may reflect higher $\mathrm{SiO}_{2}$ content. Nodular materials may contain additional Febearing phases (oxides, hydroxides, and/or salts) that contribute to the steepness of the red slope. Nevertheless, in most cases, the nodular patches are redder than general surface dust (yellow spectrum with triangle symbols in Figure 23e), which suggests that simple surface dust coverings on nodular patches is not the only reason for the 


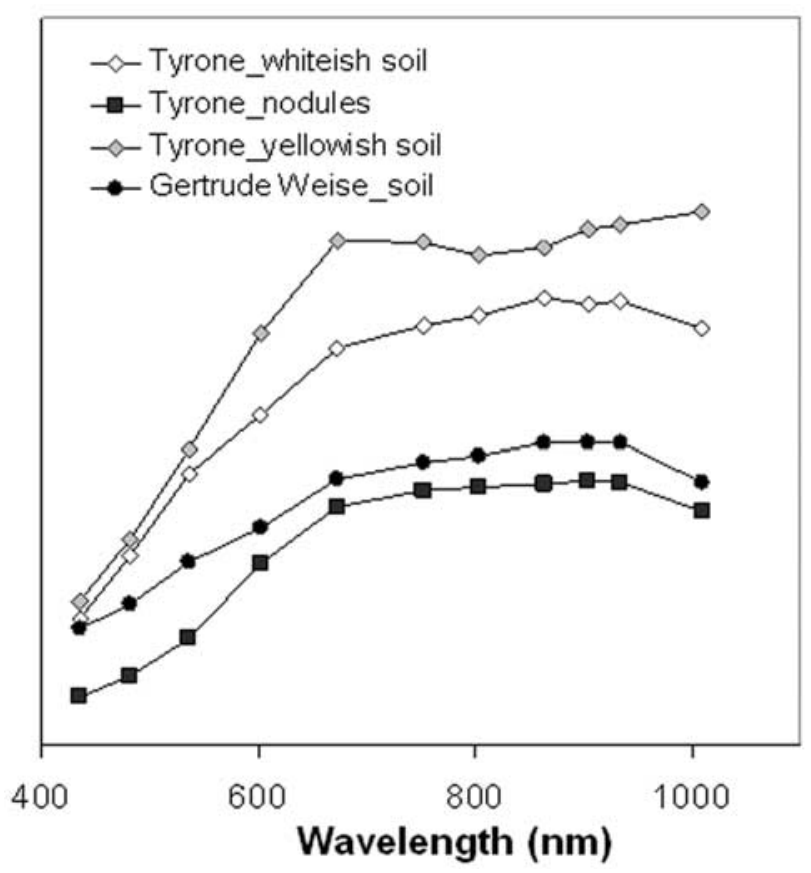

Figure 24. Typical Pancam spectra of Tyrone whitish and yellowish soils, Tyrone nodules, and Gertrude Weise soil.

nodules' redder color compared with Gertrude Weise soils. In addition to the variations in spectral slopes of Si-rich nodules, the spectrum from the Elizabeth Mahon nodular patch contains an absorption band centered at $800 \mathrm{~nm}$. These and other possible spectral variations are suggestive of variations in the composition and mineralogy of Si-rich
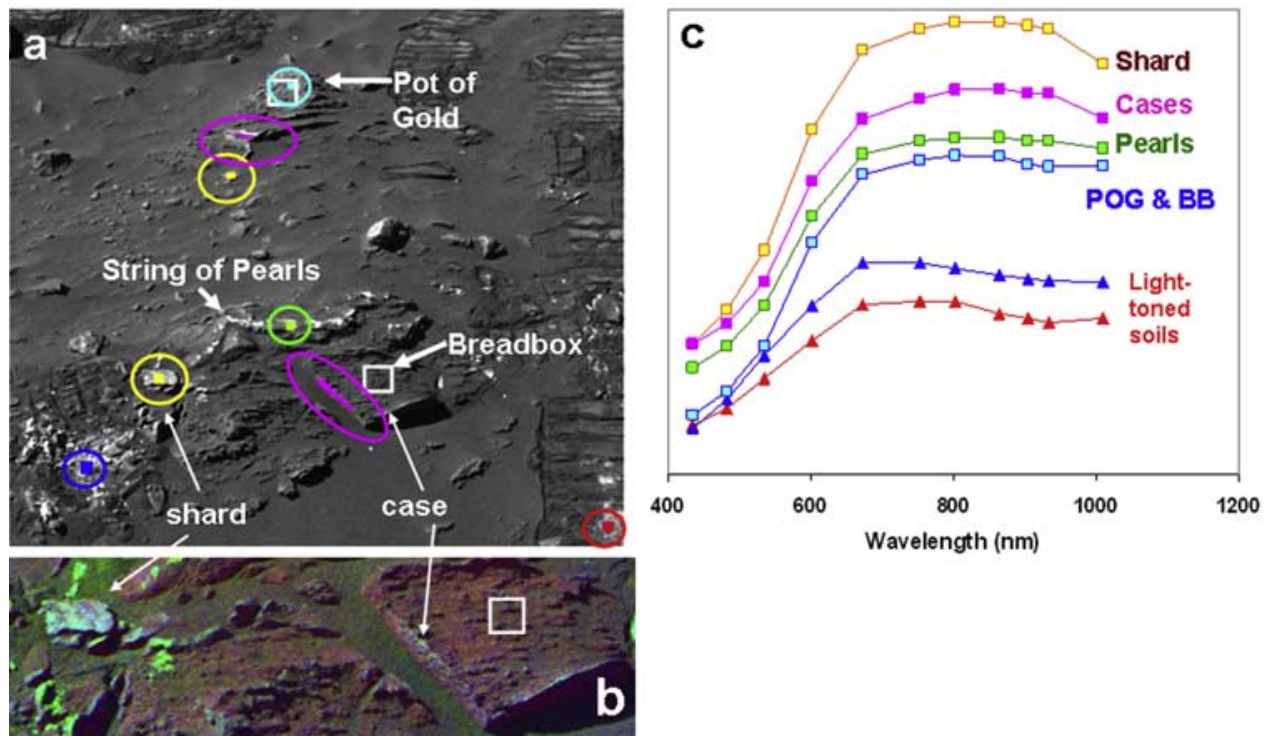

Figure 25. Pancam spectral analysis in the vicinity of rock Pot of Gold, Breadbox, and String of Peals at Hank's Hollow. (a) Pancam image through the L7 filter $(432 \mathrm{~nm}$ ) shows the ROIs, where the Vis-NIR spectra were extracted. The IDD targets are indicated by white squares. (b) Decorrelation stretched Pancam image near rock Breadbox, in which cyan color indicates the distribution of potential Si-rich species, a white square indicates Breadbox IDD target. (c) Vis-NIR spectra extracted from multispectral Pancam images, yellow spectrum from the shard (ROIs in Figure 25a, cyan color with a rectangular shape in Figure 25b) and the purple spectrum from the cases of Breadbox show characteristic spectral features of Si-rich species. The width of rover wheel track is about $16 \mathrm{~cm}$ for scale. 
Hollow Shredded site and the site near Champagne-Penny targets (Figures 20i and 20j) also show this negative slope.

[58] It is important to emphasize that the Pancam spectral features, especially the negative slope from 934 to $1009 \mathrm{~nm}$ found so far to be diagnostic of Si-rich materials on the basis of studies at Paso Robles and Tyrone, are probably not a direct reflection of their Si-rich nature (Si-bearing phases are not particularly "spectrally active" in the Vis-NIR spectral range), but rather likely a reflection of more general properties of Si-rich materials (nodules and soils) produced from a specific process, such as oxidation state, transition metal substitutions, and possession of water or hydroxyl related to specific processes. Experimental studies are being carried out by various groups [e.g., Cloutis et al., 2007; Freeman et al., 2008; Ling et al., 2008; Rice et al., 2008; Wang et al., 2006c, 2008b] to find the mineralogic origin of this Pancam spectral feature. Potential candidates include hydrous sulfates, zeolites, chlorites, water-bearing amorphous silica, and fine-grained water ice [Rice et al., 2008]. Structural or bound $\mathrm{H}_{2} \mathrm{O}$ or $\mathrm{OH}$ in these species are thought to contribute combinational mode and overtone $\left(2 \nu_{1}+\nu_{3}\right.$, or $3 \nu_{3}$, where $\nu_{1}$ and $\nu_{3}$ represent the fundamental vibrational modes for symmetric and asymmetric stretching of $\mathrm{H}-\mathrm{O}-\mathrm{H})$ that would appear as absorption bands centered in the spectral region 900-1100 nm [Herzberg, 1945]. Regardless of their unassigned status, these Pancam spectral features can be used as criteria to search for similar types of Si-rich species that potentially exist in other locations at Gusev, especially when combining them with other criteria, such as morphologic features and, whenever available, Mini-TES spectra of the same targets.

\subsubsection{In the Vicinity of Hank's Hollow}

[59] Figure 25 shows an example of applying the above empirical criteria to targets in the vicinity of Hank's Hollow, near rocks Pot of Gold, Breadbox and String of Pearls. A group of features with distinct morphologic characteristics in this area is the rectangular shaped "case" of the rock Breadbox, and two pieces of similar "cases" near Pot of Gold (Figures 25a and 25b). Previous assessment [Squyres et al., 2006] was that these cases are the residual outer shells of an extensively eroded rock, which were hardened during the erosion process, while a great deal of materials from the inner portion of the rocks was leached out leaving an extremely rough surface morphology. In situ measurements (APXS, MB, MI, Rock Abrasion Tool (RAT)) were made on spots of eroded inner portion of Pot of Gold and Breadbox (white squares in Figures 25a and 25b), but were never made on the residual cases (nor on light-toned soil patches). Multispectral Pancam imaging with high spatial resolution is extremely useful for investigating this type of fine-scale feature (at a few pixels level), that was either unreachable by the instrument deployment arm or for which a satisfactory positioning of in situ instruments could not be achieved.

[60] The purple colored spectrum in Figure 25c was extracted from the rectangular shaped residual case of the rock Breadbox and the two pieces of similar shaped cases near Pot of Gold (purple colored ROIs in Figure 25a), this spectrum exhibits spectral features similar to those of Si-rich nodules at Paso Robles and Tyrone: a steep positive spectral slope from 434 to $673 \mathrm{~nm}$ and a negative spectral slope from 934 to $1009 \mathrm{~nm}$. Because the morphology of these cases suggests a hardened outer shell compared to the interior of the original rocks, extrapolating from their Pancam spectra supports a hypothesis of their Si-rich nature. In addition, there are two rectangular shaped rock shards (yellow colored ROIs in Figure 25a) having a spectrum (yellow colored spectrum in Figure 25c) with even steeper slopes in the 434 to $673 \mathrm{~nm}$ and in the 934 to $1009 \mathrm{~nm}$ regions than those in purple colored spectrum (cases of Breadbox and Pot of Gold), further supporting a hypothesis that these shards are broken pieces of former residual cases. Figure $25 \mathrm{~b}$ is a decorrelation stretched Pancam image that shows the details of the interior and the case of Breadbox, and a nearby rock shard. The cyan color in Figure 25b indicates the distribution of potential Sirich species, and the white square indicates the target on Breadbox for in situ measurements.

[61] The interior of Breadbox has a spectrum similar to Pot of Gold (cyan colored ROI in Figure 25a and spectrum in Figure 25c), which shows an absorption band centered around $900 \mathrm{~nm}$ thus a positive slope in the 934 to $1009 \mathrm{~nm}$ region, very different from the spectrum of cases. The rock String of Pearls appears to be relatively strong, on the basis of its resistance to crushing as the rover drove over it. It has a flat spectrum (green colored spectrum in Figure 25c) in the 934 to $1009 \mathrm{~nm}$ range, and might be considered to be less eroded and thus a mixture of the spectra from typical hardened case materials and from more interior parts of these elsewhere heavily eroded rocks. Pancam spectra of adjacent light-toned soils show flat or positive spectral slopes in the 934 to $1009 \mathrm{~nm}$ region (red and blue colored spectra in Figure 25c; the red spectrum has an absorption band near $900 \mathrm{~nm}$ ) similar to some yellowish soil spectra from Paso Robles. The order of steepness of the red slopes from $434 \mathrm{~nm}$ to $673 \mathrm{~nm}$ (reflecting oxidation state) is, from high to low, shard, cases, inner portion of Pot of Gold, String of Peals, light-toned soils. The fact that Pot of Gold rock has a higher oxidation state than light-toned soils is consistent with $49 \%$ of total Fe in Pot of Gold as hematite, the third highest hematite abundance among all Gusev rocks [Morris et al., 2006].

[62] Therefore, in addition to Paso Robles, Dead Sea, and Tyrone, Hank's Hollow may be another place where lighttoned soils coexist with light-toned $\mathrm{Si}$-rich species. Two types of additional evidences suggest a general similarity between Hank's Hollow and the vicinity of Home Plate. Morphologically, a wide variety of surface morphologies of rocks was seen at Hank's Hollow (Figures 9b-9i), with many similar to the rocks in the region of Low Ridge, Mitcheltree Ridge, and the east side of Home Plate. Mineralogically, silicate glasses and Ca-sulfates [Squyres et al., 2006; Ruff et al., 2006; Wang et al., 2006b] were found to be two anomalous constituents of the rocks on West Spur (immediately above Hank's Hollow), while both materials were also found in the rocks at Home Plate region [Squyres et al., 2007; McSween et al., 2008; Schmidt et al., 2008].

\section{Spatial and Temporal Variability of Pancam Spectral Features in Tyrone Soils}

\subsection{Layered Structure of Subsurface Soils at the Tyrone Site}

[63] Two types of spectrally distinct, light-toned salty soils were exposed at Tyrone in wheel tracks and trenches 


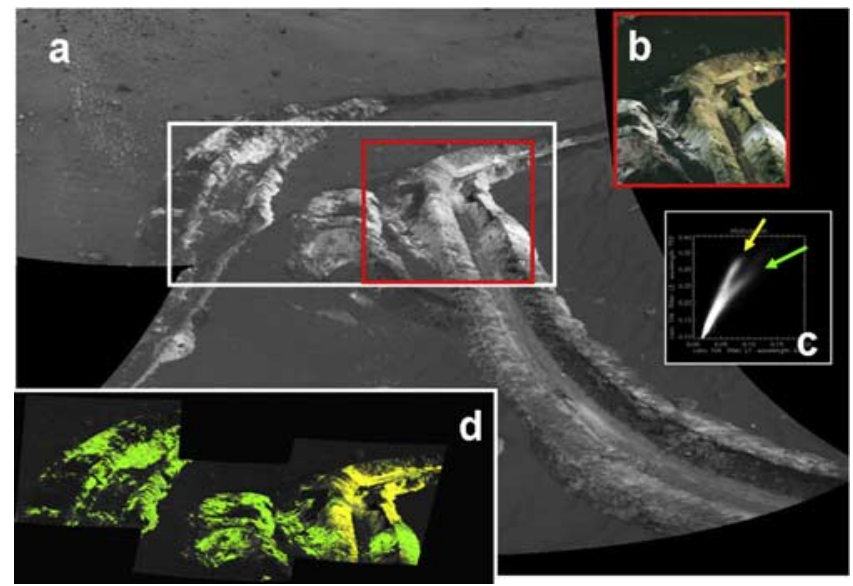

Figure 26. Light-toned salty soils at Tyrone. (a) Navcam image at position 114 of site 126 shows the locations where two Pancam images were taken. (b) Pancam false color image (sol 790_P2531) shows the coexistence of two spectrally distinct trends. (c) L2 $(750 \mathrm{~nm})$ versus L7 (432 nm) 2-dimensional histogram shows the two spectral trends as two well separated branches. (d) By color coding the two branches in the histogram, the spatial distributions of what are interpreted as two different chemical species of lighttoned soils at Tyrone site (sol 788 P2396) were obtained. The width of rover wheel track is about $16 \mathrm{~cm}$ for scale.

accidentally created as Spirit's nonrolling broken right front wheel was dragged through soft soils (Figure 26b). The majority of exposed soils in the deep trench made by right font wheel (right side in Figure 26a) have a yellowish color in Pancam $753 \mathrm{~nm}, 535 \mathrm{~nm}, 432 \mathrm{~nm}$ false color composites, whereas soils exposed in tracks made by other rolling wheels (left side in Figure 26a) are mainly whitish. Figure $26 \mathrm{c}$ shows that when plotting the reflectance values of each pixel in Pancam images taken using the L2 filter $(753 \mathrm{~nm})$ versus the $\mathrm{L} 7$ filter $(432 \mathrm{~nm})$ as a 2-dimensional histogram, the pixels from yellowish and whitish soils appear as two well-separated branches in the histogram. Figure 26d shows the distribution of yellowish and whitish soils at the Tyrone site by color coding the two branches in the 2-D histogram of Figure 26c, yellow for yellowish soils, and green for whitish soils.

[64] Figure 26d and several other similar observations demonstrate that apparently only deeper soils dug out by the right front wheel of Spirit possess the absorption band near $830 \mathrm{~nm}$ seen in their Pancam spectra, appearing yellowish (Figures 18i and 24). These yellowish soils also have a steeper spectral slope from $432 \mathrm{~nm}$ to $673 \mathrm{~nm}$ than the apparently shallower, whitish soils exposed by the other five wheels (Figure 24). The latter have a slightly negative spectral slope from 934 to $1009 \mathrm{~nm}$. Furthermore, the fact that multiple yellowish soil patches have consistent Pancam spectral shapes (Figure 18i) indicates that Tyrone yellowish soils have a relatively homogeneous nature. The same is true for Tyrone whitish soils. When comparing Tyrone whitish soils with Paso Robles and Dead Sea salty soils, which were all exposed by properly rolling rover wheels, the only difference is that Tyrone whitish soil patches have very similar Vis-NIR spectral patterns (Figure 18i and left portion of Figure 26d) while Paso Robles and Dead Sea salty soils have highly variable spectra (Figures $18 \mathrm{~g}$ and $18 \mathrm{~h}$ ). On the basis of these observations, we hypothesize a possible layered model of the distribution of these two distinct types of salty soils at Tyrone with whitish salty soils at shallow depth beneath a thin layer of surface dust and sand, and yellowish salty soils occurring deeper.

[65] The absorption band near $830 \mathrm{~nm}$ in the yellowish soils is suggestive of a similar feature seen in some ferric sulfates, and the average spectrum of whitish soils exhibits similarities to spectra of some hydrated salts such as Fe-, $\mathrm{Ca}$ - and Mg-sulfates and halides [Johnson et al., 2007; Morris et al., 2000; Lane et al., 2007]. The APXS data from two Tyrone-offset targets (mixtures of whitish soils with average dusty Gusev soil) show a correlation of $\mathrm{CaO}$ versus $\mathrm{SO}_{3}$ (Figure 16c) that implies that Ca-sulfates are one of the major components. The Pancam-based study of Johnson et al. [2007] provided additional first-order constraints on Fesulfates detections at Tyrone, and suggests that the Tyrone yellowish soils may have a much higher relative abundance of ferric sulfates than the Tyrone whitish soils.

\subsection{Spectral Property Changes of Tyrone Yellowish Soils as a Function of Surface Exposure Time}

[66] During 198 sols of Spirit's winter campaign parked at Low Ridge (from sols 864 to 1062), seven sets of 13-filter Pancam observations were taken periodically of the Tyrone site (Figure 27a). The purpose of these observations was to monitor potential changes in the Pancam spectra of freshly exposed Tyrone soils, possibly indicating changes in mineralogy, hydration state, or dust cover. As shown in Figure $27 \mathrm{~b}$ (DCS), the yellowish (red orange color in DCS) and whitish (green color in DCS) soils can be distinguished in Pancam images taken from tens of meters distance. Table 2 lists the measurement conditions for the seven sets of Pancam observations during this change detection campaign.

[67] Among the seven sets of Pancam observations, differences in spectra of the yellowish soils were obvious when using the L2 (753 nm) versus L7 (432 nm) 2-D histogram methods described above (Figure 27c, yellow colored branch for yellowish soils, green colored branch for whitish soils). We observed a reduction in the separation of the main spectral trends (two branches) for yellowish and whitish soils with time, with the most obvious change having happened in the period between sols 922 to 959 (i.e., after about 175 sols' surface exposure since sol 784; Figure 27c). A comparison of the histograms on sols 922 and 959 (Figures 28a and 28b) indicates that the decrease in the separation of the two main spectral trends is primarily caused by a decrease in the spectral slope $\left(\mathrm{R}_{753 \mathrm{~nm}} / \mathrm{R}_{432 \mathrm{~nm}}\right)$ of the yellowish soil. The spectral slope of the whitish soils does not appear to have changed with time (Figure 28b, comparing the red dashed line with solid purple line).

[68] Table 2 lists some measurement conditions for the seven sets of systematic Pancam observations acquired at Tyrone over this period of 198 sols (from sol 864 to 1062). The maximum local solar time difference among the measurements is $61 \mathrm{~min}$, and the maximum difference in solar azimuth and solar elevation angles is $28.3^{\circ}$ and $14.4^{\circ}$, respectively. Thus, we expect that the spectral effects of different illumination and viewing angle conditions are relatively minor for this monitoring campaign. During the 


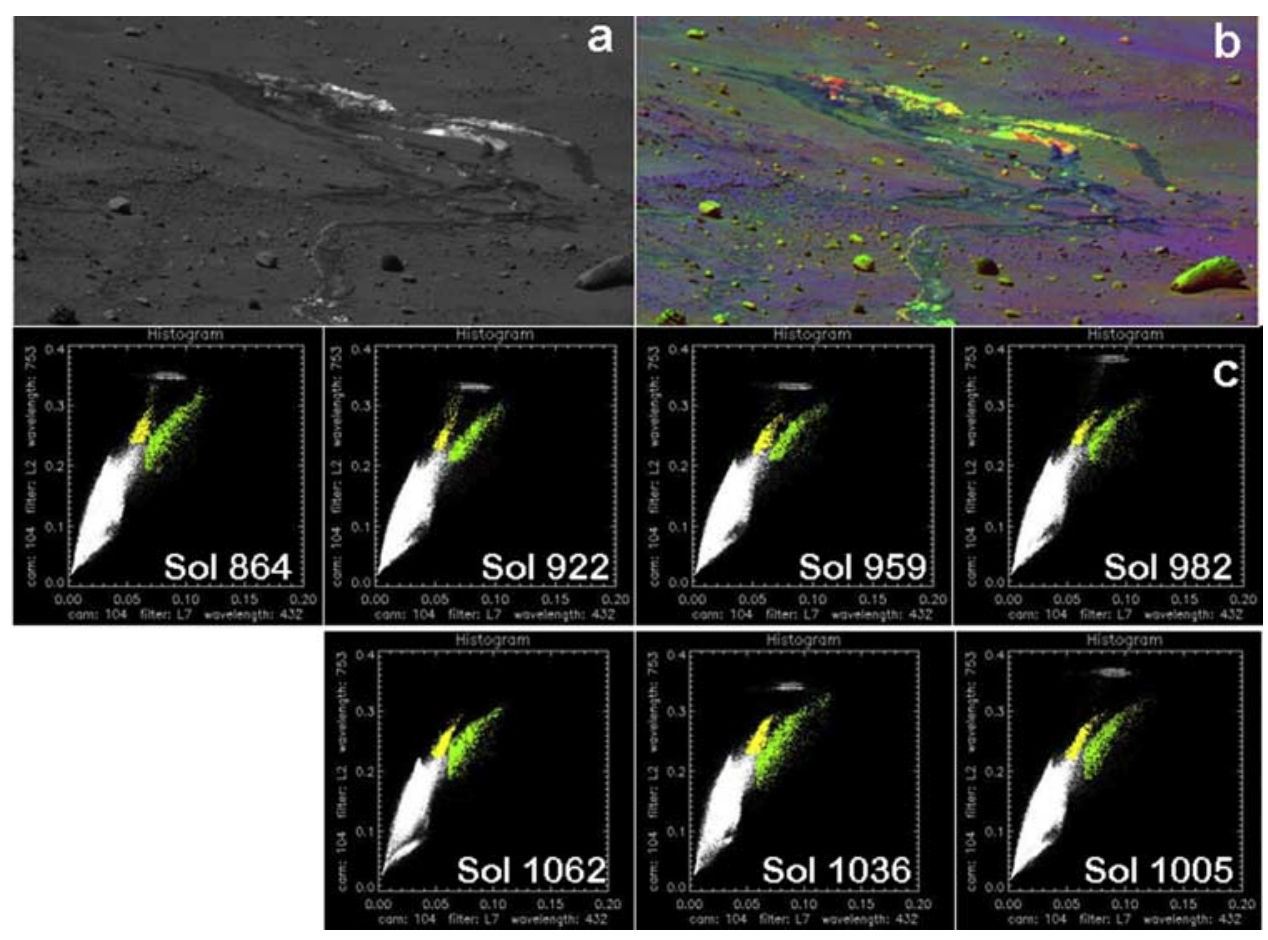

Figure 27. Periodic Pancam observations of Tyrone salty soil from Spirit's Winter Haven location (details in Table 2). (a) Pancam image of Tyrone from Low Ridge through L7 filter $(432 \mathrm{~nm})$. (b) Decorrelation stretched Pancam image, the yellowish (yellow orange color in DCS) and whitish (green color in DCS) soil patches can be distinguished from tens of meters away. (c) L2 (750 nm) versus L7 $(432 \mathrm{~nm})$ 2-dimensional histograms from seven sets of systematic observations (green branch corresponds whitish soils, yellow branch corresponds yellowish soils). The width of rover wheel track is about $16 \mathrm{~cm}$ for scale.

first set of measurements (sol 864), some image saturation was observed, but only within a few whitish soil patches in the images taken through L7 and R1 filters. Such saturation does not influence our analysis because the major changes that we discovered are in the spectral behavior of the yellowish soils, which did not exhibit saturation. During the first 141 sols (until sol 1005) of the 198 sol monitoring period, atmospheric dust opacity values as derived from Pancam solar imaging observations [e.g., Lemmon et al., 2004] were very steady (0.294 to 0.381$)$. Opacity did rise to 0.514 and 0.896 for the last two measurements, but no dramatic spectral changes were detected in association with that opacity change. We thus conclude that potential instrumental or observational factors like viewing geometry or atmospheric dust opacity did not yield systematic or large enough changes over the course of our 198 sol monitoring campaign to cause the observed changes in Pancam spectral properties seen in the yellowish soils during this time span.

\subsection{Laboratory Experiments to Observe Red Slope Changes in the Spectra of Ferric Sulfates}

[69] In order to explore the potential causes for the reduction of red slope in the $434 \mathrm{~nm}$ to $753 \mathrm{~nm}$ spectral range in a deposit newly exposed to current Martian surface conditions, (diurnal and seasonal cycles of temperature, dust, relative humidity, and water vapor pressure), we conducted a set of experiments involving heating a hydrous ferric-sulfate sample (kornelite, $\left(\mathrm{Fe}_{2}\left(\mathrm{SO}_{4}\right)_{3} \cdot 7 \mathrm{H}_{2} \mathrm{O}\right)$ ) up to

Table 2. Conditions During the Seven Sets of Pancam 13F Tyrone Observations From Low Ridge ${ }^{\mathrm{a}}$

\begin{tabular}{|c|c|c|c|c|c|c|c|}
\hline \multirow[b]{2}{*}{ Sol } & \multirow[b]{2}{*}{ Sequence } & \multicolumn{2}{|c|}{ Local True Solar Time } & \multicolumn{2}{|c|}{ Solar Angles for L2 Filter } & \multirow[b]{2}{*}{ Tau, L8 } & \multirow[b]{2}{*}{ Saturation } \\
\hline & & $\mathrm{L} 2$ & R7 & Solar Azimuth & Solar Elevation & & \\
\hline 864 & P2547 & $12: 37: 47$ & $12: 41: 31$ & 345.82 & -51.726 & 0.294 & yes* \\
\hline 922 & P2552 & $12: 02: 10$ & $12: 06: 49$ & 359.236 & -50.067 & 0.368 & no** \\
\hline 959 & $\mathrm{P} 2560$ & $12: 07: 35$ & $12: 11: 37$ & 357.239 & -51.141 & 0.345 & no \\
\hline 982 & P2566 & $12: 10: 36$ & $12: 14: 01$ & 355.919 & -52.971 & 0.381 & no \\
\hline 1005 & P2576 & $12: 23: 12$ & $12: 28: 56$ & 350.346 & -55.349 & 0.342 & no \\
\hline 1036 & P2586 & 13:03:39 & $13: 06: 53$ & 330.933 & -56.868 & 0.514 & no \\
\hline 1062 & P2596 & $12: 30: 12$ & $12: 36: 53$ & 342.181 & -64.91 & 0.896 & no \\
\hline Max difference & & $61 \mathrm{~min}$ & $60 \mathrm{~min}$ & 28.3 & 14.8 & & \\
\hline
\end{tabular}

aSpirit 2nd winter haven; one asterisk indicates saturation in L7 and R1 was observed at a few spots in "whitish" soil patches, not on "yellowish" soils; two asterisks indicates after adjusting the threshold, no saturation was observed. 


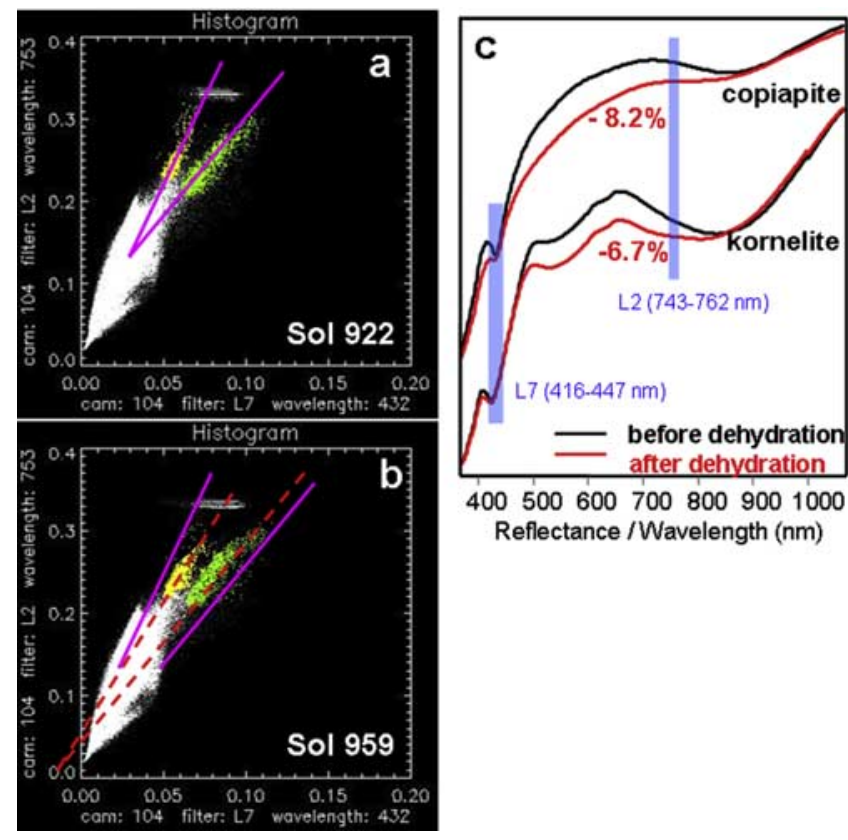

Figure 28. (a) L2 (753 $\mathrm{nm})$ versus L7 (432 nm) 2dimensional histogram from sol 922_P2252, two straight purple colored solid lines mark the central lines of the two branches. (b) L2 (753 nm) versus L7 (432 nm) 2dimensional histogram from sol 959_P2560, two straight red colored dashed lines mark the central lines of the two current branches, which can be compared with the central lines at earlier time (two purple solid lines). It appears that the red slope from $432 \mathrm{~nm}$ to $753 \mathrm{~nm}$ of the yellowish soils branch has reduced. (c) Reflectance Vis-NIR spectra obtained from two laboratory experiments: the dehydration of copiapite was carried out in a Mars simulation chamber using $660 \mathrm{~Pa} \mathrm{CO}_{2}$ at $12-26^{\circ} \mathrm{C}$ temperature range; the dehydration of kornelite was carried out in an oven at $50^{\circ} \mathrm{C}$ and $5 \% \mathrm{RH}$. The spectra from dehydration products of these two ferric sulfates (red spectra) show general reductions of spectral contrast, which also result in a decrease in spectral slopes from $432 \mathrm{~nm}$ to $753 \mathrm{~nm}$.

$50^{\circ} \mathrm{C}$ in a laboratory oven for several days $(\sim 5 \% \mathrm{RH})$, and measuring its Vis-NIR reflectance spectra before and after baking (lower spectra pair in Figure 28c). Mass measurements before and after baking indicated that a dehydration occurred and that the resulting ferric sulfate would have an average formula of $\mathrm{Fe}_{2}\left(\mathrm{SO}_{4}\right)_{3} \cdot 5.7 \mathrm{H}_{2} \mathrm{O}$. Five spectra from each sample were taken. The averaged reflectance values over $20 \mathrm{~nm}$ around $753 \mathrm{~nm}$ and $32 \mathrm{~nm}$ around $432 \mathrm{~nm}$ were used to simulate the actual spectral bandwidths of L2 and L7 filters of Pancam, and to calculate averaged slope from $432 \mathrm{~nm}$ to $753 \mathrm{~nm}$ over five spectra. A reduction of $\sim 6.7 \%$ of this spectral slope (0.98 to 0.914) was found in the dehydrated kornelite sample. A dehydration experiment run in a Mars atmospheric simulation chamber with copiapite $\left(\mathrm{Mg}, \mathrm{Fe}^{2+}\right)\left(\mathrm{Fe}^{3+}\right)_{4}\left(\mathrm{SO}_{4}\right)_{6}(\mathrm{OH})_{2} \cdot 20 \mathrm{H}_{2} \mathrm{O}$ (using $660 \mathrm{~Pa} \mathrm{CO}_{2}$ and a $12-26^{\circ} \mathrm{C}$ temperature range for a few days [Cloutis et al., 2007]) demonstrated a similar reduction of slope in the same spectral region (upper spectra pair in Figure 28c). When applying $20 \mathrm{~nm}$ (L2) and $32 \mathrm{~nm}$ (L7) as bandwidths to simulate Pancam spectra, $\sim 8.2 \%$ of slope decrease ( 0.993 to 0.912 ) was obtained after copiapite dehydration.

[70] Our observations suggest that a general effect of dehydration on the Vis-NIR spectra of ferric sulfates is decrease in spectral contrast. Because both kornelite and copiapite have absorption bands centered around 830$860 \mathrm{~nm}$, the decrease of their absorption band depth caused a reduction of slope from $434 \mathrm{~nm}$ to $753 \mathrm{~nm}$. Dehydration of goethite and two other ferric sulfates (fibroferrite and paracoquimbite in the work of Cloutis et al. [2007]) was also tested, which caused an increase of spectral slope in this region because their absorption bands centers are around $800 \mathrm{~nm}$. (near $753 \mathrm{~nm}$ ). Further combined Pancam spectral analyses and simulation experiments are needed, in order to evaluate if this slope reduction would be an indication of mineralogy in Tyrone yellowish soils.

[71] No in situ measurements were made on Tyrone yellowish soils. Mössbauer spectral analysis [Morris et al., 2008] suggests ferric sulfates in a similarly yellowish soil target (Samra) at the Dead Sea site. The $6 \mu \mathrm{m}$ spectral feature in Mini-TES spectrum of Tyrone yellowish soils (Figure 17) indicates that it is hydrous. Compared with kornelite and copiapite that we used for experiments, more complicated ferric sulfates (acidic and basic salts, sulfates with both $\mathrm{Fe}^{2+}$ and $\mathrm{Fe}^{3+}$ ) could also be present [Johnson et al., 2007]. Our laboratory experiment suggests that the dehydration of kornelite and copiapite can reduce the spectral slope from $432 \mathrm{~nm}$ to $753 \mathrm{~nm}$ in a way similar to what we observed in the Pancam data of the Tyrone yellowish soils over 198 sols. A rough estimation based on Figure 28b indicates that the slope reduction of Tyrone yellowish soils is $>20 \%$, which is larger than the values observed in the kornelite and copiapite experiments. This suggests a complex mineral assemblage in these soils, possibly with other physicochemical changes.

\subsection{Hypothesis: A Relative Humidity Gradient Beneath the Surface}

[72] If dehydration was indeed the major cause of the observed spectral changes in what had been the deepest excavated yellowish soils at Tyrone, it would support our model of a layered structure for salty soils in that area. It would also support a hypothesis that a relative humidity (RH) gradient exists in the upper few tens of centimeters depth below the surface in the Tyrone area.

[73] The relative humidity $(\mathrm{RH})$ in a local environment is determined by temperature (which changes significantly with local solar time and seasons on Mars [Smith et al., 2006]) and the absolute water vapor partial pressure (which changes with locations and seasons on Mars [e.g., Kieffer et al., 1992; Jakosky, 1992; Savijarvi, 1995]). In addition, the latter is buffered by coexisting hydrous species. At midpressure to low-pressure ranges (on Earth or on Mars), the stability field of hydrous minerals is mainly determined by temperature and relative humidity [Chou and Seal, 2003; Vaniman et al., 2004; Wang et al., 2006c].

[74] Although the absolute water vapor partial pressure is very low in Mars atmosphere, the RH at surface can exceed $100 \%$ for a few hours in early morning (e.g., morning frosts have been observed to form at the Viking Lander sites and at the Mars Exploration Rover (MER) sites) but decreases to nearly $0 \%$ over much of the sol. At a depth immediately 
beneath the surface dust and basaltic soils, the RH could be buffered by a combination of more deeply buried hydrous salts and water vapor in the atmosphere. The observation that there was little or no change in the spectral slope of what we interpret as the less deeply buried Tyrone whitish soils indicates that they may have been more or less in equilibrium with surface conditions. At depths more than ten centimeters beneath the surface, however, in the zone where the Tyrone yellowish soils may have originated, $\mathrm{RH}$ would be mostly buffered by the hydrous salts buried at that level and deeper, with much less or perhaps no influence from the atmosphere. Therefore, we hypothesize that the spectral slope change observed for yellowish soils (Figure 28b) indicates that they were originally not in equilibrium with surface conditions. Our observations acquired over the time since these soils were first exposed to current Mars surface conditions (about 175 sols) indicate that they appear to have undergone some dehydration, moving toward equilibrium with the current atmosphere.

[75] Relative humidity ( $\mathrm{RH})$ in a local environment is a function of temperature. Thermal model calculations of the temperature profiles and temperature oscillations in the subsurface on Mars [Paige, 1992; Mellon et al., 2004; Bandfield, 2007] indicated that when a regolith was made of a layer of high thermal inertia material (e.g., ground ice, $\mathrm{I}=2290 \mathrm{~J} \mathrm{~m}^{-2} \mathrm{~K}^{-1} \mathrm{~s}^{-1 / 2}$ [Mellon et al., 2004]) covered by a layer of low thermal inertia materials (e.g., Mars surface dust, 200-250 $\mathrm{J} \mathrm{m}^{-2} \mathrm{~K}^{-1} \mathrm{~s}^{-1 / 2}$ at Gusev [Fergason et al., 2006]), it produces a low-temperature zone in the high thermal inertia layer with a much smaller magnitude of temperature oscillation. This low-temperature zone will have a higher and a more stable relative humidity $(\mathrm{RH})$ beneath the local surface dust. It is also possible that the temperature in this zone drops to below the local frost-point temperature that net condensation of atmospheric water vapor could happen (ice forming), which means a relative humidity of $100 \%$. These high-RH conditions will help to maintain the stability of highly hydrated sulfates.

\section{Discussion}

\subsection{Constraints on Paleoenvironmental Conditions}

[76] The composition and mineralogy of the light-toned salty soils and coexisting Si-rich species found in Gusev by the Spirit Rover have provided some constraints on paleoenvironmental conditions under which they were formed. For example, the presence of hydrous sulfates in major exposures of the light-toned soils indicates that water was involved as one of the reactants in their formation. In addition, abundant ferric sulfates at three major exposures of light-toned soils suggest a highly acidic environment [Jerz and Rimstidt, 2003; Buckby et al., 2003; FernandezRemolar et al., 2004, 2005; Bigham and Nordstrom, 2000; Jambor et al., 2000; Tosca et al., 2005, 2008; Joeckel et al., 2005; Keith et al., 2001; Nordstrom and Alpers, 1999]. The small-scale heterogeneous distribution of salty materials with apparently distinct compositions and mineralogy at the Paso Robles and Dead Sea sites may be most consistent with gas-solid reactions or extremely low water/rock ratios [Africano and Bernard, 2000; Keith, 1991; Zimbelman et al., 2005; Stoiber and Rose, 1974; Getahun et al., 1996]. Conversely, the homogeneity in the composition and min- eralogy (to the degree seen by Pancam spectra) of the Tyrone yellowish and whitish salty soils and their layered spatial distribution could be consistent with the involvement of larger quantities of water and possibly multievent deposition [Warren, 1989].

[77] On the other hand, large amounts of excess silica implied by APXS measurements of Dead Sea salty soils and the Si-rich nodules (and other species) found coexisting with S-rich soils at Paso Robles, and potentially at Dead Sea and at Hank's Hollow, are suggestive of high-temperature hydrologic (epithermal to hydrothermal) events that can link the S-rich and Si-rich species as possible end products of the same process [Gilbert and Park, 1985]. Intimately associated sulfate-bearing, silica-rich deposits are known from terrestrial hydrothermal springs [Ellis and Mahon, 1977]. Furthermore, the coexisting S-rich soils and Si-rich nodules at the Tyrone site and the variety of Si-rich species (nodules and soils) found within the same local topographic lowland in the Tyrone-Eastern Valley region could be the result of a series of processes involving high temperatures, temperature gradients with distance from the heat source, chemical or $\mathrm{pH}$ gradients, and potentially large quantities of water, which will be discussed below.

\subsection{Relationships to the Alteration of Local Rocks}

[78] Yen et al. [2008] have argued that some trace elements in local rocks, especially at Paso Robles (high P, low $\mathrm{Cr}$ ) and at Dead Sea (low P), may have been carried into the chemistry of salty soils found in those locations. Our study of the geomorphic settings and remote sensing studies of all of the light-toned soils detected in Gusev, in combination with in situ measurements at particular sites, indicate that the degree of alteration of local rocks is reflected in the major chemistry of salty soils found at these locations, especially for the Gusev basaltic plains, West Spur-Shredded, and Tyrone-Eastern Valley regions.

[79] For example, basaltic rocks on the Gusev basaltic plains (from Spirit's landing site to the base of the Columbia Hills) show little or no evidence of alteration [e.g., Squyres et al., 2004; McSween et al., 2004] such that only limited dissolution of olivine occurs [Hurowitz et al., 2006] The typical composition of Gusev plains olivine is $\mathrm{Fo}_{50-60}$ as indicated by mineral model analysis based on APXS data [McSween et al., 2004, 2006, 2008] and by Mini-TES spectral deconvolution [Christensen et al., 2004]. Thus, $\mathrm{Mg}, \mathrm{Fe}$ and $\mathrm{Si}$ would be the primary cations released from the olivine dissolution process with $\mathrm{Mg}$ and Fe being most mobile under low-pH conditions. Some evidence for a low degree of olivine alteration is reflected in the major element chemistry of sulfate-rich regolith at two of the plains trench sites (Big Hole and The Boroughs). The main components of the sulfates found in the trench soils are Mg-sulfates, implied by compositional correlation of $\mathrm{MgO}$ and $\mathrm{SO}_{3}$ in APXS data, with little or no additional $\mathrm{Ca}$ - and Fe-sulfates based on mineral model calculations [Wang et al., 2006a]. The Fe released from low-degree olivine dissolution may contribute part of the nanophase Fe-oxide component, thus increasing the $\mathrm{Fe}^{3+} / \mathrm{Fe}_{\text {total }}$ ratios in these trench regoliths compared with typical Gusev soils [Morris et al., 2006].

[80] Conversely, Ca-sulfates appear to be the major sulfate component found in Tyrone whitish soils, in the interior of all West Spur rocks [Ming et al., 2006; Wang et al., 
2006b], and very possibly in the Hank's Hollow Shredded light-toned soils at the foot of West Spur, on the basis of compositional correlations of $\mathrm{CaO}$ and $\mathrm{SO}_{3}$ revealed by APXS. However, we note that $\mathrm{Fe}$ - and $\mathrm{Mg}$-sulfates have also been inferred on the basis of mineral model calculations [Yen et al., 2008] in the Tyrone-offset whitish soils. The formation of Ca-sulfates requires a certain amount of calcium to be released from crystalline igneous minerals like clinopyroxene and feldspar. In an acidic environment, the dissolution of these two minerals would be an indicator of a much higher degree of alteration than olivine dissolution [Nesbitt and Wilson, 1992; Hurowitz and McLennan, 2007].

[81] More severe alteration than simple olivine dissolution was observed in the local rocks of the above areas. Olivine (in the form of $\mathrm{Fe}^{2+}$ in the fayalitic component of olivine) was identified by $\mathrm{MB}$ measurements in all rocks investigated in Gusev Crater except the rocks in three regions in which very little to almost no fayalitic olivine was found [e.g., Morris et al., 2006, 2008]. They are the Clovis class rocks on West Spur, the Barnhill class outcrop at Home Plate, and the outcrops in the vicinity of the rock Independence. Two common characteristics of the Clovis rocks at West Spur and Barnhill outcrops at Home Plate are (1) that they both have little or no $\mathrm{Fe}$ in fayalitic olivine: only $1-3 \%$ in total Fe for abraded and brushed West Spur rocks and $0-18 \%$ in total $\mathrm{Fe}$ for undisturbed and brushed Home Plate outcrops [Morris et al., 2008]; and (2) that they both have large amounts of silicate glasses as indicated by Mini-TES spectral deconvolution: $~ 33 \%$ estimated in Clovis class rocks [Ruff et al., 2006] and $\sim 45 \%$ in the Barnhill class outcrop at Home Plate [Squyres et al., 2007].

[82] In an acidic environment, the order of dissolution among igneous minerals is typically phosphate $\rightarrow$ olivine $\rightarrow$ pyroxene $\sim$ Fe-Ti oxides $\sim$ mafic silicate glass $\rightarrow$ plagioclase $\sim$ felsic silicate glass [e.g., Nesbitt and Young, 1984; Nesbitt and Wilson, 1992; Wolff-Boenisch et al., 2004]. The reason for the high dissolution rate of silicate glass is the loss of translational symmetry in its framework, which normally reduces the threshold energy for chemical reactions and phase transitions [e.g., Langmuir, 1997; Gooding and Keil, 1978]. The dissolution of silicate glasses releases $\mathrm{Ca}$ and $\mathrm{Al}$, in addition to $\mathrm{Mg}$ and $\mathrm{Fe}$. Thus, the discovery of Ca-sulfates inside of West Spur rocks and as the major sulfates in light-toned salty soils in the vicinity of Home Plate outcrops (in which silicate glass was identified) is an indication that the degree of alteration of local rocks was more severe than the olivine dissolution process experienced by the rocks at Gusev basaltic plains. As yet there is little evidence and few constraints on whether the degree of alteration of local rocks in the vicinity of Paso Robles, Dead Sea, and Tyrone ever reached the level of dissolution of clinopyroxene or feldspar.

\subsection{Origin of Light-toned, Salty Soils in Columbia Hills}

[83] Because the light-toned, salty soils found at different locations in Columbia Hills are so different in terms of their geomorphic settings, spatial distributions, chemistry, mineralogy, and their chemical and mineral heterogeneities, they should not be evaluated as one entity when discussing possible formation mechanisms. Thus, in the following analysis, we seek to gain a general understanding of the different types of mechanisms that may be able to explain the origins of salty soils at these different locations.

\subsubsection{Contributed Mainly by Aeolian Processes}

[84] The trace amounts of light-toned soils that accumulated near large outcrops at high elevations (geomorphic setting 3, near Jibsheet and Hillary) appear to have been transported into that setting by aeolian processes. The layers of light-toned soils appear to be thin, thus did not cause travel difficulty for Spirit Rover, in contrast to the situations at the Paso Robles, Dead Sea, and Tyrone sites. The more or less homogeneous spectra from different soil patches in the same Pancam images (e.g., section 3.1 and Figures 20c and 20d) indicate the well-mixed nature of these particular lighttoned soils, consistent with aeolian transportation and deposition. Large outcrops (Jibsheet and Hillary) may have served as a barrier and acted to reduce wind speed, thereby causing the deposition of materials suspended by winds. The most convincing evidence for the role of aeolian transport may be that light-toned soils were found even at the summit area of Husband Hill. While there is no way to currently constrain the timing of this transport and deposition, the occurrence of these light-toned soils just beneath the surface dust and dark soils may suggest recent accumulation. More importantly, this observation indicates that there was a period(s) in the history of Gusev Crater when large quantities of light-toned weathering products may have been well exposed, widely spread, and easily accessible, thus making them available for aeolian transport and subsequent deposition in large areas within the Columbia Hills. Differences in Vis-NIR spectra extracted from Pancam images (mainly an absorption band centered near 934 $\mathrm{nm}$ in Figure 20k and the blue spectrum in Figure 201) further suggest some additional sources for the light-toned soils mainly found near Jibsheet Outcrop from those generally found at the summit of Husband Hill.

\subsubsection{Contributed Mainly by In-Place Formation}

[85] The light-toned soils found at Hank's Hollow Shredded site (geomorphic setting 2) and Champagne-Penny site (geomorphic setting 4) exhibit small-scale heterogeneity in their spatial distribution (distinct phases occur within ranges of centimeters to tens of centimeters, Figures 20a and 20b). This heterogeneity could suggest an in-place formation mechanism, because aeolian or fluvial transport would tend to homogenize any delivered materials. In addition, smallscale heterogeneity as seen at these two locations may decrease (but not rule out) the possibility of multievent aeolian deposition or gravitational transportation and accumulation (for example, caused by steep slopes), which might be expected to produce heterogeneity on larger spatial scales. In-place gas-solid reactions or water-rock reactions at extremely low water/rock ratios may be the best candidate mechanism to form these light-toned soils, especially in terms of explaining their small-scale heterogeneity.

[86] A volcanic origin (e.g., fumarolic processes) would particularly suit the light-toned soils at the Hank's Hollow Shredded area at the base of the West Spur, because vesicular basalts were also found in this area and silicate glasses are suggested by Mini-TES analysis to be one of the major components of West Spur rocks [Ruff et al., 2006; Squyres et al., 2006]. Other supporting evidence includes (1) most rocks at West Spur have a corundum-normative 
chemistry suggesting nonisochemical alteration [Ming et al., 2006]; (2) excess of $\mathrm{SiO}_{2}$ and $\mathrm{Al}_{2} \mathrm{O}_{3}$ in the rocks Wooly Patch and Clovis, compared to typical basaltic mineralogy, with cation/anion ratios in these rocks that best fit to a kaolinite-serpentine type of alteration formed in acidic and well-drained environments [Wang et al., 2006b]; and (3) the possible Si-rich materials in residual cases of heavily altered rocks (e.g., Breadbox and Pot of Gold) at the base of West Spur [Wang et al., 2007c]. In addition, short-distance aeolian transportation and impact ejecta origin cannot be ruled out.

[87] The light-toned salty soils at the Paso Robles and Dead Sea sites show evidence for multiple types of salts, on the basis of their APXS and MB derived compositions and Fe-mineralogy [e.g., Yen et al., 2008; Morris et al., 2008] and by observed variations in Pancam spectra (Figures $18 \mathrm{~g}$ and $18 \mathrm{~h}$ [Johnson et al., 2007]). Another common characteristic of the salty soils at these two sites is small-scale heterogeneity in the spatial distribution of what appear to be distinct types of salty soils: they occur randomly next to each other within centimeters distances after excavation (Figures 18d, 18e, 18g, and 18h). The major differences between the two sites are that a large amount of salty soil was exposed at the Dead Sea site in a local topographic low, while the Paso Robles site, found on a slope, exposed a moderate amount and a spotty distribution of light-toned salty soils (Figures 15f, 15g, 15h, and 15i).

[88] At the Dead Sea site, the large variations in the chemistry and mineralogy of light-toned soils combined with their small-scale heterogeneous distribution provide support for a model of in-place salt formation by processes with limited transport capability. Fumarolic activity (e.g., gas-solid reactions) is one example of such a process. Another example is liquid rock reactions with extremely low water/rock ratios. In addition, the relatively high quantity of excess $\mathrm{SiO}_{2}$ in these light-toned soils based on APXS data (especially at the target Samra) and the potentially Si-rich light-toned nodules seen in the vicinity of the Dead Sea site (Figure 4c) are consistent with the involvement of hydrothermal fluids [Squyres et al., 2008].

[89] Furmarolic and volcanic hydrothermal processes often occur together. For example, when supercritical fluids with various dissolved elements ( $\mathrm{S}$ with or without $\mathrm{Si}$, depending on $\mathrm{pH}$ and temperature) rise to the surface, decompression will induce the separation of a gaseous phase and a liquid phase. Volatile components $\left(\mathrm{H}_{2} \mathrm{O}, \mathrm{H}_{2} \mathrm{~S}\right.$, $\mathrm{HCl}, \mathrm{HF}, \mathrm{CO}_{2}$, etc) carried by the gaseous phase can solidify directly to form minerals (e.g., sulfur and salts) and also react with surrounding materials to form various chlorides, sulfates, oxides, sulfides, tridymite, topaz, etc [Gilbert and Park, 1985]. The spatial distribution of those kinds of deposits and reaction products would exhibit smallscale heterogeneity because of the relatively low transport efficiency of gases. The liquid phase, once separated from the supercritical fluid, could retain a large amount of dissolved $\mathrm{SiO}_{2}$. The solubility of amorphous silica is strongly dependent on the temperature of the liquid phase [White et al., 1956; Krauskopf, 1956; Krauskopf and Bird, 1995; Fournier and Potter, 1982]. When the temperature drops, $\mathrm{SiO}_{2}$ would precipitate to form minerals like geyserite (fiorite), opal, amorphous silica, and/or fine-grained quartz [Gilbert and Park, 1985].
[90] Both processes may have happened at the Dead Sea site. If the excess $\mathrm{SiO}_{2}$ in Dead Sea soil requires the involvement of hydrothermal fluid(s), then the small-scale heterogeneity would require an extremely low water/rock ratio during the hydrothermal process. Because of low water/rock ratio $(\mathrm{s})$, reactions such as solidification of the volatile component, reaction with surrounding materials, and deposition of $\mathrm{SiO}_{2}$ and sulfates could all happen in place. The geomorphic setting of the Dead Sea site (on a partially enclosed terrace near the valley floor) can help, but is not a necessary condition, to retain the fluids locally. In other words, the deposition of S-rich and Si-rich materials at the Dead Sea site could have happened at different times but physically occurred next to each other. This is consistent with the APXS composition of the Samra target (yellow soil patch in the middle of Figures $2 \mathrm{a}$ and $18 \mathrm{~b}$ ), which is highly enriched in $\mathrm{S}\left(35.06 \mathrm{wt} \% \mathrm{SO}_{3}\right)$ but also has $\sim 34 \mathrm{wt} \%$ excess $\mathrm{SiO}_{2}$ [Yen et al., 2008].

[91] On the other hand, hydrothermal fluids can be neutral, alkaline, or acidic. If the initial fluid had a low $\mathrm{pH}$ value (without or low in $\mathrm{Si}$ content) as implied by the abundant ferric sulfates in Dead Sea soils, it could leach out $\mathrm{Mg}, \mathrm{Fe}, \mathrm{Ca}$, and $\mathrm{Al}$ from the surrounding igneous rocks, leaving Si-rich residual deposits behind. $\mathrm{Mg}-, \mathrm{Fe}-, \mathrm{Ca}$, and Al-sulfates will be precipitated from the fluids following further decrease in temperature. Supporting evidence for the third hypothesis is that Dead Sea S- and Si-rich soils were found coexisting with light-toned nodules (Figure 4c) that may be Si-rich on the basis of analogy with the similar morphology of Si-rich nodules at the Tyrone sites (Figure 7b), although no in situ measurements were made on these materials.

[92] Furthermore, because of the relatively low topographical position of the Dead Sea site, gravitational transportation, impact ejecta, and aeolian accumulations (e.g., slumps, surges, etc.) cannot be entirely ruled out.

[93] A similar combination of fumarolic and hydrothermal processes, but on a smaller scale, could have operated in the Paso Robles area. In addition, the small areal coverage of Paso Robles light-toned soils, especially their spotty distribution (Figure 15), may be suggestive of contributions from an alternative mechanism such as ejecta from a distant impact.

\subsubsection{Processed by Relatively Large Quantities of Acidic Hydrothermal Fluids}

[94] The major difference that we found in Tyrone salty soils from those at Dead Sea and Paso Robles is the lack of "small-scale heterogeneity" of different types of salty soils, evidenced by Pancam spectral analysis (Figures 18g, 18h, and 18i). The layered structure and the homogeneous nature of whitish (upper layer) and yellowish (lower layer) Tyrone light-toned soils suggest the possibility that these materials have been transported and homogenized at different times by aqueous processes, in which relatively large quantities of water were involved.

[95] The water involvement is suggested by three observations: (1) both types of Tyrone salty soils (whitish and yellowish) show a $6 \mu \mathrm{m}$ spectral feature in their Mini-TES spectra (Figure 17), indicative of the presence of hydrated minerals (A. T. Knudson et al., manuscript in preparation, 2008); (2) hydrothermal aqueous fluid is suggested to be the essential reaction agent in the two formation mechanisms of 
Si-rich species (soils and nodules) in Tyrone-Eastern Valley region [Squyres et al., 2008]; and (3) changes in the Pancam spectra of Tyrone yellowish soils after 198 sols' exposure suggests that they were not in equilibrium with current surface environmental conditions. The putative existence of a humidity gradient (as discussed above) suggests that the environment under which yellowish soils accumulated may have had a higher humidity, and that they are precipitates from aqueous solutions [Wang et al., 2007a].

[96] The involvement of relatively large amounts of aqueous solution (transportation, homogenization, and deposition) is indicated mainly by the homogeneity in chemical and physical properties within the two distinct types of Tyrone salty soils, i.e., a quantity of aqueous solution larger than the area of excavated soils at Tyrone $(5.4 \times 3.8 \mathrm{~m}$, Table 1$)$, or an open flow system. A small quantity of salty solution in a closed system, when dried, will leave deposits with a highly variable composition. During each cycle of evaporation and precipitation, the chemistry of residual solution (which will tightly constrain the chemistry of later deposits) will change greatly as the chemistry of precipitated phases evolves. Thus a small quantity of salty solution will produce evaporites with highly heterogeneous compositions and physical properties [e.g., Last, 1989a]. This may not be the case when a large quantity of aqueous solution is present or when an open system exists. Under these conditions, the salt assemblage that is deposited would be expected to be more homogeneous in chemistry and other properties over the meter scales being considered [e.g., Last, 1989b]. Depending on salt solubility and the properties of aqueous solutions ( $\mathrm{T}$, $\mathrm{Eh}, \mathrm{pH}$ ), different salts (or salt assemblages) will precipitate at different periods and may form layered deposits of larger scale [Last, 1989b; Warren, 1989]. Currently, we cannot constrain whether the layered structure of Tyrone salts was formed during a sequenced precipitation, or if the two layers were formed from different events with different solution chemistries.

[97] The second major difference, when compared with Dead Sea site, is that the S-rich and Si-rich materials in Tyrone-Eastern Valley region are better separated, either residing in different species (as S-rich soils and Si-rich nodules at Tyrone site), or separated by large distance (Tyrone S-rich soils and Gertrude Weise Si-rich soils, $\sim 75 \mathrm{~m})$.

[98] Tyrone soils are enriched in S. In contrast to $34 \mathrm{wt} \%$ excess $\mathrm{SiO}_{2}$ content of Samra (yellowish soil patch, Figures $2 \mathrm{a}$ and $2 \mathrm{~d}$ ) at the Dead Sea site, Tyrone soils are much less enriched in $\mathrm{Si}$ on the basis of the APXS measurements made on Berkner Island and Mount Darwin targets (whitish soils). The implied amounts of excess silica for these samples [Yen et al., 2008] are almost negligible, although these values were greatly affected by large uncertainties in estimating the proportions of basaltic soils mixed in with these two samples. On the basis of Pancam analysis, Tyrone whitish soils do have a certain probability to be Si-bearing, but not Tyrone yellowish soils (Figure 24). Nevertheless, soils that are extremely enriched in $\mathrm{Si}$ were found in the same topographic low, but $\sim 75$ m away: the Gertrude Weise soil has $>90 \mathrm{wt} \% \mathrm{SiO}_{2}$ content, which corresponds $\sim 98$ $\mathrm{wt} \% \mathrm{SiO}_{2}$ when removing local soil contaminants [Squyres et al., 2008]. Another major difference is that in the Tyrone-Eastern Valley region, a much larger number of light-toned nodular patches occur in a much wider area (Figure 6a). Their Si-rich natures were either identified by in situ APXS measurements (61.8-72.8 wt $\% \mathrm{SiO}_{2}$ [Ming et al., 2008]), or determined by Mini-TES [Ruff et al., 2008].

[99] Compared with the Dead Sea site, the large amounts of the S-rich and Si-rich materials in the Tyrone-Eastern Valley region and their better separations may indicate the involvement of larger quantities hydrothermal fluids.

[100] Two potential processes that can produce high concentrations of opaline silica in hydrothermal settings were discussed by Squyres et al. [2008], both involving hydrothermal fluids: (1) the silica precipitates directly from hydrothermal fluids after the fluid temperature decreases (silica sinter); or (2) the silica forms from the remnants of former basaltic materials after extensive open system leaching of metallic cations by acidic fluids. The first hypothesis requires a relatively high original fluid temperature so that it can retain high concentrations of $\mathrm{SiO}_{2}$ and can then deposit the silica abruptly upon cooling (e.g., $>98 \mathrm{wt} \% \mathrm{SiO}_{2}$ in one sample). The second hypothesis requires high acidity of the original fluid, enabling the leaching of metal cations from the local rocks thus allowing high $\mathrm{SiO}_{2}$ concentrations in the rock residue. High temperature would increase the efficiency and rate of the second process, but is not required. Squyres et al. [2008] favor the second process mainly on the basis of elevated $\mathrm{TiO}_{2}$ levels in Si-rich targets of the Home Plate region. The coexistence of Si-rich species and major S-rich soil exposures may also point toward a common origin. Indirect evidence for the second hypothesis also comes from the tentative detection of diaspore ( $\mathrm{Al}$ oxyhydroxide) on the Martian surface [Bell et al., 2000]. Diaspore most commonly forms in areas subjected to intense and pervasive leaching [Cloutis and Bell, 2000, and references therein].

[101] On the basis of our study on the topographic relationship of the targets in Tyrone-Eastern Valley region, the Pancam spectral homogeneity within each of two types of Tyrone soils, and the observation of common Pancam spectral features in all Si-rich species (soils and nodules) and possibly in Tyrone whitish soils, we propose that the Srich Tyrone soils and Si-rich species in Tyrone-Eastern Valley are two end-member products from a single process (possibly multiple events). These $\mathrm{S}$-rich and Si-rich materials found within the same local topographic low $(45 \mathrm{~m}$ contour line in Figure 6a) but separated by large distances (typified by the two possible end-members of Tyrone S-rich soils and Gertrude Weise Si-rich soils, $75 \mathrm{~m}$ apart) are indicative of chemically sorted and aqueously transported and homogenized weathering products, possibly processed by hydrothermal acidic solutions.

[102] Low-pH hydrothermal solution(s) could have scavenged $\mathrm{Ca}, \mathrm{Fe}, \mathrm{Mg}, \mathrm{Al}$ (etc.) cations from local outcrops on Low Ridge or on Mitcheltree Ridge, (e.g., Ca-enriched Halley type outcrops or Riquelme type outcrops with clastic textures [Lewis et al., 2008]), leaving Si-rich nodules behind. These nodules have a typical surface morphology similar to broken-off pieces from the clastic texture of Riquelme type outcrops. A relatively large quantity of hydrothermal fluid and a temperature gradient would be helpful in order to produce large amounts of Si-enriched 
Table 3a. Water Content in Pure Phyllosilicates and Zeolites

\begin{tabular}{lcc}
\hline \multicolumn{1}{c}{ Silicates $^{\mathrm{a}}$} & Min Water wt $\%$ & Max Water wt $\%$ \\
\hline smectite group $^{\mathrm{b}}$ & 4.2 & $>10$ \\
Kaolinite-serpentine group $^{\mathrm{T}}$ & 9.7 & 13.9 \\
Talc-pyrophyllite group & 3.8 & 5 \\
Muscovite-biotite group & 3.5 & 4.5 \\
some common zeolites & 8.2 & 21.3 \\
silica sinters and geysers $^{\mathrm{c}}$ & $<1$ & 15 \\
\hline
\end{tabular}

${ }^{\mathrm{a}}$ Calculated water weight percent $(\mathrm{wt} \%)$ was based on standard formulas of minerals. Deer et al. [1997].

${ }^{\mathrm{b}}$ Because of the extremely complicate structure and chemistry of smectite group minerals, the value for Min water wt $\%$ was accounted with only hydroxyls and removal all interlayer water (e.g., Na-rich nontronite), while the value for Max water wt $\%$ can be quite high. The experiments suggest that it can be higher than $10 \%$ depending on environment $\mathrm{RH}$ and the type of interlayer cations [Bish et al., 2003; Chipera et al., 1997].

${ }^{\mathrm{c} J o n e s}$ and Renaut [2003].

species in Eastern Valley, and to carry $\left(\mathrm{SO}_{4}\right)^{2-}$ and some $\mathrm{Ca}^{2+}, \mathrm{Fe}^{2+, 3+}, \mathrm{Mg}^{2+}, \mathrm{Al}^{3+}$ cations in acidic solution for a distance (e.g., $\sim 75 \mathrm{~m}$ ), then to precipitate sulfates (and other salts, e.g., halides, bromides, etc.) at lower temperatures as at the Tyrone site. Specifically, the location of excavated Tyrone salty soils is at the edge of the lowest area (marked by the 44.5 meter contour line in Figure 6a, notice that their existence within the lowest area cannot be excluded), which supports aqueous transportation hypothesis. In addition, the large range of $\mathrm{SiO}_{2}$ contents of Eastern Valley soils and nodular materials (although the surface dust contaminants on nodules have not been removed) may be an indication of fine-scale temperature and $\mathrm{pH}$ gradients. Sirich nodular patches found near Tyrone S-rich soils site (e.g., Tyrone nodules in Figures 6a and 23a) suggest that the $\mathrm{pH}$ values of $\left(\mathrm{SO}_{4}\right)^{2-}$-bearing aqueous solutions are quite low when they reached the vicinity of the Tyrone site, and thus were able to leach the local rocks and to leave the insoluble species as Si-rich nodules. This hypothesis is consistent with the results of Pancam spectral analysis by Johnson et al. [2007] on yellowish Tyrone soils, in which five types of ferric sulfates ( $82 \mathrm{wt} \%$ of totals sulfates) were suggested.

\subsection{Water Budget in the Vicinity of Gusev Crater}

[103] The Neutron Spectrometer (NS) instrument on the Mars Odyssey orbiter observed high concentrations of Water Equivalent Hydrogen (WEH) within two large equatorial regions on Mars [Feldman et al., 2004]. Gusev Crater is within one of the high WEH regions. Using the NS epithermal neutron data, Feldman et al. [2005] suggested about $6-7 \mathrm{wt} \%$ average water content within the uppermost meter of regolith in a region $\sim 600 \mathrm{~km}$ in diameter that covers the whole of Gusev Crater, part of Ma'adim Vallis, and Apollinaris Patera.

[104] The candidates to explain this enhancement in WEH are either hydrated minerals or ground ice. Whether ground ice would be stable in the uppermost meter at equatorial latitudes depends on the local thermal gradient, which is a function of the thermal conductivities of underlay materials [Mellon et al., 2004], the porosity of the regolith, and the concentration of water in various phases [Schubert et al., 1992].

[105] Among hydrated minerals, phyllosilicates, zeolites, and salts (mainly sulfates) are the major candidates that have been considered [Clark et al., 1976, 1982; Clark, 1993; Bish et al., 2003; Vaniman et al., 2004; Chou and
Seal, 2007; Wang et al., 2006c]. However, in order to match the WEH level detected by NS in the vicinity of Gusev, quite large amounts of phyllosilicates would be needed, because even in their pure forms (without mixing with basaltic component), only a few phyllosilicates can hold $>6 \mathrm{wt} \%$ water in their structures (Table 3a [Deer et al., 1997]). Common phyllosilicates in the smectite group (e.g., montmorillonite, saponite, nontronite), which form under alkaline conditions on Earth, can maintain $>10 \mathrm{wt} \%$ water depending on the type of interlayer cations [Bish et al., 2003; Chipera et al., 1997]. Minerals in the kaoliniteserpentine group (e.g., nacrite, dickite and halloysite), representing a higher degree of open system chemical weathering, and mildly acidic conditions [Langmuir, 1997], can maintain up to 14 wt\% water. During Spirit's surface exploration at Gusev, phyllosilicates were implied in some rocks in Columbia Hills on the basis of mineral model analyses using the data of APXS, MB, and other Athena payload instruments [Clark et al., 2007; Wang et al., 2006b].

[106] The water "storage" capabilities of some sulfates can be extremely high compared to phyllosilicates (Table 3b) [Deer et al., 1997]. Hydrous Mg-sulfates, with nine hydration states (from one to eleven structural waters per $\left(\mathrm{SO}_{4}\right)^{2-}$ plus amorphous phases) can hold 13-62 $\mathrm{wt} \%$ water in their structures; among them meridianiite $\left(\mathrm{MgSO}_{4} \cdot 11 \mathrm{H}_{2} \mathrm{O}, 62 \mathrm{wt} \%\right.$ water) is stable at temperature $<2{ }^{\circ} \mathrm{C}$ with sufficient $\mathrm{P}_{\mathrm{H} 2 \mathrm{O}}$ [Chou and Seal, 2007; Peterson et al., 2007; Wang et al., $2007 \mathrm{~d}$ ]. The full-scale swing in relative humidity (from almost $0 \% \mathrm{RH}$ to $100 \% \mathrm{RH}$ ) during a Martian diurnal cycle [Smith et al., 2006] can induce a series of changes in the hydration states of Mg-sulfates [e.g., Chipera and Vaniman, 2007; Chou et al., 2002; Chou and Seal, 2003, 2007; Vaniman et al., 2004; Vaniman and Chipera, 2006; Wang et al., 2006c, 2007d, 2008b; Freeman et al., 2007a, 2007b]. The two hydration states of Ca-sulfates hold less structural water $(6.2-20.9 \mathrm{wt} \%)$, and the vapor-solid transitions between them are relatively slow [Hardie, 1967; Blount and Dickson, 1973; Moller, 1988].

[107] $\mathrm{Fe}^{3+}$-sulfates may be more important for the current water budget at equatorial latitudes on Mars, because they (and some Al-sulfates) can hold 20-50 wt \% water in their structures (Table 3b) [Deer et al., 1997]. $\mathrm{Fe}^{3+}$-bearing sulfates were indeed detected by Mössbauer spectral analysis in the Meridiani Outcrop and also in the salty soils at the Paso Robles, Dead Sea and Tyrone sites at Gusev [Morris et al., 2004, 2008]. In later analyses, no specific mineral identification was given, thus their hydration states are unknown. The potential existence of Al-sulfates was also

Table 3b. Water Content in Pure Sulfates

\begin{tabular}{|c|c|c|}
\hline Sulfates $^{\mathrm{a}}$ & $\begin{array}{c}\text { Min Water } \\
\mathrm{wt}^{\mathrm{t}} \%\end{array}$ & $\begin{array}{c}\text { Max Water } \\
\text { wt } \% \\
\end{array}$ \\
\hline Mg-sulfates $\left(1-11\right.$ water $\left./ \mathrm{SO}_{4}\right)$ & 13 & 62.2 \\
\hline Ca-sulfates $\left(0.5-2\right.$ water/ $\left.\mathrm{SO}_{4}\right)$ & 6.2 & 20.9 \\
\hline Al-sulfates $\left(3-8\right.$ water $\left./ \mathrm{SO}_{4}\right)$ & 13 & 47.1 \\
\hline $\mathrm{Fe}^{2+}$-sulfates $\left(1-7\right.$ water $\left./ \mathrm{SO}_{4}\right)$ & 10.6 & 45.3 \\
\hline $\mathrm{Fe}^{3+}$-sulfates $\left(2-3.3\right.$ water $\left./ \mathrm{SO}_{4}\right)$ & 21.3 & 31 \\
\hline $\mathrm{Fe}^{2+, 3+}$-sulfates $\left(3.3-5.5\right.$ water/ $\left.\mathrm{SO}_{4}\right)$ & 31.4 & 41.8 \\
\hline $\mathrm{Fe}^{3+}$-sulfates w/H, OH $\left(3-8\right.$ water/SO $\left.\mathrm{SO}_{4}\right)$ & 22.7 & 48.8 \\
\hline
\end{tabular}

${ }^{\mathrm{a}}$ Calculated water wt $\%$ was based on standard formulas of minerals. Deer et al. [1997]. 
Table 4. Estimated Water Contents in Gusev Targets Based on Mixing Model Analyses and Sulfate Stability Studies ${ }^{\mathrm{a}}$

\begin{tabular}{|c|c|c|c|c|c|c|c|}
\hline \multirow[b]{2}{*}{ Targets at Gusev and Meridiani } & \multirow{2}{*}{$\begin{array}{c}\text { Assumed Non-Water- } \\
\text { Bearing Phases } \\
\end{array}$} & \multicolumn{4}{|c|}{ Water-Bearing Components } & \multirow{2}{*}{\multicolumn{2}{|c|}{$\begin{array}{c}\text { Water Contents After } \\
\text { Renormalization } \\
\end{array}$}} \\
\hline & & Mg-Sulfates & Fe-Sulfates & Ca-Sulfates & Kaolinite & & \\
\hline Percent water relative to dry formulas & 0.0 & $15.0-59.8$ & $29.4-46.4$ & $6.6-26.4$ & 16.2 & lower limit & upper limit \\
\hline Big Hole RS2 (mode) $)^{\mathrm{b}}$ & 86.1 & 13.9 & & & & & \\
\hline Water \% & & $2.1-8.3$ & & & & 2 & 8 \\
\hline Big Hole_Trio (mode) ${ }^{\mathrm{b}}$ & 87.3 & 12.7 & & & & & \\
\hline Water $\%$ & & $1.9-7.6$ & & & & 2 & 7 \\
\hline The Boroughs_wall (mode) ${ }^{\mathrm{b}}$ & 78.8 & 21.2 & & & & & \\
\hline Water \% & & $3.2-12.7$ & & & & 3 & 11 \\
\hline The Boroughs_floor (mode) ${ }^{\mathrm{b}}$ & 83.1 & 16.9 & & & & & \\
\hline Water $\%$ & & $2.5-10.1$ & & & & 2 & 9 \\
\hline WP_Mastodon $(\text { mode })^{\mathrm{c}}$ & 84.0 & 1.0 & & 3.0 & 12.0 & & \\
\hline Water \% & & $0.2-0.6$ & & $0.2-0.8$ & 1.9 & 3 & 3 \\
\hline WP_Sabre $(\text { mode })^{\mathrm{c}}$ & 80.0 & 1.2 & & 3.6 & 15.3 & & \\
\hline Water $\%$ & & $0.2-0.7$ & & $0.2-0.9$ & 2.5 & 3 & 4 \\
\hline Dead Sea Samra $(\text { mode })^{d}$ & 43.0 & 11.0 & 46.0 & & & & \\
\hline Water \% & & $1.6-6.6$ & $13.5-21.3$ & & & 13 & 22 \\
\hline Dead Sea_Hula (mode) ${ }^{\mathrm{d}}$ & 33.0 & 26.0 & 33.0 & 8.0 & & & \\
\hline Water \% & & $3.9-15.6$ & $9.7-15.3$ & $0.5-2.1$ & & 12 & 25 \\
\hline Paso Robles Paso1 (mode) ${ }^{\mathrm{d}}$ & 52.0 & 11.0 & 37.0 & & & & \\
\hline Water \% & & $1.6-6.6$ & 10.917 .2 & & & 11 & 19 \\
\hline Paso Robles Paso $2(\text { mode })^{\mathrm{d}}$ & 55.0 & 9.0 & 36.0 & & & & \\
\hline Water \% & & $1.4-5.4$ & $10.6-16.7$ & & & 11 & 18 \\
\hline Tyrone_BerknerIsland (mode) ${ }^{\mathrm{d}}$ & 74.0 & 4.0 & 14.0 & 8.0 & & & \\
\hline Water $\overline{\%}$ & & $0.6-2.4$ & $4.1-6.5$ & $0.5-2.1$ & & 5 & 10 \\
\hline Tyrone_MountDarwin (mode) ${ }^{\mathrm{d}}$ & 58.0 & 9.0 & 18.0 & 15.0 & & & \\
\hline Water $\overline{\%}$ & & $1.4-5.4$ & $5.3-8.4$ & $0.1-4.0$ & & 7 & 15 \\
\hline Meridiani Outcrop (mode) ${ }^{\mathrm{e}}$ & 65 & 17 & 10 & 9 & & & \\
\hline Water \% & & $2.6-10.2$ & 2.80 & $0.6-2.4$ & & 6 & 13 \\
\hline
\end{tabular}

${ }^{\mathrm{a}}$ Unit is percent.

${ }^{\mathrm{b}}$ Wang et al. [2006a].

${ }^{\mathrm{c}}$ Wang et al. [2006b].

${ }^{\mathrm{d}}$ Yen et al. [2008].

${ }^{\mathrm{e}}$ Clark et al. [2005].

recognized, but again without any positive identification [Yen et al., 2008]. Because of the lack of more sophisticated instruments for definitive mineralogy identification (especially the hydration states of these sulfates), terrestrial analog study and simulation experiments on the stability fields of these Fe-sulfates (primarily $\mathrm{Fe}^{3+}$ ), Al-sulfates, and their phase transition pathways bear tremendous significance for building the link between the results from surface in situ exploration and from orbital remote sensing [Chipera et al., 2007; Crowley et al., 2003; Ling et al., 2008].

[108] In the early phase of Spirit's exploration, hydrous sulfates were rarely found except for two cases. The existence of $\mathrm{Mg}$-sulfates was implied $\left(\mathrm{MgO}\right.$ versus $\mathrm{SO}_{3}$ compositional correlation) in excavated soils of two trenches in the Gusev basaltic plains, with the highest abundance of total sulfates $(\sim 21 \mathrm{wt} \%)$ in the soils on the wall of The Boroughs trench [Wang et al., 2006a]. The existence of Ca-sulfates was implied (by $\mathrm{CaO}$ versus $\mathrm{SO}_{3}$ compositional correlation) in the interiors of Clovis class rocks on West Spur, with the highest abundances $\sim 11 \mathrm{wt} \%$ [Wang et al., 2006b]. If we assume their hydration states to be the same as the $\mathrm{Mg}$-sulfate and Ca-sulfate phases identified from orbit by the OMEGA instrument on the Mars Express orbiter (kieserite and gypsum respectively [e.g., Arvidson et al., 2005; Gendrin et al., 2005; Bibring et al., 2005], the total amount of water in those targets can only make up 3-4 wt\% (Table 4 ). Even adding $\sim 3 \mathrm{wt} \%$ water as adsorbed water on the surfaces of soil grains and within the interstitial spaces among the grains, the average water content on the Gusev basaltic plains would be less than 3-4 wt \%, on the basis of the rarity of finding such altered species during the early part of Spirit's exploration [Wang et al., 2006c]. In order to match the NS-derived WEH value in the vicinity of Gusev, either minerals (e.g., Mg-sulfates) with higher hydration states would have to be stable under current Mars subsurface conditions, or there needs to be a much wider and deeper distribution of hydrous phases at Gusev.

[109] To address the first possibility, we are conducting three series of experiments to study the stability fields and phase transition pathways of hydrous $\mathrm{Mg}$-sulfates, $\mathrm{Fe}^{3+}$ sulfates, and mixtures of Mg-sulfates with other phases [Wang et al., 2007d, 2008b; Freeman et al., 2007a, 2007b; Ling et al., 2008]. The results from Mg-sulfate experiments suggest that the stability and metastability fields for Mg-sulfates with higher hydration states might be reached under current Mars conditions. Specifically, not only kieserite, but starkeyite $\left(\mathrm{MgSO}_{4} \cdot 4 \mathrm{H}_{2} \mathrm{O}\right)$ and amorphous $\mathrm{Mg}$-sulfates (which can hold up to 3 water molecules) can also be stable on Mars. Even hexahydrite $\left(\mathrm{MgSO}_{4} \cdot 6 \mathrm{H}_{2} \mathrm{O}\right)$ can be retained for a much longer period than anticipated, if it was originally mixed with Ca-sulfates. Therefore, assuming starkeyite was stable at the two trench sites, the structural water in Mg-sulfates could constitute up to $7-11 \mathrm{wt} \%$ of the regolith in these trenches (Table 4, column of "upper limit").

[110] The discovery of hydrous sulfate-rich soils at eight locations (with four types of geomorphic settings) in Columbia Hills region during the extended mission of Spirit has partially addressed the second possibility. Notably, 
ferric sulfate(s) was identified in three major exposures of light-toned soils. We used the model proportions of sulfates given by Yen et al. [2008] to estimate the water content in these soils, in which kieserite, bassanite, and rhomboclase were used as the relatively "dry end-members" for Mg-, $\mathrm{Ca}$-, and Fe-sulfates, and starkeyite, gypsum, and copiapite as the "wet end-members." Without counting water potentially carried by amorphous silica and as adsorbed water, we conservatively estimate a range of water contents (lower and upper limits in Table 4) in these salty soils. We found that structural water in sulfates alone could make up $12-25 \mathrm{wt} \%$ of salty soils at the Dead Sea site, for example. Similarly, the structural water in sulfates would make up to $11-19 \mathrm{wt} \%$ of salty soils at Paso Robles, and 5-15 wt $\%$ of the salty soils plus basaltic soils mixtures at the Tyrone-offset sites. We anticipate that the water content of the salty soils at Tyrone itself should be roughly at the same levels as the salty soils at Dead Sea. The lower limits of water contents in these soils are well above the WEH values detected by Neutron Spectrometer on Mars Odyssey Orbiter.

[111] In a region where large quantities of hydrous sulfates have accumulated, e.g., in places like the Tyrone and the Dead Sea sites, a gradient of relative humidity $(\mathrm{RH})$ can be maintained by the hydrous salts buried at depth [Greenspan, 1977]. Deeper salty soils would be able to hold more water, as hypothesized for the Tyrone yellowish soils. On the basis of Pancam spectral analysis, it is possible that ferric sulfates may be up to five times more abundant in the deeper yellowish soils than in the shallower whitish soils at Tyrone [Johnson et al., 2007]. Absolute abundance estimates are highly uncertain on the basis of Pancam multispectral modeling, however. Regardless, our hypothesis of higher $\mathrm{RH}$ at depth is also supported by the observation of spectral changes that we interpret as evidence of dehydration of the newly exposed yellowish soils, as they come to equilibrium with the much drier surface conditions.

[112] This proposed high degree of sulfate-related hydration at depth could be what is being sensed by the Neutron Spectrometer (NS) on Mars Odyssey and could potentially lead to the $6-7 \mathrm{wt} \%$ estimated water content in the vicinity of Gusev Crater. While the thin layer of light-toned soils found at high elevations adjacent to large outcrops (e.g., Jibsheet and Hillary) may not be a significant contributor to the overall water budget in the Gusev region, we would predict (on the basis of remote sensing results from NS, OMEGA, and other studies) that the types of highly hydrated soil accumulations discovered serendipitously by Spirit at the Tyrone and Dead Sea sites may be widespread throughout Gusev and the surrounding region. They could exist in many of the relative topographic lows in the Columbia Hills region seen but not visited by Spirit, and they could exist at many other suitable geologic settings within and outside of Gusev Crater that Spirit may never be able to explore. Hopefully, continued exploration of these fascinating and revealing deposits will yield important new insights into their origin and history.

\section{Summary}

[113] The exploration conducted by the Mars Exploration Rover Spirit at Gusev Crater during its extended mission has exposed light-toned salty soils at eight locations from the foot of West Spur to Home Plate. The geomorphic settings of these exposures include local topographic lows, the bases of steep slopes, the slopes themselves, and adjacent to large outcrops at high elevations. The lighttoned materials at those locations have been determined to be mainly hydrous sulfates mixed with local soils, on the basis of detailed remote sensing (Pancam, Mini-TES) [Ruff et al., 2008; Wang et al., 2007a, 2007b, 2007c, 2008a; A. T. Knudson et al., manuscript in preparation, 2008] and in situ (APXS, Mössbauer) measurements [Ming et al., 2008; Morris et al., 2008; Yen et al., 2008] The light-toned soils, plus the salty soils excavated by two trenches in Gusev basaltic plains, are dominated by $\mathrm{Mg}$-, or $\mathrm{Fe}-$, or $\mathrm{Ca}-$ sulfates, depending on location. The major sulfate cation generally correlates with the degree of alteration of local rocks, and also sometimes correlates with the trace element signatures of the local rocks, suggesting a linkage between local precursor rock sources and locally derived altered soils. Near the major exposures of S-rich soils, Si-rich nodules (and in one case, almost pure silica soil [Arvidson et al., 2008; Squyres et al., 2008]) were found; and in some soils, silica may be mixed with sulfates [Ming et al., 2008] We consider various mechanisms to be responsible for the formation and accumulation of these light-toned salty soils, and there is evidence that the major formation mechanisms vary from place to place, depending on the geomorphic setting, chemistry and mineralogy, and the observed or inferred spatial distribution of distinct mineral assemblages at each of the different locations. In the Tyrone-Eastern Valley region, relatively large quantities of acidic hydrothermal fluids may have been involved, which can provide a habitable environment for microbial life.

[114] On the basis of the MER observations described here, combined with orbital remote sensing observations of the Gusev Crater region, we suggest that hydrous salty soils may be relatively common at similar geomorphic settings in the Columbia Hills region, throughout Gusev Crater, and even across the much larger Gusev region. Although there is very little quantitative information that can be used to set specific limits on the timing of the formation and the accumulation of the salty materials found at various locations in Gusev, some relative time-stratigraphic relationships can still be inferred. For example, some of the youngest sulfate deposits (mainly $\mathrm{Mg}$-sulfates) may be the ones discovered in the two shallow trenches excavated in the Gusev basaltic plains. These salty soils formed after the emplacement of the basaltic lava flows that cover the majority of the Gusev Crater floor. Similarly, the light-toned soils found adjacent to the large outcrops at high elevations in the Columbia Hills must have accumulated prior to what appear to be relatively recent, perhaps even active, aeolian deposits.

[115] Our observations lead us to hypothesize that there is a gradient in relative humidity with depth in the uppermost tens of cm (at least) below the surface dust in places where large quantities of salty materials are buried. Such a humidity gradient would enable the stability of minerals (mainly sulfates, and possibly also clays or other hydrated phases) with much higher hydration states than would be predicted to be thermodynamically stable in the current Mars surface environment [Greenspan, 1977]. Buried sulfates with high hydration states (Mg-, Fe-, Al-sulfates), like 
some of the light-toned soil deposits serendipitously discovered by Spirit in Gusev Crater, at depth and over widely distributed locations, could be the major phase(s) responsible for the $6-7 \mathrm{wt} \%$ average water content in the vicinity of Gusev Crater determined by the Neutron Spectrometer on the Mars Odyssey orbiter [Feldman et al., 2004, 2005].

[116] After surviving a major planet-wide dust storm during the summer of 2007, Spirit is continuing to explore the Home Plate region. New discoveries will hopefully provide additional information with which to confirm, refute, or modify our current hypotheses for the genetic relationships among the $\mathrm{S}$-rich soil, Si-rich soils and nodules, and other coexisting rock and soil materials in this region.

[117] Acknowledgments. We thank NASA for funding the MER Athena Science team and the JPL engineering team for continuing to successfully operate the Mars Exploration rovers. We thank all members of the science and engineering team who have been working in collaboration to make successful observations related to the light-toned soils, sometimes under very challenging circumstances. We thank the two reviewers, David Vaniman and Kevin Lewis, for their instructive comments and suggestions helped us to strengthen this paper. Data credits are as follows: R. Rieder, http://pds-geosciences.wustl.edu/mer/mer1_mer2-m-apxs-5-oxide-sci-v1/ merap_2xxx; K. Herkenhoff, http://pds-geosciences.wustl.edu/mer/mer2m-mi-3-rdr-sci-v1/mer2mi 1 1xxx/; P. Christensen, http://pds-geosciences. wustl.edu/mer/mer2-m-mtes-4-emr-v1/mer2mt_3xxx/; G. Klingelhöfer, $\mathrm{http} / / / \mathrm{pds}$-geosciences.wustl.edu/mer/mer2-m-mb-4-sumspec-sci-v1/ mer2mb_1xxx/; J. F. Bell III, http://pds-geosciences.wustl.edu/mer/mer2m-pancam-3-radcal-rdr-v1/mer2pc_1xxx/.

\section{References}

Africano, F., and A. Bernard (2000), Acid alteration in the fumarolic environment of Usu volcano, Hokkaido, Japan, J. Volcanol. Geotherm. Res., 97, 475-495, doi:10.1016/S0377-0273(99)00162-6.

Arvidson, R. E., et al. (2005), Spectral reflectance and morphologic correlations in eastern Terra Meridiani, Mars, Science, 307, 591-1593, doi:10.1126/science.1109509.

Arvidson, R. E., et al. (2006a), Overview of the Spirit Mars Exploration Rover Mission to Gusev Crater: Landing site to Backstay Rock in the Columbia Hills, J. Geophys. Res., 111, E02S01, doi:10.1029/ 2005JE002499.

Arvidson, R. E., et al. (2006b), Nature and origin of the hematite-bearing plains of Terra Meridiani based on analyses of orbital and Mars Exploration rover data sets, J. Geophys. Res., 111, E12S08, doi:10.1029/ 2006JE002728.

Arvidson, R. E., et al. (2008), Spirit Mars Rover Mission to the Columbia Hills, Gusev Crater: Mission overview and selected results from the Cumberland Ridge to Home Plate, J. Geophys. Res., 113, E12S33, doi:10.1029/2008JE003183.

Bandfield, J. (2007), High-resolution subsurface water-ice distribution on Mars, Nature, 447, doi:10.1038/nature05781.

Bell, J. F., III, E. A. Cloutis, D. R. Klassen, and R. N. Clark (2000), Spectroscopic evidence for diaspore $(\alpha-\mathrm{AlOOH})$ on Mars (CD-ROM), Lunar Planet. Sci., XXXI, abstract 1227.

Bell, J. F., III, et al. (2003), The Mars Exploration Rover Athena Panoramic Camera (Pancam) investigation, J. Geophys. Res., 108(E12), 8063, doi:10.1029/2003JE002070.

Bell, J. F., III, J. Joseph, J. N. Sohl-Dickstein, H. M. Arneson, M. J. Johnson, M. T. Lemmon, and D. Savransky (2006), In-flight calibration and performance of the Mars Exploration Rover Panoramic Camera (Pancam) instruments, J. Geophys. Res., 111, E02S03, doi:10.1029/ 2005JE002444.

Bibring, J. P., et al. (2005), Mars surface diversity as observed by the OMEGA/Mars Express investigation, Science, 307, 1576-1581, doi:10.1126/science.1108806

Bigham, J. M., and D. K. Nordstrom (2000), Iron and aluminum hydroxysulfates from acid sulfate waters, Rev. Mineral., 40, 351-403.

Bish, D. L., J. W. Carey, D. T. Vaniman, and S. J. Chipera (2003), Stability of hydrous minerals on the Martian surface, Icarus, 164, 96-103, doi:10.1016/S0019-1035(03)00140-4.

Blount, C. W., and F. W. Dickson (1973), Gypsum-anhydrite equilibria in systems $\mathrm{CaSO}_{4}-\mathrm{H}_{2} \mathrm{O}$ and $\mathrm{CaSO}_{4}-\mathrm{NaCl}-\mathrm{H}_{2} \mathrm{O}$, Am. Mineral., 58 , $323-331$
Buckby, T., S. Black, M. L. Coleman, and M. E. Hodson (2003), Fe-sulphate-rich evaporative mineral precipitates from the Rio Tinto, Southwest Spain, Mineral. Mag., 67(2), 263-278, doi:10.1180/ 0026461036720104.

Chipera, S. J., and D. T. Vaniman (2007), Experimental stability of magnesium sulfate hydrates that may be present on Mars, Geochim. Cosmochim. Acta, 71, 241-250, doi:10.1016/j.gca.2006.07.044.

Chipera, S. J., J. W. Carey, and D. L. Bish (1997), Controlled humidity XRD analyses: Application to the study of smectite expansion/contraction, in Advances in X-ray Analysis, vol. 39, edited by J. V. Gilfrich et al., pp. 713-722, Plenum, New York.

Chipera, S. J., D. T. Vaniman, and D. L. Bish (2007), The effect of temperature and water on ferric-sulfates, Lunar Planet. Sci. [CD-ROM], XXXVIII, abstract 1409 .

Chou, I.-M., and R. R. Seal II (2003), Determination of epsomite-hexahydrite equilibria by the humidity-buffer technique at $0.1 \mathrm{MPa}$ with implications for phase equilibria in the system $\mathrm{MgSO}_{4}-\mathrm{H}_{2} \mathrm{O}$, Astrobiology, 3, 619-629, doi:10.1089/153110703322610708.

Chou, I.-M., and R. R. Seal II (2007), Magnesium and calcium sulfate stabilities and the water budget of Mars, J. Geophys. Res., 112, E11004, doi:10.1029/2007JE002898.

Chou, I.-M., R. R. Seal II, and B. S. Hemingway (2002), Determination of melanterite-rozenite and chalcanthite-bonattite equilibria by humidity measurements at $0.1 \mathrm{MPa}$, Am. Mineral., 87, 108-114.

Christensen, P. R., et al. (2003), Miniature Thermal Emission Spectrometer for the Mars Exploration Rovers, J. Geophys. Res., 108(E12), 8064, doi:10.1029/2003JE002117

Christensen, P. R., et al. (2004), Initial Results from the Mini-TES Experiment in Gusev Crater from the Spirit Rover, Science, 305, 837-842, doi:10.1126/science.1100564.

Clark, B. C. (1993), Geochemical components in Martian soil, Geochim. Cosmochim. Acta, 57, 4575-4581, doi:10.1016/0016-7037(93)90183-W.

Clark, B. C., et al. (1976), Inorganic analyses of Martian surface samples at the Viking landing sites, Science, 194, 1283-1288, doi:10.1126/ science.194.4271.1283.

Clark, B. C., A. K. Baird, R. J. Weldon, D. M. Tsusaki, L. Schnabel, and M. P. Candelaria (1982), Chemical composition of Martian fines, J. Geophys. Res., 87(B12), 10,059-10,067, doi:10.1029/JB087iB12p10059.

Clark, B. C., et al. (2005), Chemistry and mineralogy of outcrops at Meridiani Planum, Earth Planet. Sci. Lett., 240(1), 72-94.

Clark, B. C., et al. (2007), Evidence for montmorillonite or its compositional equivalent in Columbia Hills, Mars, J. Geophys. Res., 112, E06S01, doi:10.1029/2006JE002756.

Cloutis, E. A., and J. F. Bell III (2000), Diaspores and related hydroxides: Spectral-compositional properties and implications for Mars, J. Geophys. Res., 105(E3), 7053-7070, doi:10.1029/1999JE001188.

Cloutis, E. A., et al. (2007), Stability of hydrated minerals on Mars, Geophys. Res. Lett., 34, L20202, doi:10.1029/2007GL031267.

Crowley, J. K., et al. (2003), Spectral reflectance properties $(0.4-2.5 \mu \mathrm{m})$ of secondary Fe-oxide, Fe-hydroxide, and Fe-sulphate-hydrate minerals associated with sulphide-bearing mine wastes, Geochem. Explor. Environ. Anal., 3, 219-228, doi:10.1144/1467-7873/03-001.

Deer, W. A., R. A. Howie, and J. Zussman (1997), Rock-Forming Minerals, 2nd ed., Geol. Soc., London.

Ellis, A. J., and W. A. J. Mahon (1977), Chemistry and Geothermal Systems, 392 pp., Academic, New York.

Farrand, W. H., J. F. Bell III, J. R. Johnson, S. W. Squyres, J. Soderblom, and D. W. Ming (2006), Spectral variability among rocks in visible and near-infrared multispectral Pancam data collected at Gusev Crater: Examination using spectral mixture analysis and related techniques, J. Geophys. Res., 111, E02S15, doi:10.1029/2005JE002495.

Feldman, W. C., et al. (2004), Global distribution of near-surface hydrogen on Mars, J. Geophys. Res., 109, E09006, doi:10.1029/2003JE002160.

Feldman, W. C., et al. (2005), Topographic control of hydrogen deposits at low latitude to midlatitudes of Mars, J. Geophys. Res., 110, E11009, doi:10.1029/2005JE002452

Fergason, R. L., et al. (2006), Physical properties of the Mars Exploration Rover landing sites as inferred from Mini-TES derived thermal inertia, J. Geophys. Res., 111, E02S21, doi:10.1029/2005JE002583.

Fernandez-Remolar, D. C., et al. (2004), The Tinto River, an extreme acidic environment under control of iron, as an analog of the Terra Meridiani hematite site of Mars, Planet. Space Sci., 52, 239-248, doi:10.1016/ j.pss.2003.08.027.

Fernandez-Remolar, D. C., R. V. Morris, J. E. Gruener, R. Amils, and A. H. Knoll (2005), The Riacute; o Tinto Basin, Spain: Mineralogy, sedimentary geobiology, and implications for interpretation of outcrop rocks at Meridiani Planum, Mars, Earth Planet. Sci. Lett., 240, 149-167, doi:10.1016/j.eps1.2005.09.043

Fournier, R. O., and R. W. Potter II (1982), An equation correlating the solubility of quartz in water from $20^{\circ}$ to $900^{\circ} \mathrm{C}$ at pressures up to 10,000 
bars, Geochim. Cosmochim. Acta, 46, 1969-1973, doi:10.1016/00167037(82)90135-1.

Freeman, J. J., A. Wang, and B. L. Jolliff (2007a), $\mathrm{MgSO}_{4} \bullet 11 \mathrm{H}_{2} \mathrm{O}-$ Powder XRD, Raman, and Vis-NIR Spectroscopic Characterization, Lunar Planet. Sci. [CD-ROM], XXXVIII, abstract 1197.

Freeman, J. J., A. Wang, and B. L. Jolliff (2007b), Pathways to Form Kieserite from Epsomite at mid-low Temperatures, Lunar Planet. Sci. [CD-ROM], XXXVIII, abstract 1298 .

Freeman, J. J., M. Jin, and A. Wang (2008), D $2 \mathrm{O}$ Substitution Experiment on Hydrated Iron and Magnesium Sulfates and its Application for Spectral Interpretation of Martian Sulfates, Lunar Planet. Sci. [CD-ROM], $X X X I X$, abstract 2390

Gellert, R., et al. (2006), Alpha Particle X-Ray Spectrometer (APXS): Results from Gusev Crater and calibration report, J. Geophys. Res., 111, E02S05, doi:10.1029/2005JE002555.

Gendrin, A., et al. (2005), Sulfates in Martian Layered Terrains: The OMEGA/Mars Express View, Science, 307, 1587-1591, doi:10.1126/ science. 1109087.

Getahun, A., M. H. Reed, and R. Symonds (1996), Mount St. Augustine volcano fumarole wall rock alteration: Mineralogy, zoning, composition and numerical models of its formation process, J. Volcanol. Geotherm. Res., 71, 73-107, doi:10.1016/0377-0273(95)00071-2.

Gilbert, J. M., and C. F. Park Jr. (1985), The Geology of Ore Deposits, chap 3 , pp. 25-54; chap. 4, pp. 126-133; and chapter 12, pp. 533-537, W. H. Freeman, New York.

Gillespie, A., A. Kahle, and R. Walker (1986), Color enhancement of highly correlated images: I. Decorrelation and HIS contrast enhancement, Remote Sens. Environ., 20, 209-235, doi:10.1016/0034-4257(86)90044-1.

Gooding, J. L., and K. Keil (1978), Alteration of glass as a possible source of clay minerals on Mars, Geophys. Res. Lett., 5, 727-730, doi:10.1029/ GL005i008p00727.

Greenspan, L. (1977), Humidity fixed points of binary saturated aqueous solution, J. Res. Natl. Bur. Standards, Ser. A, 81(1), 89-96.

Hardie, L. A. (1967), The gypsum-anhydrite equilibrium at one atmosphere pressure, Am. Mineral., 52, 171-200.

Haskin, L. A., et al. (2005), Water Alteration of Rocks and Soils from the Spirit Rover Site, Gusev Crater, Mars, Nature, 436, 66-69, doi:10.1038/ nature 03640.

Herkenhoff, K. E., et al. (2003), Athena Microscopic Imager investigation, J. Geophys. Res., 108(E12), 8065, doi:10.1029/2003JE002076

Herkenhoff, K. E., et al. (2006), Overview of the Microscopic Imager Investigation during Spirit's first 450 sols in Gusev Crater, J. Geophys. Res., 111, E02S04, doi:10.1029/2005JE002574.

Herzberg, G. (1945), Infrared and Raman Spectra, p. 281, Table 60, Van Nostrand Reinhold, New York.

Hurowitz, J. A., and S. M. McLennan (2007), A 3.5 Ga record of waterlimited, acidic weathering conditions on Mars, Earth Planet. Sci. Lett. 260, 432-443, doi:10.1016/j.eps1.2007.05.043.

Hurowitz, J. A., S. M. McLennan, N. J. Tosca, R. E. Arvidson, J. R. Michalski, D. W. Ming, C. Schröder, and S. W. Squyres (2006), In situ and experimental evidence for acidic weathering of rocks and soils on Mars, J. Geophys. Res., 111, E02S19, doi:10.1029/2005JE002515.

Jakosky, B. M. (1992), The Seasonal behavior of water on Mars, in Mars, edited by H. H. Kieffer et al., chap. 28, pp. 969-1016, Univ. of Arizona Press, Tucson.

Jambor, J. L., D. K. Nordstrom, and C. N. Alpers (2000), Metal-sulfate salts from sulfide mineral oxidation, Rev. Mineral., 40, 303-350.

Jerz, J. K., and J. D. Rimstidt (2003), Efflorescent iron sulfate minerals; paragenesis, relative stability, and environmental impact, Am. Mineral., 88(11-12), 1919-1932.

Joeckel, R. M., B. J. Ang Clement, and L. R. VanFleet Bates (2005), Sulfate-mineral crusts from pyrite weathering and acid rock drainage in the Dakota Formation and Graneros Shale, Jefferson County, Nebraska, Chem. Geol., 215, 433-452, doi:10.1016/j.chemgeo. 2004.06.044.

Johnson, J. R., J. F. Bell III, E. Cloutis, M. Staid, W. H. Farrand, T. McCoy, M. Rice, A. Wang, and A. Yen (2007), Mineralogic constraints on sulfurrich soils from Pancam spectra at Gusev Crater, Mars, Geophys. Res. Lett., 34, L13202, doi:10.1029/2007GL029894.

Jones, B., and R. W. Renaut (2003), Hot springs and geyser sinters: The integrated product of precipitation, replacement, and deposition, Can. J. Earth Sci., 40, 1549-1569, doi:10.1139/e03-078.

Keith, D. C., et al. (2001), Geochemical models of the impact of acidic groundwater and evaporative sulfate salts on Boulder Creek at Iron Mountain, California, Appl. Geochem., 16, 947-961, doi:10.1016 S0883-2927(00)00080-9.

Keith, T. E. C. (1991), Fossil and active fumaroles in the 1912 eruptive deposits, Valley of Ten Thousand Smokes, Alaska, J. Volcanol. Geotherm. Res., 45, 227-254, doi:10.1016/0377-0273(91)90061-4.
Kieffer, H. H., B. M. Jakosky, and C. E. W. Snyder (1992), The planet Mars: From antiquity to the present, in Mars, edited by H. H. Kieffer et al., chap. 1, pp. 1-33, Univ. of Arizona Press, Tucson.

Kirk, R. L., et al. (2008), Ultrahigh resolution topographic mapping of Mars with MRO HiRISE stereo images: Meter-scale slopes of candidate Phoenix landing sites, J. Geophys. Res., 113, E00A24, doi:10.1029/ 2007JE003000.

Klingelhöfer, G., et al. (2003), Athena MIMOS II Mössbauer spectrometer investigation, J. Geophys. Res., 108(E12), 8067, doi:10.1029/ 2003JE002138.

Krauskopf, K. B. (1956), Dissolution and precipitation of silica at low temperatures, Geochim. Cosmochim. Acta, 10, 1-26, doi:10.1016/ 0016-7037(56)90009-6.

Krauskopf, K. B., and Bird (1995), Introduction of Geochemistry, 647 pp., McGraw-Hill, New York.

Lane, M. D., et al. (2007), The ferric sulfate and ferric phosphate minerals in the light-toned Paso Robles rover track soils: A multi-instrument analysis, in Seventh International Conference on Mars [CD-ROM], abstract 3331, Jet Propul. Lab., Pasadena, Calif.

Langmuir, D. (1997), Aqueous Environmental Geochemistry, 600 pp., Prentice Hall, N. J.

Last, W. M. (1989a), Sedimentology of a saline playa in the northern Great Plains, Canada, Sedimentology, 36, 109-123, doi:10.1111/j.13653091.1989.tb00823.x.

Last, W. M. (1989b), Sedimentology of playa lakes of the northern Great Plains, Can. J. Earth Sci., 21, 107-125.

Lemmon, M. T., et al. (2004), Atmospheric Imaging Results from the Mars Exploration Rovers: Spirit and Opportunity, Science, 306, 1753-1756, doi:10.1126/science. 1104474 .

Lewis, K. W., O. Aharonson, J. P. Grotzinger, S. W. Squyres, J. F. Bell III, L. S. Crumpler, and M. E. Schmidt (2008), Structure and stratigraphy of Home Plate from the Spirit Mars Exploration Rover, J. Geophys. Res., 113, E12S36, doi:10.1029/2007JE003025.

Li, R., et al. (2006), Spirit Rover localization and topographic mapping at the landing site of Gusev Crater, Mars, J. Geophys. Res., 111, E02S06, doi: $10.1029 / 2005$ JE002483.

Li, R. X., et al. (2008), Characterization of traverse slippage experienced by Spirit Rover on Husband Hill at Gusev Crater, J. Geophys. Res., doi:10.1029/2008JE003097, in press.

Ling, Z. C., A. Wang, B. L. Jolliff, R. E. Arvidson, and H. R. Xia (2008), A Systematic Raman, Mid-IR, and Vis-NIR Spectroscopic Study of Ferric Sulfates and Implications for Sulfates on Mars, Lunar Planet. Sci. [CD-ROM], $X X X I X$, abstract 1463 .

McSween, H. Y., et al. (2004), Basaltic Rocks Analyzed by the Spirit Rover in Gusev Crater, Science, 305, 842-845, doi:10.1126/science.3050842.

McSween, H. Y., et al. (2006), Characterization and petrologic interpretation of olivine-rich basalts at Gusev Crater, Mars, J. Geophys. Res., 111, E02S10, doi:10.1029/2005JE002477.

McSween, H. Y., et al. (2008), Mineralogy of volcanic rocks in Gusev Crater, Mars: Reconciling Mössbauer, Alpha Particle X-Ray Spectrometer, and Miniature Thermal Emission Spectrometer spectra, J. Geophys. Res., 113, E06S04, doi:10.1029/2007JE002970.

Mellon, M. T., W. C. Feldman, and T. H. Prettyman (2004), The presence and stability of ground ice in the southern hemisphere of Mars, Icarus, 169, 324-340, doi:10.1016/j.icarus.2003.10.022.

Ming, D. W., et al. (2006), Geochemical and mineralogical indicators for aqueous processes in the Columbia Hills of Gusev Crater, Mars, J. Geophys. Res., 111, E02S12, doi:10.1029/2005JE002560.

Ming, D. W., et al. (2008), Geochemical properties of rocks and soils in Gusev Crater, Mars: Results of the Alpha Particle X-ray Spectrometer from Cumberland Ridge to Home Plate, J. Geophys. Res., doi:10.1029/ 2008JE003195, in press.

Moller, N. (1988), The prediction of mineral solubilities in natural waters: A chemical equilibrium model for the $\mathrm{Na}-\mathrm{Ca}-\mathrm{Cl} \mathrm{SO}_{4}-\mathrm{H}_{2} \mathrm{O}$ system, to high temperature and concentration, Geochim. Cosmochim. Acta, 52, 821-837, doi:10.1016/0016-7037(88)90354-7.

Morris, R. V., et al. (2000), Mineralogy, composition, and alteration of Mars Pathfinder rocks and soils: Evidence from multispectral, elemental, and magnetic data on terrestrial analogue, SNC meteorite, and Pathfinder samples, J. Geophys. Res., 105(E1), 1757-1817, doi:10.1029/ 1999JE001059.

Morris, R. V., et al. (2004), Mineralogy at Gusev Crater from the Mössbauer spectrometer on the Spirit Rover, Science, 305, 833-836.

Morris, R. V., et al. (2006), Mössbauer mineralogy of rock, soil, and dust at Gusev Crater, Mars: Spirit's journey through weakly altered olivine basalt on the plains and pervasively altered basalt in the Columbia Hills, $J$. Geophys. Res., 111, E02S13, doi:10.1029/2005JE002584.

Morris, R. V., et al. (2008), Iron mineralogy and aqueous alteration from Husband Hill through Home Plate at Gusev Crater, Mars: Results from 
the Mössbauer instrument on the Spirit Mars Exploration Rover, J. Geophys. Res., doi:10.1029/2008JE003201, in press.

Nesbitt, H. W., and R. E. Wilson (1992), Recent chemical weathering of basalts, Am. J. Sci., 292, 740-777.

Nesbitt, H. W., and G. M. Young (1984), Prediction of some weathering trends of plutonic and volcanic rocks based on thermodynamic and kinetic considerations, Geochim. Cosmochim. Acta, 48, 1523-1534, doi:10.1016/0016-7037(84)90408-3.

Nordstrom, D. K., and C. N. Alpers (1999), Negative pH, efflorescent mineralogy, and consequences for environmental restoration at the Iron Mountain Superfund site, California, Proc. Natl. Acad. Sci. U. S. A., 96, 3455-3462, doi:10.1073/pnas.96.7.3455.

Paige, D. A. (1992), The thermal stability of near surface ground ice on Mars, Nature, 356, 43-45, doi:10.1038/356043a0.

Peterson, R. C., W. Nelson, B. Madu, and H. F. Shurvell (2007), Meridianiite: A new mineral species observed on Earth and predicted to exist on Mars, Am. Mineral., 92, 1756-1759, doi:10.2138/am.2007.2668.

Reid, R. J., et al. (1999), Imager for Mars Pathfinder (IMP) image calibration, J. Geophys. Res., 104(E4), 8907-8926, doi:10.1029/ 1998JE900011.

Rice, M. S., J. F. Bell III, A. Wang, and E. A. Cloutis (2008), Vis-NIR Spectral Characterization of Si-Rich Deposits at Gusev Crater, Mars, Lunar Planet. Sci. [CD-ROM], XXXIX, abstract 2138.

Rieder, R., R. Gellert, J. Brückner, G. Klingelhöfer, G. Dreibus, A. Yen, and S. W. Squyres (2003), The new Athena Alpha Particle X-Ray Spectrometer (APXS) for the Mars Exploration rovers, J. Geophys. Res., 108(E12), 8066, doi:10.1029/2003JE002150.

Ruff, S. W., P. R. Christensen, D. L. Blaney, W. H. Farrand, J. R. Johnson, J. R. Michalski, J. E. Moersch, S. P. Wright, and S. W. Squyres (2006), The rocks of Gusev Crater as viewed by the Mini-TES instrument, J. Geophys. Res., 111, E12S18, doi:10.1029/2006JE002747.

Ruff, S. W., et al. (2008), The Nature and Distribution of Silica at Home Plate in Gusev Crater, Mars: Evidence for A Hydrothermal System, Lunar Planet. Sci. [CD-ROM], XXXIX, abstract 2213.

Savijarvi, H. (1995), Mars boundary-layer modeling-diurnal moisture cycle and soil properties at the Viking-Lander-1 site, Icarus, 117, 120-127, doi:10.1006/icar.1995.1146.

Schmidt, M. E., et al. (2008), Hydrothermal origin of halogens at Home Plate, Gusev Crater, J. Geophys. Res., 113, E06S12, doi:10.1029/ 2007JE003027.

Schubert, G., et al. (1992), Origin and thermal evolution of Mars, in Mars, edited by H. H. Kieffer et al., pp. 147-183, Univ. of Ariz. Press, Tucson. Smith, M. D., M. J. Wolff, N. Spanovich, A. Ghosh, D. Banfield, P. R. Christensen, G. A. Landis, and S. W. Squyres (2006), One Martian year of atmospheric observations using MER Mini-TES, J. Geophys. Res., 111, E12S13, doi:10.1029/2006JE002770.

Sohl-Dickstein, J., et al. (2005), Modeling Visible/Near-Infrared photometric properties of dustfall on a known substrate, Lunar Planet Sci. [CD-ROM], $X X X V I$, abstract 2235.

Squyres, S. W., et al. (2004), The Spirit Rover's Athena Science Investigation at Gusev Crater, Mars, Science, 305, 794-799, doi:10.1126/ science. 3050794.

Squyres, S. W., et al. (2006), The Rocks of the Columbia Hills, J. Geophys. Res., 111, E02S11, doi:10.1029/2005JE002562.

Squyres, S. W., et al. (2007), Pyroclastic Activity at Home Plate in Gusev Crater, Mars, Science, 316(5825), 738-742, doi:10.1126/ science. 1139045 .

Squyres, S. W., et al. (2008), Discovery of silica-rich deposits on Mars by the Spirit Rover, Science, 320(1063), doi:10.1126/science.1155429.

Stoiber, R. E., and W. I. Rose (1974), Fumarole incrustations at active Central American volcanoes, Geochim. Cosmochim. Acta, 38, 495-516, doi:10.1016/0016-7037(74)90037-4.

Tosca, N. J., et al. (2005), Geochemical modeling of evaporation processes on Mars: Insight from the sedimentary record at Meridiani Planum, Earth Planet. Sci. Lett., 240, 122-148, doi:10.1016/j.eps1.2005.09.042.

Tosca, N. J., S. M. McLennan, M. D. Dyar, E. C. Sklute, and F. M. Michel (2008), Fe oxidation processes at Meridiani Planum and implications for secondary Fe mineralogy on Mars, J. Geophys. Res., 113, E05005, doi:10.1029/2007JE003019.

Vaniman, D. T., and S. J. Chipera (2006), Transformations of Mg- and Casulfate hydrates in Mars regolith, Am. Mineral., 91, 1628-1642, doi:10.2138/am.2006.2092.
Vaniman, D. T., et al. (2004), Magnesium sulfate salts and the history of water on Mars, Nature, 431, 663-665, doi:10.1038/nature02973.

Wang, A., et al. (2006a), Sulfate deposition in subsurface regolith in Gusev Crater, Mars, J. Geophys. Res., 111, E02S17, doi:10.1029/ 2005JE002513.

Wang, A., et al. (2006b), Evidence of phyllosilicates in Wooly Patch, an altered rock encountered at West Spur, Columbia Hills, by the Spirit Rover in Gusev Crater, Mars, J. Geophys. Res., 111, E02S16, doi:10.1029/2005JE002516.

Wang, A., J. J. Freeman, B. L. Jolliff, and I. M. Chou (2006c), Sulfates on Mars: A systematic Raman spectroscopic study of hydration states of magnesium sulfates, Geochim. Cosmochim. Acta, 70, 6118-6135.

Wang, A., J. F. Bell III, and R. Li (2007a), Salty Soils at Gusev Crater as Revealed by Mars Exploration Rover Spirit, Lunar Planet. Sci. [CD-ROM], XXXVIII, abstract 1196.

Wang, A., et al. (2007b), Salty Soils at Gusev Crater investigated by Mars Exploration Rover Spirit, Eos Trans. AGU, 88(23), Jt. Assem. Suppl., abstract P32A-07.

Wang, A., et al. (2007c), Sulfate-Rich Soils Exposed by Spirit Rover at Multiple Locations in Gusev Crater on Mars, in Seventh International Conference on Mars [CD-ROM], abstract 3348, Jet Propul. Lab., Pasadena, Calif.

Wang, A., J. J. Freeman, and B. L. Jolliff (2007d), Formation Rate of Amorphous Magnesium Sulfates at low Temperatures Approaching the Current Surface Conditions on Mars, Lunar Planet. Sci. [CD-ROM], XXXVIII, abstract 1195 .

Wang, A., J. F. Bell III, M. Rice, and E. A. Cloutis (2008a), Coexistence of Si-rich and S-rich Materials at Gusev Crater, Columbia Hills, Lunar Planet. Sci. [CD-ROM], XXXIX, abstract 2186.

Wang, A., J. J. Freeman, and R. E. Arvidson (2008b), Study of two Structural Polymorphs of $\mathrm{MgSO}_{4} \cdot \mathrm{H}_{2} \mathrm{O}$ by Raman, IR, XRD, and Humidity Buffer Experiments-Implication for Martian Kieserite, Lunar Planet. Sci. [CD-ROM], XXXIX, abstract 2172.

Warren, J. K. (1989), Evaporite Sedimentology. Importance in Hydrocarbon Accumulation, 285 pp., Prentice Hall, N. J.

White, D. E., W. W. Brannock, and K. J. Murata (1956), Silica in hot-spring waters, Geochim. Cosmochim. Acta, 10, 27-59, doi:10.1016/00167037(56)90010-2.

Wolff-Boenisch, D., et al. (2004), The dissolution rates of natural glasses as a function of their composition at $\mathrm{pH} 4$ and 10.6, and temperatures from 25 to $74^{\circ} \mathrm{C}$, Geochim. Cosmochim. Acta, 68, 4843-4858, doi:10.1016/ j.gca.2004.05.027.

Yen, A. S., et al. (2005), An Integrated View of the Chemistry and Mineralogy of Martian Soils, Nature, 436, 49-54, doi:10.1038/nature03637.

Yen, A. S., et al. (2008), Hydrothermal processes at Gusev Crater: An evaluation of Paso Robles class soils, J. Geophys. Res., 113, E06S10, doi:10.1029/2007JE002978.

Zimbelman, D. R., R. O. Rye, and G. N. Breit (2005), Origin of secondary sulfate minerals on active andesitic stratovolcanoes, Chem. Geol., 215, 37-60, doi:10.1016/j.chemgeo.2004.06.056.

R. E. Arvidson, R. Greenberger, A. T. Knudson, and A. Wang, Department of Earth and Planetary Science and McDonnell Center for Space Sciences, Washington University, St. Louis, MO 63130, USA. (alianw@levee.wustl.edu)

J. F. Bell III and S. W. Squyres, Department of Astronomy, Cornell University, Ithaca, NY 14853, USA.

W. Chen and R. Li, Center for Mapping, CEEGS, Ohio State University, Columbus, $\mathrm{OH} 43210$, USA.

E. A. Cloutis, Department of Geography, University of Winnipeg, 515 Portage Avenue, Winnipeg, MB R3B 2E9, Canada.

L. Crumpler, New Mexico Museum of Natural History and Science, Albuquerque, NM 87104, USA.

W. H. Farrand, Space Science Institute, 4750 Walnut Street, Boulder, CO 80301, USA.

K. E. Herkenhoff and J. R. Johnson, U.S. Geological Survey, Flagstaff, AZ 86001, USA.

S. M. McLennan, Department of Geosciences, State University of New York at Stony Brook, Stone Brook, NY 11794-2100, USA.

S. W. Ruff, School of Earth and Space Exploration, Arizona State University, Tempe, AZ 85287, USA. 